VOLUME I

\title{
MEN'S EXPERIENCES OF ENGAGING IN PSYCHOLOGICAL THERAPY IN A FORENSIC MENTAL HEALTH SETTING
}

By

Shazia Hussain

A THESIS SUBMITTED IN PARTIAL FULFILMENT TO THE UNIVERSITY OF BIMRINGHAM FOR THE DEGREE OF DOCTOR OF FORENSIC CLINICAL PSYCHOLOGY

Centre of Applied Psychology

School of Psychology

The University of Birmingham

June 2018 


\section{UNIVERSITYOF BIRMINGHAM}

\section{University of Birmingham Research Archive \\ e-theses repository}

This unpublished thesis/dissertation is copyright of the author and/or third parties. The intellectual property rights of the author or third parties in respect of this work are as defined by The Copyright Designs and Patents Act 1988 or as modified by any successor legislation.

Any use made of information contained in this thesis/dissertation must be in accordance with that legislation and must be properly acknowledged. Further distribution or reproduction in any format is prohibited without the permission of the copyright holder. 


\section{RESEARCH THESIS \\ Author's Declaration}

Full name (block capitals, surname first): HUSSAIN, SHAZIA

Full title of thesis/dissertation (block capitals): MEN'S EXPERIENCES OF PSYCHOLOGICAL THERAPY IN A FORENSIC MENTAL HEALTH SETTING

College/School/Department (block capitals): CENTRE OF APPLIED PSYCHOLOGY

Date of award of degree (leave blank):

1. I understand that one printed and one electronic copy of my thesis/dissertation (the Work) will be deposited in the University Library (the Library) and in a suitable electronic repository, for permanent retention.

2. Without changing the content, the Library or any third party with whom it has an agreement to do so, may convert either copy into a format or medium for the purpose of long-term retention, accessibility and preservation.

3. The Library will publish, and/or arrange with appropriate third parties for the non-exclusive publication of, a bibliographic description of the thesis/dissertation, and the author's abstract.

4. Unless arrangements are made to the contrary, (see paragraph 6. below), the Library is authorised to make the Work available for consultation in the Library, and via a recognised inter library loans system. The Library is authorised to make the electronic copy of the Work freely accessible to individuals and institutions - including automated agents - via the Internet.

5. Rights granted to the University of Birmingham through this agreement are entirely non-exclusive. I retain all my rights in the Work in its present version or future derivative works.

6. I understand that I may apply to the University to retain the right to withhold access to the content of my thesis/dissertation. Access to the paper version may be withheld for a period which shall not normally exceed four calendar years from the congregation at which the degree is conferred. The actual length of the period will be specified in the application, together with the precise reasons for making that application. The electronic copy may be withheld from dissemination via the web or other networks for any period.

7. I have obtained permission for any use made of substantial amounts of published or unpublished copyright material (text, illustrations, etc) where the rights are owned by a third party, other than as permitted under either The Copyright Designs and Patents Act 1988 (as modified by any related or successor legislation) or the Terms and Conditions of any Licence governing its use.

8. The content of the copies I shall deposit with the Library will be the final version of my thesis, as approved by the Examiners.

9. I understand that the Library and administrators of any electronic theses repository do not hold any obligation to take legal action on behalf of myself, or other rights holders, in the event of a breach of intellectual property rights, or any other right, in the material deposited.

10. I understand that, in the event of my thesis/dissertation being not approved by the Examiners, this declaration will become null ghd void.

Signature:

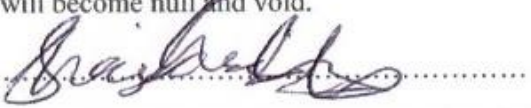

Date: $14 / 10 / 2018$

For Library use (please leave blank):

Classmark: 


\section{Overview}

This thesis is submitted in partial fulfilment of the requirements for the degree of Doctor of Forensic Clinical Psychology (ForenClinPsyD) at the University of Birmingham. The thesis consists of two volumes.

Volume I is comprised of three chapters. The first chapter presents a synthesis of the qualitative literature pertaining to men's experiences of psychosis. The second chapter presents the empirical paper of a qualitative study exploring men's experiences of engaging in psychological therapy in a forensic mental health setting. Finally, the third chapter contains a public domain paper outlining the research undertaken in the empirical paper suitable for a public audience.

Volume II contains five Clinical Practice Reports (CPRs) which represent clinical work carried out across various specialities: Adult Mental Health, Learning Disability, Child and Adolescent Mental Health and Prison. The first report presents a cognitive-behavioural and psychodynamic formulation to understand the presenting problems of a South Asian male. The second report presents a service evaluation examining the level of engagement with psychological interventions on a medium-secure inpatient Personality Disorder recovery ward. The third report is a case study of an adult male in a medium-secure unit presenting with Personality Disorder and Autism Spectrum Disorder traits. The fourth report is a single-case experimental design investigating the change in self-harming behaviour of an adolescent female. Lastly, the final CPR was a case study of a female prisoner delivered as an oral presentation for which an abstract is presented. 
To my parents and sisters for all your sacrifices, so I could reach my goals. 


\section{Acknowledgements}

First and foremost, thank you to my Academic Supervisor, Professor John Rose and Clinical Research Supervisor, Dr Abdullah Mia for their unwavering support and incredible patience throughout the completion of this thesis, especially when it seemed near impossible! Your faith in me has been invaluable.

I would also like to express my appreciation to Dr Ashley-Christopher Fallon for his advice, guidance and insights over the course of the research project, and to Dr Andrew Fox for supporting me with the qualitative analysis.

Thank you to the men who contributed to my research project by giving me their time and kindly sharing their stories with me. I hope I have captured the essence of your unique experiences.

Last but by no means least, my heartfelt gratitude to my family, friends and supervisors who persistently stood by me during my several "crises of confidence", with unrelenting encouragement, love and words of wisdom. Thank you for being my strength when I needed it most, without you I would not have made it through. 


\section{CONTENTS}

VOLUME I: Research Component

\section{Chapter I: Literature Review}

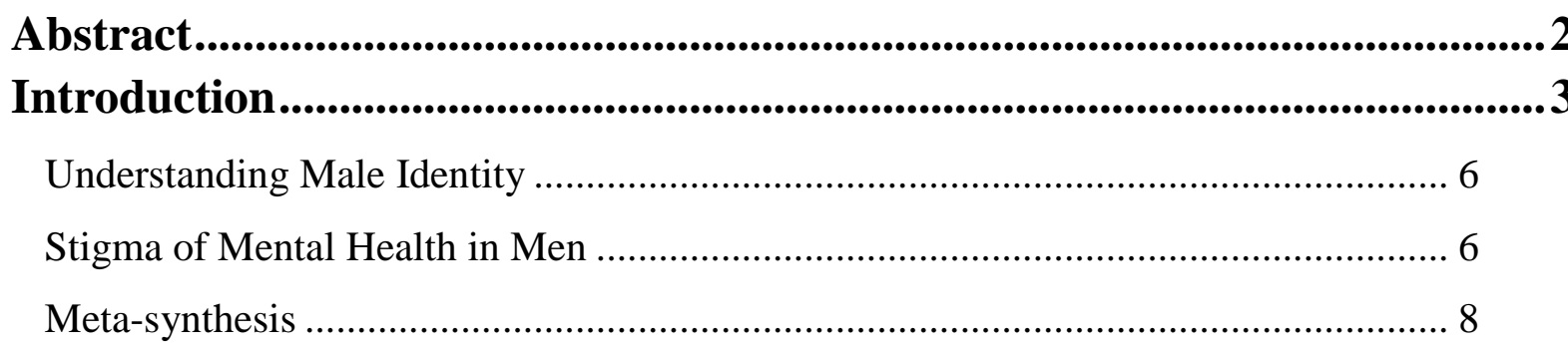

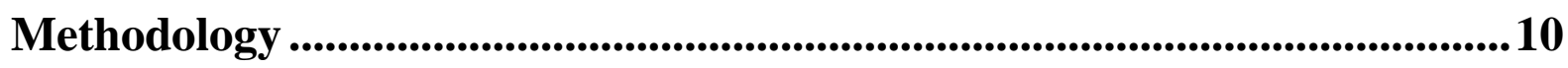

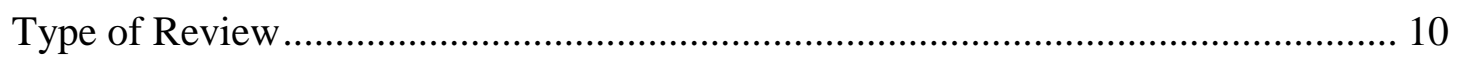

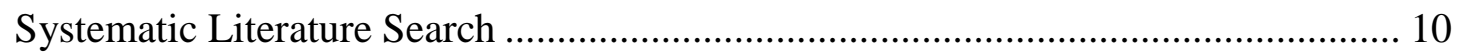

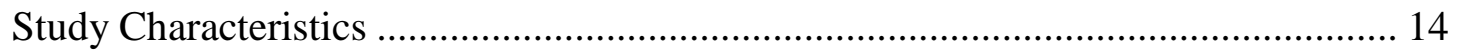

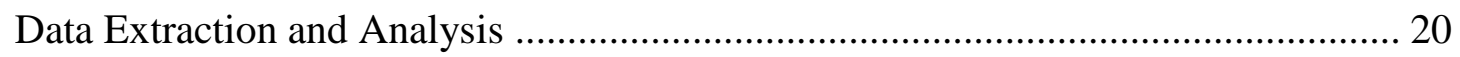

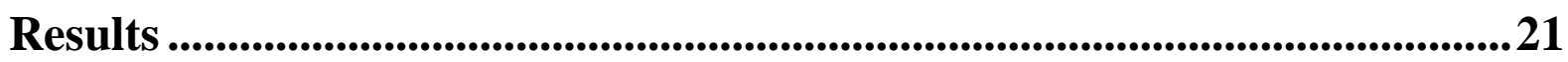

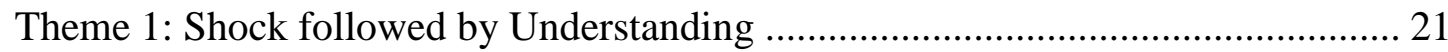

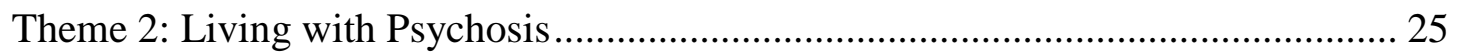

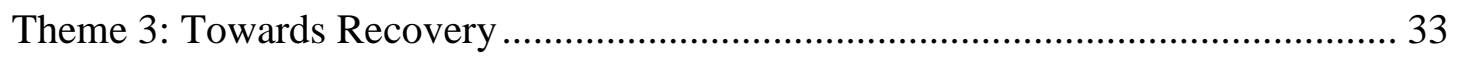

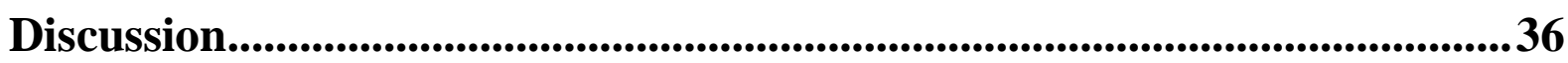

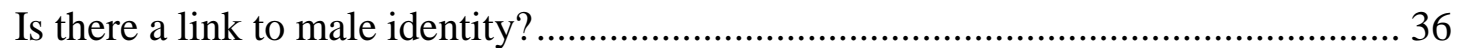

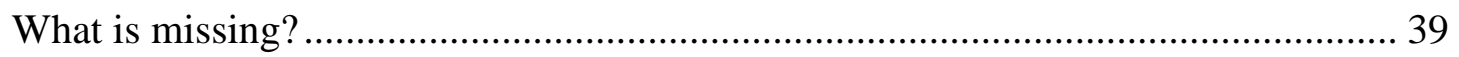

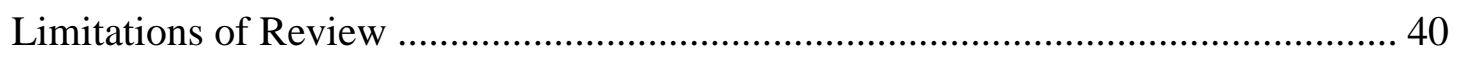

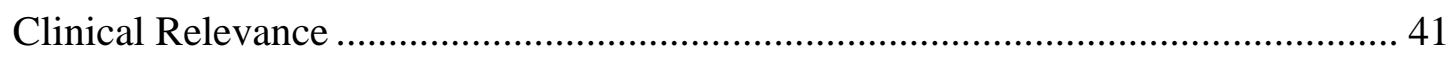

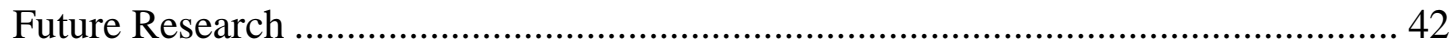

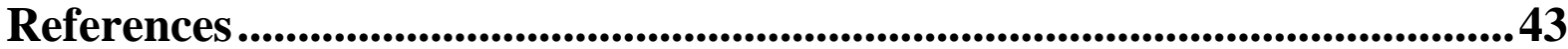

\section{Chapter II: Empirical Paper}

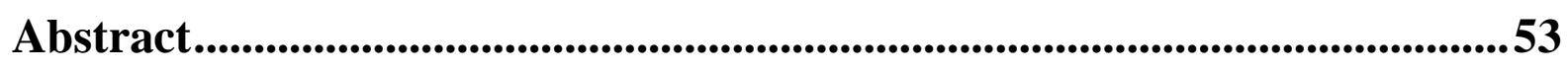

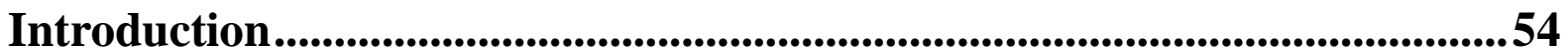

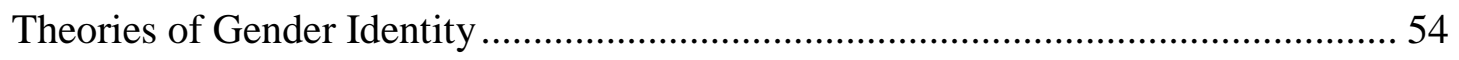


Gender Identity and Psychological Distress ....................................................... 58

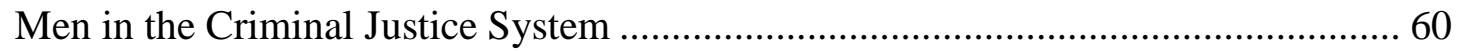

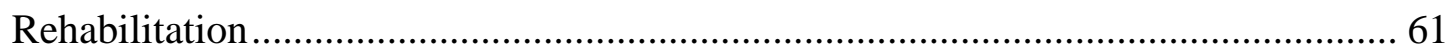

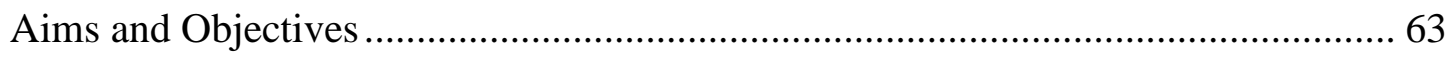

Methodology ............................................................................................................. 64

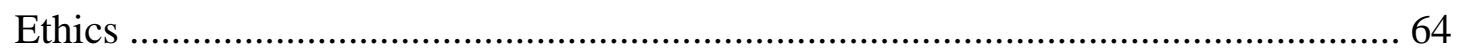

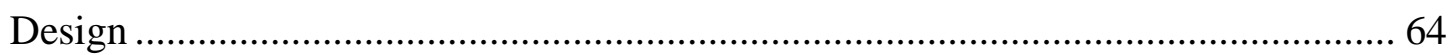

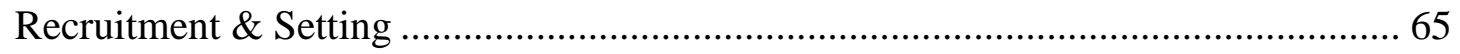

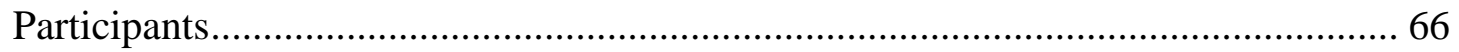

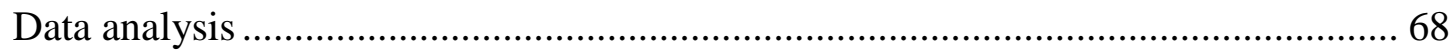

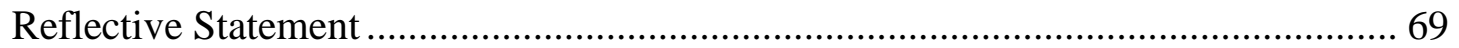

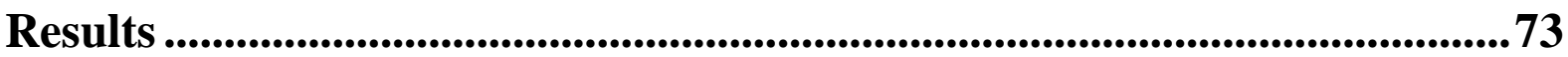

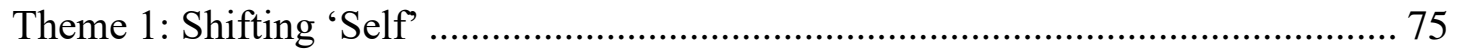

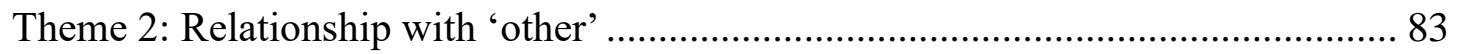

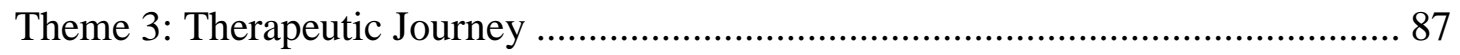

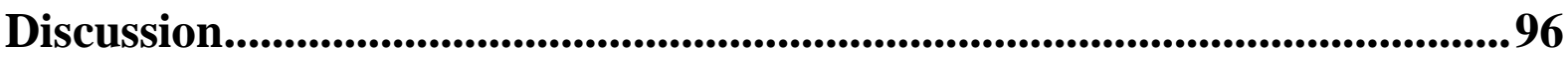

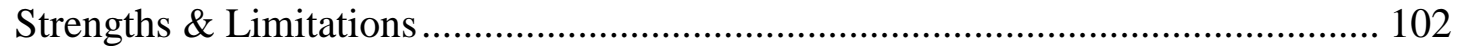

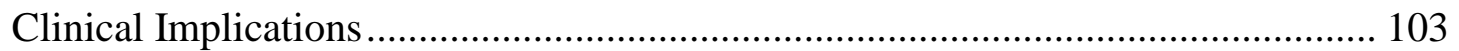

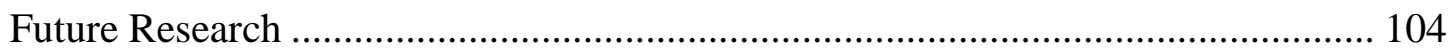

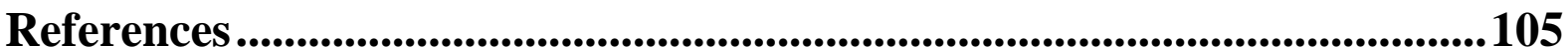

\section{Chapter III: Public Domain Paper}

Literature Review: Men's Experiences of Psychosis ....................................120

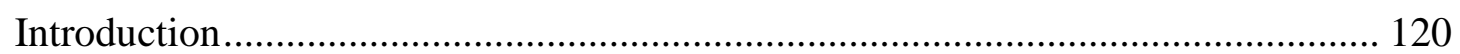

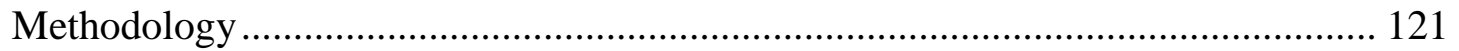

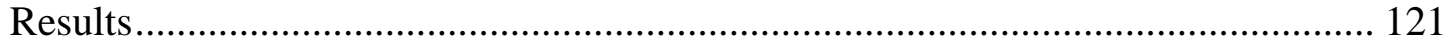

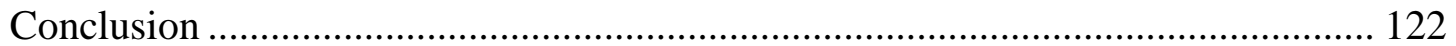

Empirical Paper: Men's Experiences of Engaging in Psychological Therapy in a Forensic Mental Health Setting.......................................................................124

Why did we do the study? 
What did we want to find out?

How did we do this?

What did we find?

What does this tell us?

\section{Appendices: Literature Review}

Appendix A: Quality Appraisal Checklist (NICE, 2012) ................................................130

Appendix B: Details of Quality Appraisal Check .................................................................131

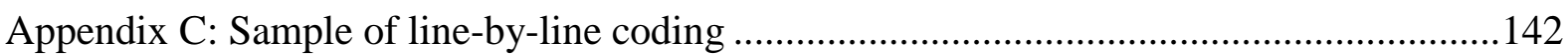

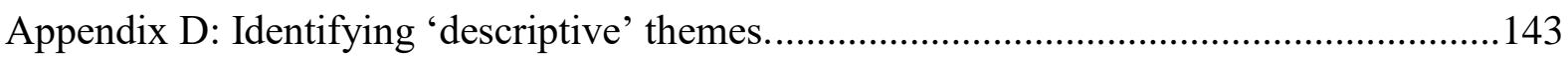

Appendix E: Transforming 'descriptive' themes into 'analytical' themes........................... 144

\section{Appendices: Empirical Paper}

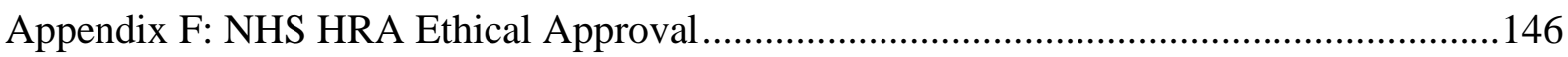

Appendix G: Ethical Approval from Participating NHS Trust ...........................................149

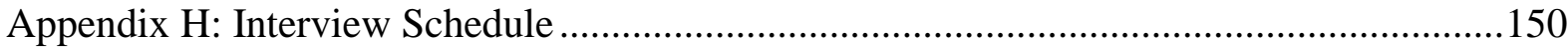

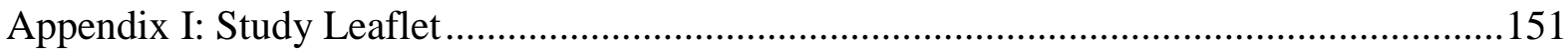

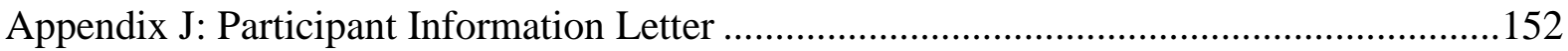

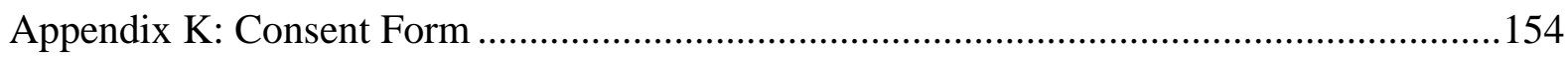

Appendix L: Sample Transcript with Line-by-line Coding ................................................ 155

Appendix M: Sample of Identifying Emerging Themes across Cases ................................156

Appendix N: Table with Example Quotes .....................................................................157

VOLUME II: Clinical Practice Reports

VOLUME II: Clinical Practice Reports

I. Clinical Practice Report (1): A Clinical-Forensic Case Formulated from

Two Psychological Models

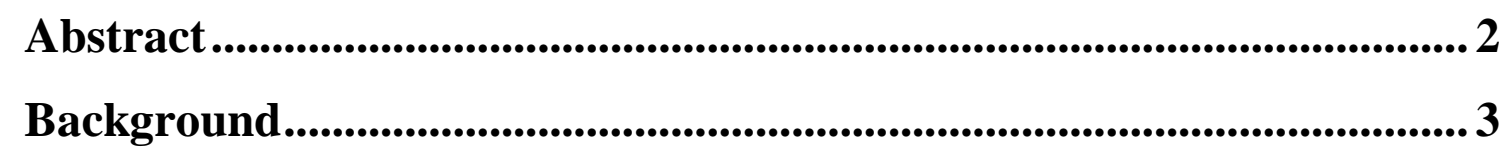




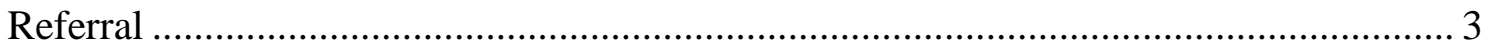

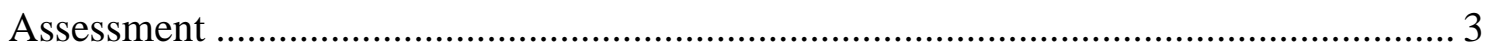

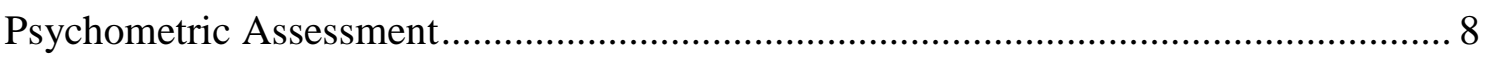

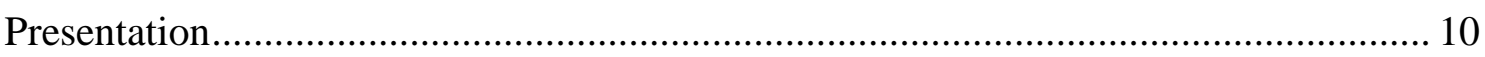

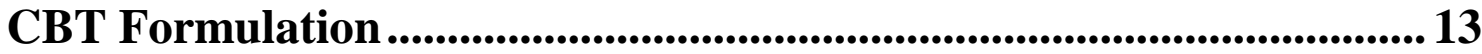

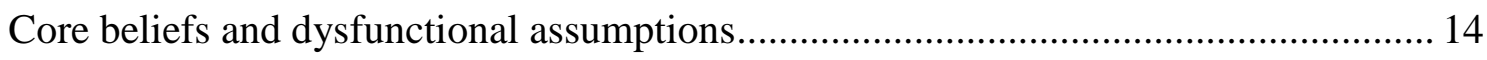

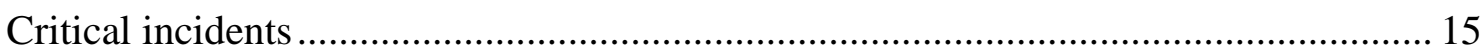

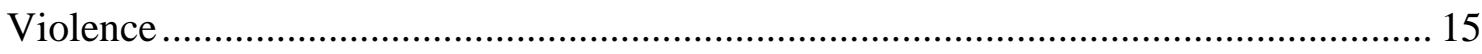

Psychodynamic Formulation .................................................................... 18

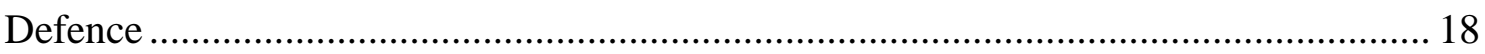

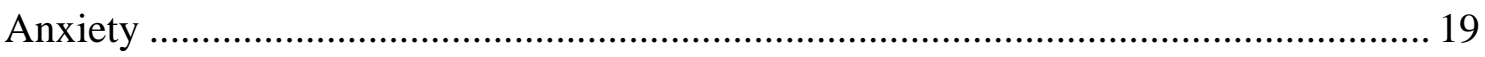

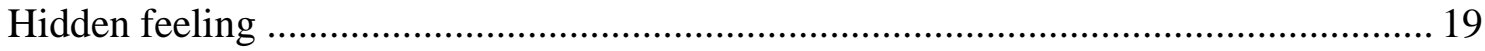

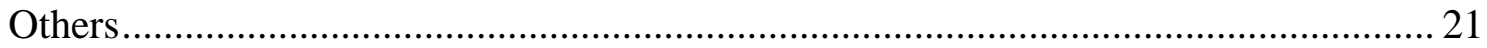

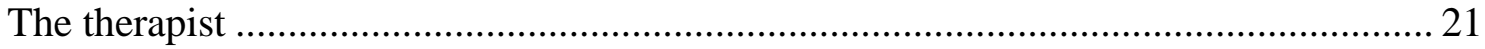

Reflections ................................................................................ 24

References ................................................................................................................227

II. Clinical Practice Report (2): An Evaluation of the Implementation of Direct Psychological Input in a Male Recovery-Focused Personality Disorder Service

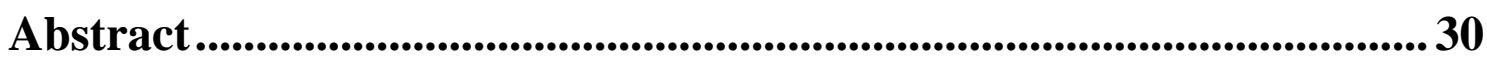

Introduction ................................................................................................... 31

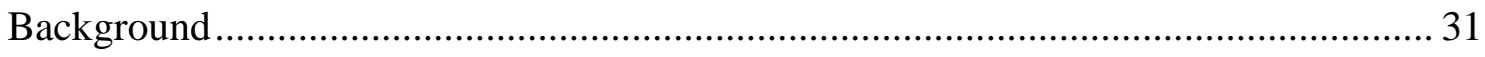

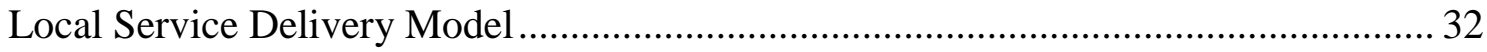

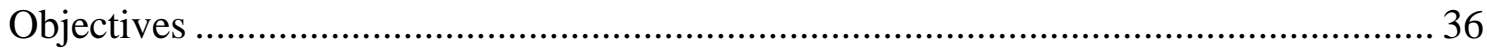

Method....................................................................................................... 37

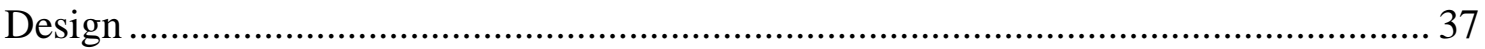

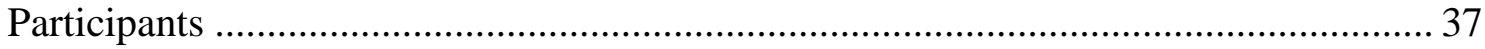

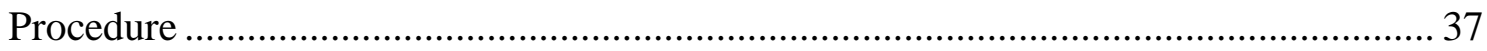

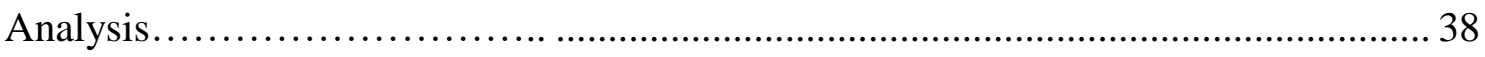

Results .................................................................................................. 39 


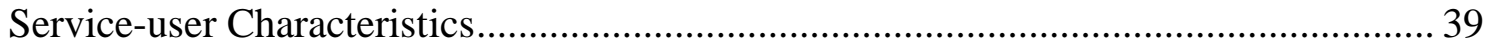

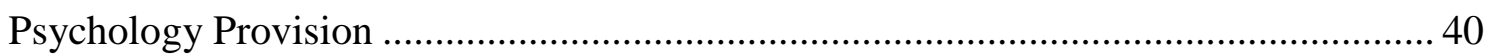

Service-user engagement with psychology programme .......................................... 41

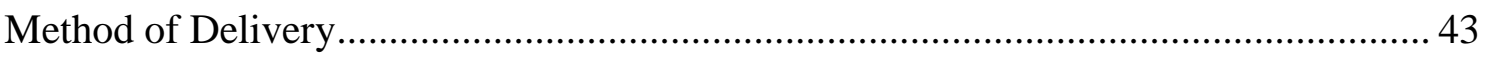

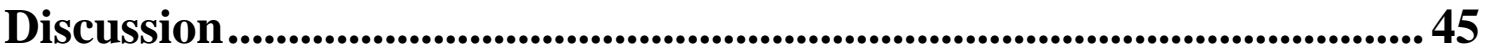

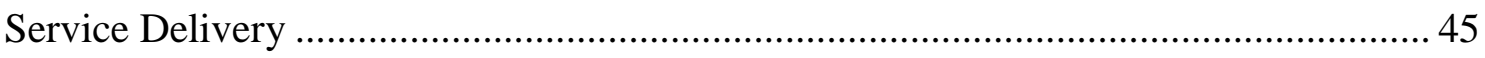

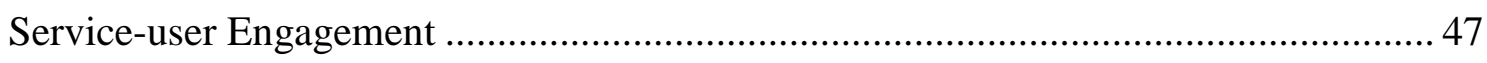

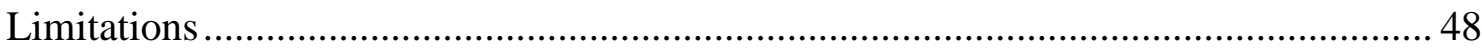

References ............................................................................................................... 51

III. Clinical Practice Report (3): The Case of Peter, a 25-year-old man presenting with High-functioning Autism and Antisocial Personality Traits Abstract ..........................................................................................................55

Background Information............................................................................................56

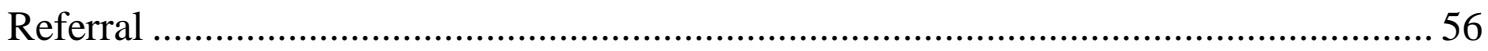

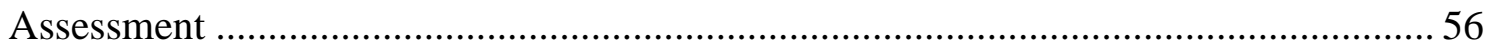

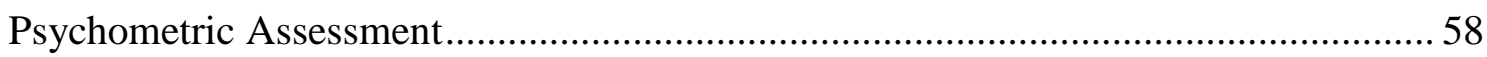

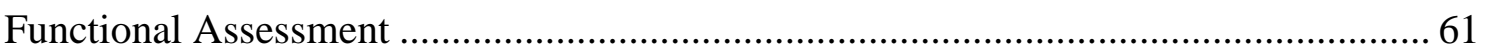

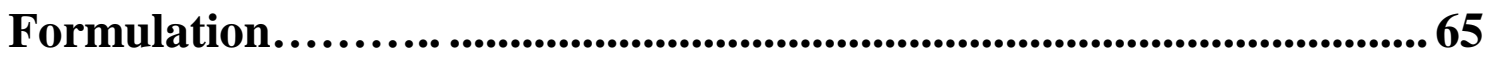

Behavioural Formulation (Nezu, Nezu, and Lombardo, 2004) ................................... 65

Intervention ...................................................................................................69

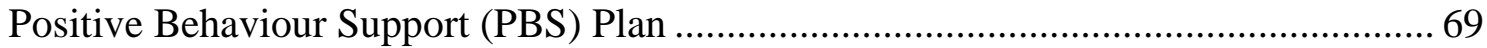

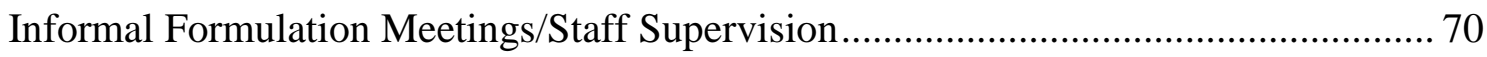

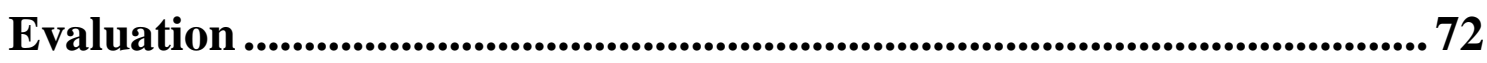

Reflections ...................................................................................................................... 74

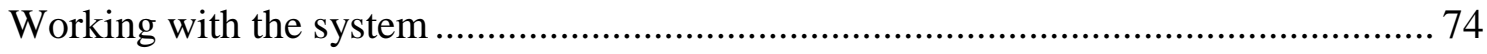

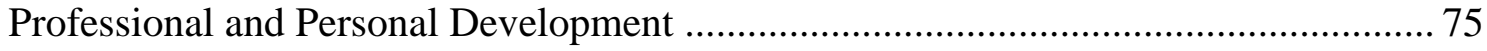

References .................................................................................................. 76 
IV. Clinical Practice Report (4): Single-Case Experimental Design: A Case from the Forensic CAMHS Service

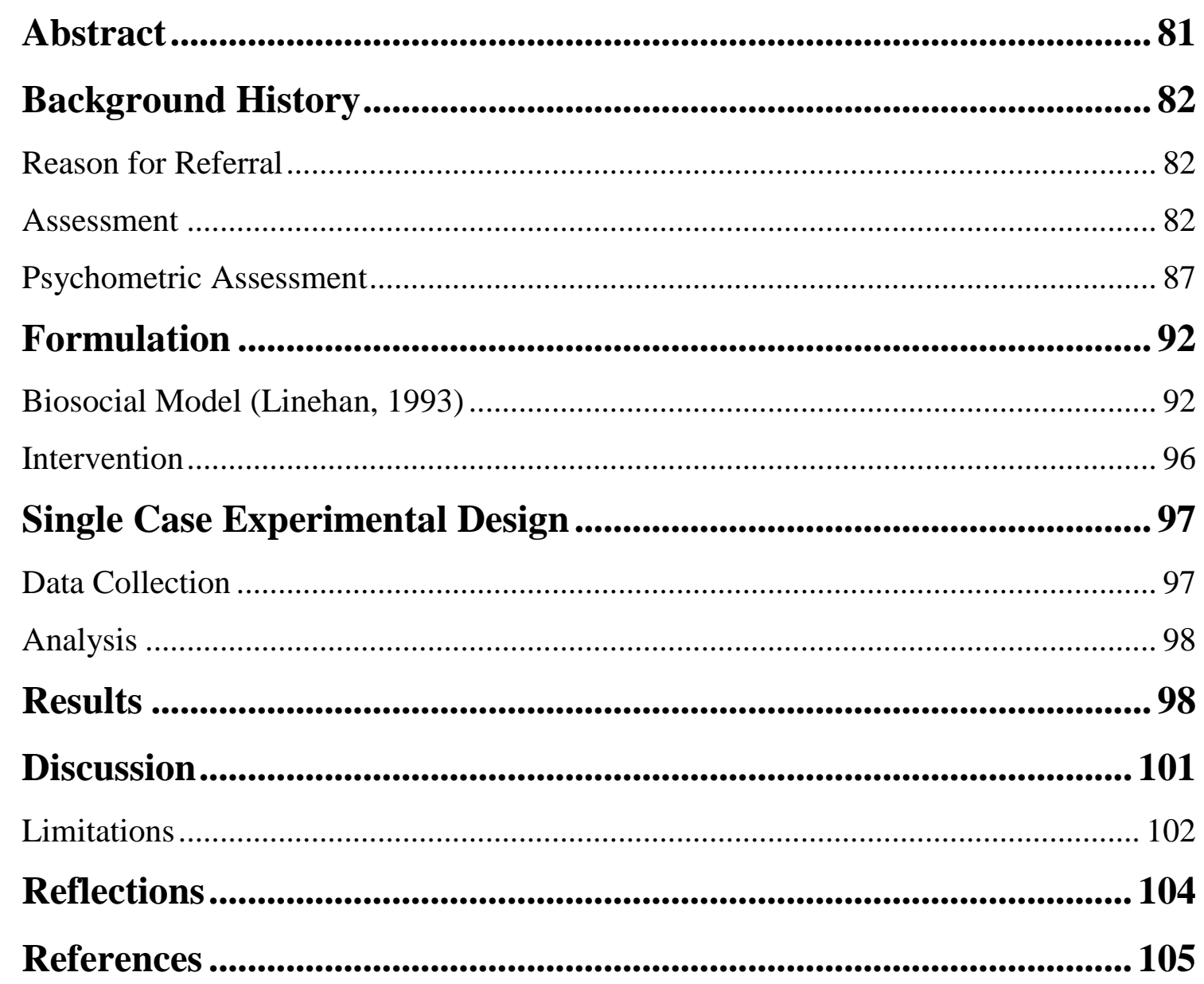

V. Clinical Practice Report (5): A Case Study of a Female Prisoner

Abstract.

\section{Appendices}

Appendix 1: NRES Guidance 


\section{VOLUME I: List of illustrations}

Figure 1.1: Stages of thematic synthesis detailed by Thomas and Harden (2008).................. 10

Figure 1.2: Flow diagram depicting study selection process............................................. 13

Figure 1.3: Summary of superordinate and subordinate themes. ........................................ 21

Figure 2.1: Multi-factor Offender Readiness Model (Ward et al., 2004)................................ 62

Figure 2.2: Analysis process as indicated by Smith, Flowers \& Larkin (2009)..................... 69

Figure 2.3: Diagrammatic representation of links between superordinate themes and subthemes

\section{VOLUME II: List of illustrations}

Figure 1.1: A cognitive formulation of the development of Karim's difficulties (adapted from

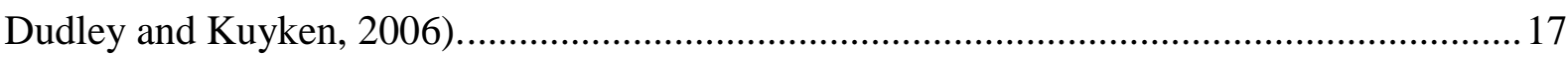

Figure 1.2: Karim's triangles of conflict and person (adapted from Malan, 2001).................23

Figure 2.1:Five stages of the SCALE Model of service delivery ........................................... 33

Figure 2.2: A diagrammatic representation of the tiered psychological approach on the Male Recovery-Focused Personality Disorder Service

Figure 2.3: Bar chart showing the overall percentage of psychology sessions attended (blue) or resulting in DNA (red) from October 2013 to March 2015.

Figure 2.4: Bar chart showing the individual overall rate of attendance to psychology sessions per service-user.

Figure 2.5: Bar Chart showing the overall percentage of ward-based group sessions attended across different programmes from October 2013 to March 2015.

Figure 2.6: Bar chart showing the overall percentage of high intensity group sessions attended across different programmes from October 2013 to March 2015.

Figure 3.1: Behavioural formulation of Peter's challenging behaviour ( $\mathrm{Nezu}, \mathrm{Nezu}$, and Lombardo, 2004). 68

Figure 3.2: Peter's Positive Behaviour Support (PBS) Plan

Figure 3.3: Management of red and green behaviours .70

Figure 4.1: Family Genogram 84

Figure 4.2: Lucy’s Biosocial Formulation (Linehan, 1993). 95 
Figure 4.3: Graph illustrating the baseline and intervention time points over the course of 134 days

\section{VOLUME I: List of tables}

Table 1.1: Search terms used. 11

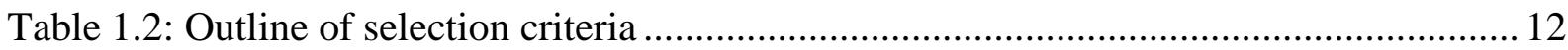

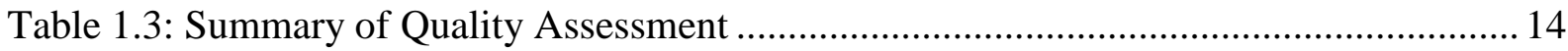

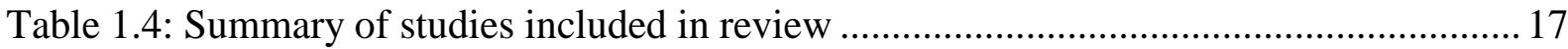

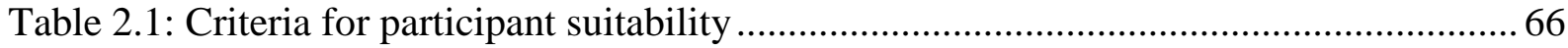

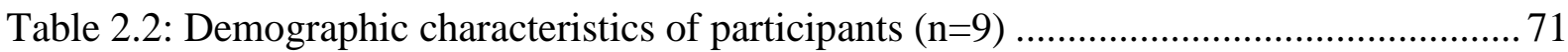

Table 2.3: Annotation of changes introduced to verbatim script. ........................................... 75

\section{VOLUME II: List of tables}

Table 1.1: Millon Clinical Multi-Axial Inventory base rate scores across subscales...........8

Table 1.2: Summary of HCR-20 subscale scores.......................................

Table 2.1: Outline of the demographic details of the 12 service-users who currently reside on

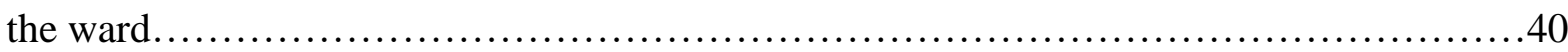

Table 2.2: Outlines the distribution of psychology service provision over the past 18

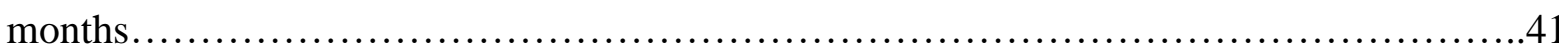

Table 4.1: Lucy's SAVRY assessment scores....................................... 88

Table 4.2: Lag-1 autocorrelation coefficients, slope and significance value, and type of test

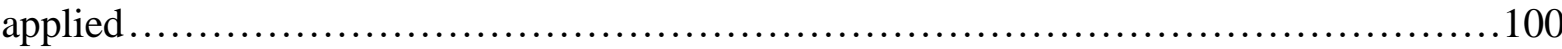




\section{LITERATURE REVIEW}

Men's Experiences of Psychosis 


\begin{abstract}
Aims: Research suggests that there are gender differences between men and women's response to and management of psychosis, with men more likely to present with severe psychopathology, higher levels of substance use and poorer psychosocial outcomes. Recent public health concerns regarding men's mental health provide further incentive to explore the role of male gender identity in the manifestation, adjustment and management of distress associated with psychosis.

Method: A systematic review of the qualitative literature exploring men's experiences of psychosis was conducted. The search for empirical papers was guided through Embase, Medline and Psychinfo databases and papers suitable for inclusion were quality appraised using the NICE Qualitative Framework (2012). All data that related to male participants in the selected studies was extracted. A Thematic Synthesis of the available data was conducted to identify common themes across the studies.
\end{abstract}

Results: A total of 11 studies were included in the synthesis, yielding a total of three superordinate themes: 'shock followed by understanding', 'living with psychosis' and 'towards recovery'.

Conclusions: Three subthemes linked to 'living with psychosis' offered certain insights associated with the dilemmas faced by men when attempting to reconcile their psychological needs within the rigid constraints of gender role socialisation. These included difficulties associated with expressing vulnerability, shame associated with loss and seeking support. The remaining themes described the men's general struggle with psychosis and steps taken towards recovery. 


\section{Introduction}

Psychosis is a symptom or feature of certain mental illnesses, including Schizophrenia, Schziphreniform Disorder, Schizoaffective Disorder, Bipolar Affective Disorder, Delusional Disorder and Drug-induced Psychosis. It is a distinct phenomena characterised by a loss of contact with external reality. The degree of disintegration experienced has debilitating consequences for one's cognitive functioning (McFarlane, 2011), social functioning (Penn, Waldheter, Perkins, Mueser, \& Lieberman, 2005) and overall quality of life (Malla, 2005). The impact extends to individuals' families and healthcare professionals who suffer from burn-out under the weight of the caretaking burden placed upon them (McDonell, Short, Berry, \& Dyck, 2003). Due to the poor long-term prognosis associated with psychosis, especially where the duration of untreated illness (DUI) is greater (Fraguas et al., 2014), research has sought to better understand the origins of the illness and common risk factors (Yung, Phillips, Yuen, \& McGorry, 2004). Diagnostic terms are most commonly used in the literature to identify the population of individuals who experience these difficulties, hence within this thesis Schizophrenia may be used interchangeably with psychosis to esnure continuity with the main body of literature.

Emerging evidence suggests that changes in feelings, thoughts, perceptions and behaviours may occur in the brain prior to onset, referred to as the prodromal phase (Yung \& McGorry, 1996). In addition to this, at the onset of first episode psychosis (FEP) there is a 'crtical period' and timely intervention at this stage could alter the subsequent course of illness (Birchwood \& Fiorillo, 2000; Birchwood, Todd, \& Jackson, 1998). FEP is commonly reported 
to coincide with the period of transition from adolescence to adulthood, specifically late teenage years to early twenties (Kessler et al., 2007).

Spurred on by these developments, over the years significant changes have been made to services to faciliate the early detection and management of psychosis. Assertive Outreach Services (AOS) were employed to fulfill this task with the following aims:

- To reduce the time between onset of psychotic symptoms and effective treatment.

- To accelerate remission through effective biological and psychosocial interventions.

- To reduce the individual's adverse reactions to the experience of psychosis and to maximise social and work functioning.

- To prevent relapse and treatment resistance (Spencer, Birchwood, \& McGovern, 2001).

Despite this, services continue to face obstacles in engaging young people who may doubt the usefulness of professional help, posses negative stereotypes of mental illness and fear mental health services (Lincoln \& McGorry, 1995). Under such circumstances disengagement is a real issue, influenced by DUI, symptom severity, substance use issues and forensic history (Conus et al., 2010; Doyle et al., 2014). Thus, understanding what constitutes engagement, helps or hinders engagement is at the core of improving access to services. Wright and colleagues (2011) conducted a recent qualitative study where they interviewed 14 professionals and 13 service-users from an Early Intervention Service (EIS) to gain a better understanding of 'engagement'. Four superordinate themes were identified: contact, dialogue, transformation and shared understanding. There was a recognition that fostering a good therapeutic alliance 
through establishing dialogue and maintaining contact was a key aspect of engagement, achieved through listening and offering practical support (Wright, Callaghan, \& Bartlett, 2011).

Nasser and colleagues (2002) have argued that the predominence of biomedical and neurological approaches to understanding psychosis in order to inform preventative strategies has meant that socio-cultural influences on the manifestation and subjective exeprience of psychosis have been neglected. Research within this field has been dominated by a medical model understanding of mental illness and distress, thus diagnostic categories, such as Schizophrenia have been used to identify individuals who typically experience psychosis. However, the emergence of the Power Threat Meaning Framework (BPS, 2018) provides an alternative way of understanding mental illness which takes into account the subjective meanings and experiences of individuals in the context of biological, psychological, social and environmental factors. These factors are paramount to the the day-to-day clinical task of engaging individuals in treatment and supporting them through recovery.

Men in particular were reported to suffer from higher rates of negative sysmptoms, were more likley to be isolative and use substances in comparison to women (Ochoa, Usall, Cobo, Labad, \& Kulkarni, 2012). Sajatovic et al. (2005) found that psychosis impacted on men's and women's perception of their gender identity. Thus, "elucidation of the complex role of gender in illness processes is an important research direction that would enhance understanding of the heterogeneity in the manifestation and subjective experience of schizophrenia." (Nasser, Walders \& Jenkins, 2002, pg. 351). These issues are worth exploring as they hold implications for fostering practices that support the succesful engagement of high-risk populations. 


\section{Understanding Male Identity}

Male gender identity in the literature appears to be synonymous with masculinity, whereby the terms are used interchangeably. It has been argued that the construct of masculinity is in fact ill-defined (Seidler, 1997) and can consist of a variety of roles, attributes and behaviours which arise through an individual's interaction with dominant socio-cultural ideas regarding gender, that are context and time specific (Connell \& Messerschmidt, 2005). In this respect the construct of masculinity is dynamic and multifaceted. Most likely to be expressed differently in different contexts.

Nevertheless, researchers within the field have been able to identify certain key features of masculinity commonly observed in adolescents and adult men (Levant \& Pollack, 1995) to varying degrees. These include, restricted emotional expression, rejection of feminity, strength, sexual prowess, success, achievement, competitiveness, control, power and dominance (Mahalik et al., 2003a). Some men may be more likely to rigidly adhere to these masculine norms in comparison to other men (O’Neil, 2008), whilst some may endorse certain masculine norms more readily than other norms (Addis \& Cohane, 2005). For those men where male identity and masculinty is central to their self-concept, it is likely to colour their perceptions and interpretation of their experiences (Kahn, 2009). Subsequently influencing how they view psychosis, how they view seeking-help for psychosis and how they interact with services that offer this help.

\section{Stigma of Mental Health in Men}

Adherence to masculine norms can be functional, as evidenced in research related to positive masculinity (Englar-Carlson \& Kiselica, 2013). However myths associated with masculinty often distort what it means to be a man (Seidler, 1997) leading individuals to strive towards an ideal image that is extreme and unrealistic. It is this distorted perception which gives 
rise to Gender Role Conflit (GRC; O’Neil, 2008) when men recognise the discrepnacies in themselves in relation to socially accepted gender role norms. This can lead to personal restriction, devaluation or violation of self or others. Suffering from any form of mental illness is thus likely to trigger feelings of inadequacy, inferiority or failure (Mansfield, Addis, \& Mahalik, 2003). Such circumstances can adversely affect help-seeking behaviour in men (Galdas, Cheater, \& Marshall, 2005) who may prefer to avoid or conceal psychological distress (Kingerlee, Precious, Sullivan, \& Barry, 2014) rather than risk being judged by others (Krugman, 1995).

Shame plays a prominent role in men's lives and male culture is often described as shame-phobic (Wright, 1987). Men's reflexive urge to repel intolerable shame states results in them externalising distress through compulsive behaviours such as alcoholism, substance use or violence (Kingerlee et al., 2014; Rice et al., 2015). In clinical practice, it is commonly observed that men struggle to discuss their symptoms, and indeed their 'negative' feelings, without a strong sense of shame (Shepard \& Rabinowitz, 2013). This struggle may present itself as 'resistance', 'defence' or 'avoidance' in a therapeutic setting where it is labelled as 'interfering', causing increased frustration in the clinician and possible friction (Mahalik, Good, Tager, Levant, \& Mackowiak, 2012), inadvertently creating a cycle of misunderstanding unconducive to successful engagement.

Indeed, there is emerging research in the mental health field, specifically related to depression, that associates masculinity with men's perceptions, understanding and management of their mental illness (Emslie, Ridge, Ziebland, \& Hunt, 2006). Warren (1983) has argued that depression is 'incompatible' with masculinity: tearfulness and crying are associated with femininity; the sense of powerlessness in depression is the antithesis of competence; loss of 
control and vulnerability contradict toughness and self-reliance. An excerpt from the selfnarrative of Brett Smith (1999) expresses this conflict:

"Pull yourself together, Brett. You shouldn't be here. Men don't go and see anyone about these "soft" and "wimpy" things. Yeah, you read about "women” being depressed, but "men," no way! "Men" deal with these little side issues themselves-don't they? Anyway, "men" don't feel like this-do they? Real "men” don't moan. They don't hurt. They just don't do emotions. They get on with life" (pg. 274)

Provided the challenges faced by AOS in terms of ensuring engagement to assess and treat individuals at high risk of psychosis to support prevention and minimise long-term negative outcomes, it is worth understanding the unique experiences of particular groups of people - in this case namely men. Questions such as, how men make sense of their experiences of psychosis, what this means for them, how they deal with it, open a dialogue to start exploring the gender-specific factors that may be influencing men's understanding of their symptoms and utilisation of services to improve recovery outcomes in this group.

\section{Meta-synthesis}

With the increased popularity of qualitative methods in healthcare research, aggregating results can provide useful insights into specific phenomena under study and to patient care or service delivery (Walsh \& Downe, 2005). Meta-synthesis offers the integration and comparison of findings from numerous qualitative studies, defined as "the bringing together and breaking down of findings, examining them, discovering the essential features, and, in some way, combining phenomena into a transformed whole" (Fingfeld, 2003, pg. 893). A recent qualitative synthesis exploring women's experiences of psychosis was conducted (Chernomas et al., 2017). Consequently, this review aims to draw together men's experiences of psychosis as represented 
in the qualitative literature (considering the observed gender differences) to explore whether any distinguished or substantive insights could be derived (Finfgeld, 2003). 


\section{Methodology}

\section{Type of Review}

As the review aimed to understand men's experiences of psychosis in particular, which would require the extraction of specific data, the method of meta-synthesis adopted was Thematic Synthesis (Thomas \& Harden, 2008) as detailed in Figure 1.1.

Stages of Thematic Synthesis:

1. Preparing for thematic synthesis

a. Searching

b. Quality assessment

c. Extracting data from studies

2. Thematic synthesis
a. Line-by-line coding
b. Developing 'descriptive' themes
c. Generating 'analytical' themes

Figure 1.1: Stages of thematic synthesis detailed by Thomas and Harden (2008)

\section{Systematic Literature Search}

\section{Search strategy}

A literature search was conducted using the three different databases: Psychinfo (19672017), Medline (1946-2017) and Embase (1974-2017), using the keywords as depicted in Table 1.1. Due to the limited time-frame and the volume of research literature conducted in the field of psychosis and Schizophrenia, the search was limited to literature from the year 2000 onwards. The initial search using a combination of the search terms described, yielded a total of 2,275 papers prior to de-duplication. Since qualitative literature can be difficult to search for 
and identify (Shaw et al., 2004), the combination of searches yielded several unrelated studies, including quantitative studies. After an examination of the study titles against the inclusion criteria, a total 149 papers were found to be most relevant to the topic being investigated.

Table 1.1: Search terms used.

\begin{tabular}{|c|c|}
\hline Terms used & Combinations \\
\hline $\begin{array}{l}\text { 1. Psychosis, schizophrenia, } \\
\text { schizoaffective disorder }\end{array}$ & \multirow{3}{*}{$\begin{array}{l}1 \text { AND } 2 \\
1 \text { AND } 2 \text { AND } 3 \\
1 \text { AND } 2 \text { OR } 3\end{array}$} \\
\hline $\begin{array}{l}\text { 2. Experiences, phenomenological, } \\
\text { narrative, qualitative }\end{array}$ & \\
\hline 3. Men, male, patient, service user & \\
\hline Limits placed on paper selection: ' 2000 & nber 2017' \\
\hline
\end{tabular}

\section{Inclusion/Exclusion Criteria}

As the aim of the review was to examine the qualitative literature, only empirical papers utilising qualitative methodology were included. Studies which employed mixed-method designs were excluded due to the added complexity of the empirical evaluation that would be required, as it has been argued that mixed methods research may be based on very different epistemological assumptions due to the multiple levels and combination of analyses involved in this research (Gough, 2015).

There were numerous qualitative studies which referred to a range of participants' experiences. These included, the treatment process and the care participants received, experiences of hospitalisation, using psychotropic medication, the recovery process, the impact on their sense of self, stigma of mental illness, carer's experiences, and papers specific to their 
experience of their illness and symptoms. It was concluded that though all these papers related to the participants' experience, they examined separate and distinct phenomena. The aim of the review was to focus on participants' experience of living with psychosis and how it may have impacted on their day-to-day life. Hence, only studies which focused explicitly on the participants' narrative of their psychotic experiences or period of illness were included.

Finally, due to the specific interests in 'male' participants' experiences, only studies which identified male participants as part of their sample were included. Studies referring explicitly to women or parents were excluded (see Table 1.2 for further details).

Table 1.2: Outline of selection criteria

\begin{tabular}{|l|l|}
\hline Inclusion criteria & Exclusion criteria \\
\hline Design: Qualitative studies & Design: Mixed methods and quantitative \\
Topic areas: Living with psychosis, & studies \\
experience of psychosis, course of illness, & Topic areas: treatment, intervention, \\
perceptions of psychosis, impact of psychosis & hallucinations, hearing voices, impact on \\
Sample: minimum of 3 male participants in & self, experiences of stigma, recovery and \\
study & carer's experiences, hospitalisation. \\
Language: English & Sample: women only studies, parents \\
National and international studies & Language: Non-English \\
\hline
\end{tabular}

\section{Screening and Quality Appraisal}

After the 149 papers were appraised based on the inclusion criteria a total of 11 papers remained. 131 papers were deemed unrelated to the current interest. A further six, though 
relevant, could not be included in the analysis as the gender of participants was difficult to deduce from the data presented (see Figure 1.2).

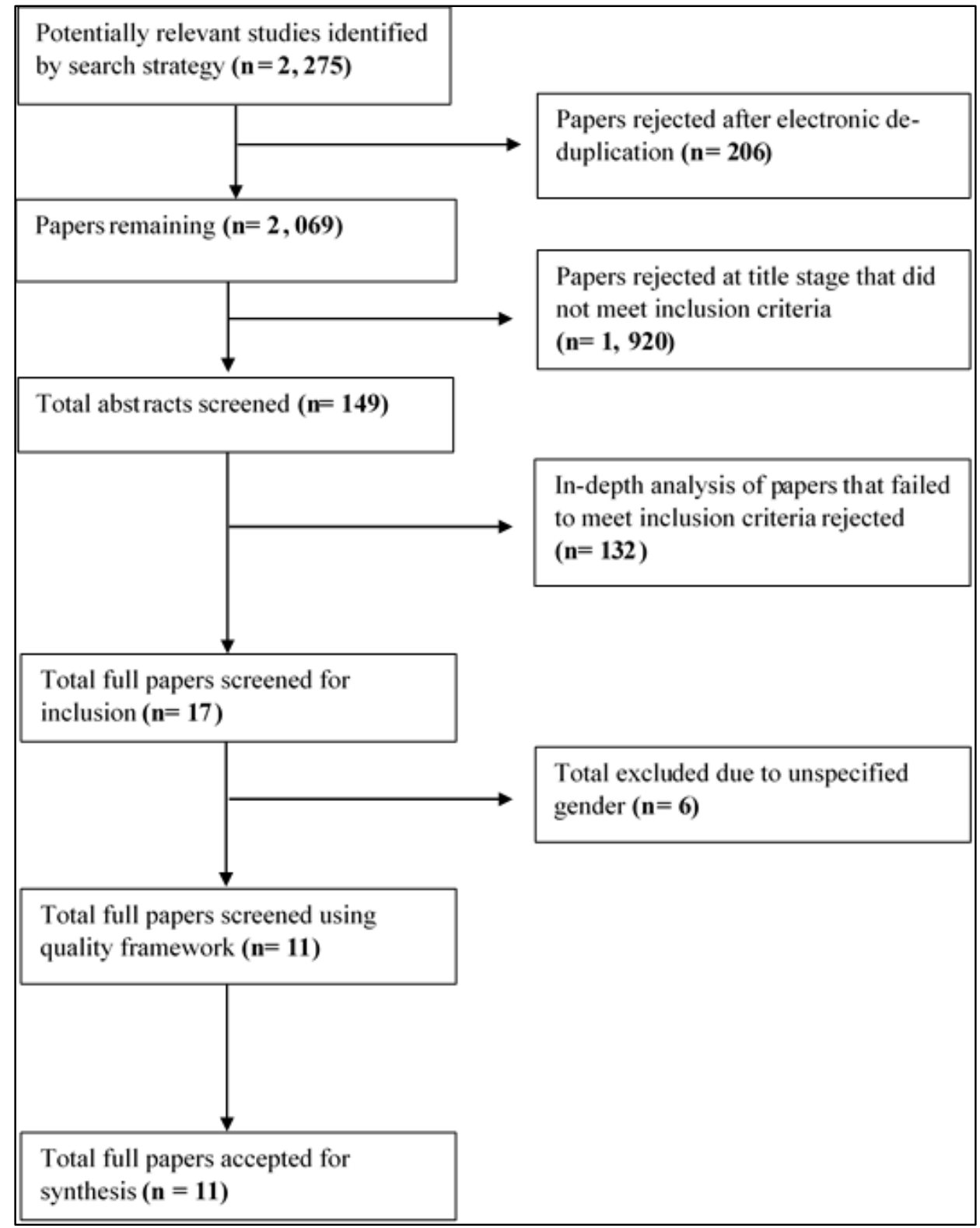

Figure 1.2: Flow diagram depicting study selection process.

The final 11 papers were appraised using the Qualitative Appraisal Framework recommended by the National Institute of Health and Clinical Excellence (NICE, 2012). This framework provided three categorisations for the overall quality of papers: $(++)$ indicated all or most of the checklist criteria being fulfilled; (+) indicated some of the checklist criteria being 
fulfilled; and (-) for few or no checklist criteria being fulfilled (the criteria can be viewed in appendix A). Studies which met the minimum criteria $(+)$ were deemed suitable for further analysis.

As indicated in Table 1.3, two studies met all the criteria, seven studies met most of the criteria and two studies met some of the criteria. For those studies that did not meet the essential criteria, four $(2,4,5,8,10)$ were limited by their lack of discussion regarding the ethical issues apparent in the research and how they attempted to resolve these. Other studies $(1,2,4,6,8,9$, 10) were less robust in their reporting of methodological procedures and demonstrating reliability, either due to the lack of transparency surrounding data analysis or failure to describe or implement processes to increase reflexivity and minimise bias, for example the use of additional sources, triangulation or blind coding (see appendix B for details).

\section{Study Characteristics}

There was a total combined sample size of 478 participants (approximately 276 males and 184 females), with particularly large sample sizes in specific studies (1, $6 \& 10)$. The ages ranged from 18 to 66 years. Six studies were from outside the United Kingdom (UK). Across the studies a range of qualitative methodologies were employed. The participant population was defined through a formal diagnosis of Schizophrenia or label of 'psychosis', and their symptoms were in remission at the time of the interview. Ten studies recruited participants from community services, with one study (9) where hospitalised individuals were interviewed (see Table 1.4). 
Table 1.3: Summary of Quality Assessment

\begin{tabular}{|c|c|c|c|c|c|c|c|c|c|c|c|c|c|c|c|}
\hline \multirow[b]{2}{*}{ Author(s) } & \multicolumn{2}{|c|}{$\begin{array}{l}\text { Theoretical } \\
\text { Approach }\end{array}$} & \multirow[b]{2}{*}{ 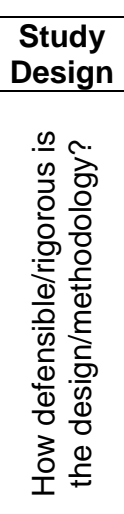 } & \multirow[b]{2}{*}{ 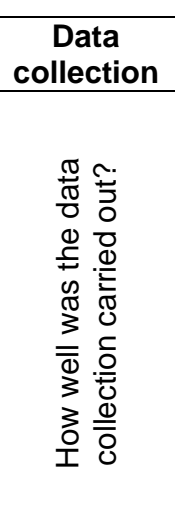 } & \multicolumn{3}{|c|}{ Trustworthiness } & \multicolumn{6}{|c|}{ Analysis } & \multirow[b]{2}{*}{ 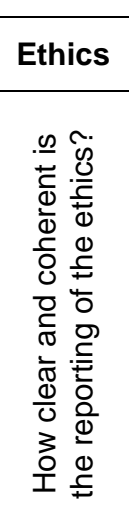 } & \multirow[b]{2}{*}{ Summary of Quality } \\
\hline & 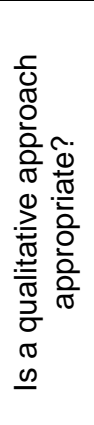 & 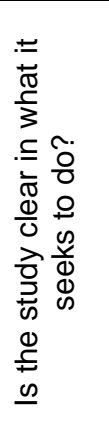 & & & 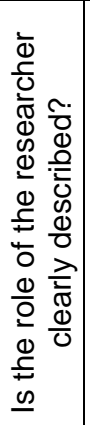 & 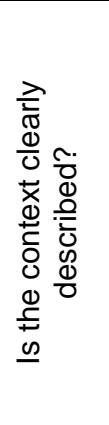 & 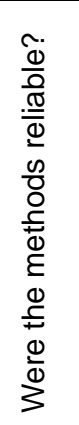 & 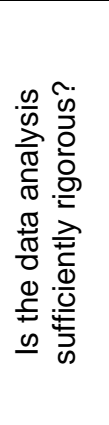 & 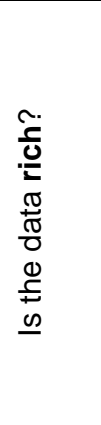 & 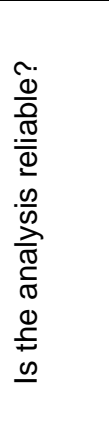 & 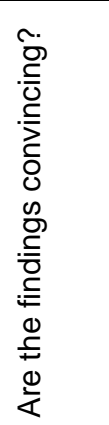 & 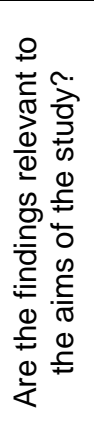 & $\begin{array}{l}\frac{0}{0} \\
\frac{0}{0} \\
\frac{D}{0} \\
\frac{0}{0} \\
0 \\
0\end{array}$ & & \\
\hline $\begin{array}{c}(1) \\
\text { Alshowkan, } \\
\text { Curtis \& } \\
\text { White, (2015). }\end{array}$ & $\checkmark$ & $\checkmark$ & $\checkmark$ & $\checkmark$ & $?$ & $?$ & $?$ & $\checkmark$ & $\checkmark$ & $?$ & $\checkmark$ & $\checkmark$ & $\checkmark$ & $\checkmark$ & $\begin{array}{l}++ \text { (Few weaknesses) } \\
\text { Most of the criteria } \\
\text { were met. The areas of } \\
\text { weakness } \\
\text { predominantly related } \\
\text { to trustworthiness and } \\
\text { reliability checks which } \\
\text { were not explained. }\end{array}$ \\
\hline $\begin{array}{c}(2) \\
\text { Gajwani, } \\
\text { Larkin \& } \\
\text { Jackson, } \\
\text { (2017) }\end{array}$ & $\checkmark$ & $\checkmark$ & $\checkmark$ & $\checkmark$ & ? & $\checkmark$ & & $\checkmark$ & $\checkmark$ & $\checkmark$ & $\checkmark$ & $\checkmark$ & $\checkmark$ & $?$ & $\begin{array}{l}\text { ++ (Few weaknesses) } \\
\text { Nearly all criteria were } \\
\text { met, the study's } \\
\text { weakness was in its } \\
\text { limited description of } \\
\text { ethical considerations } \\
\text { and issues of } \\
\text { reflexivity. }\end{array}$ \\
\hline $\begin{array}{c}(3) \\
\text { Gee, Pearce, } \\
\text { \& Jackson, } \\
\text { (2003). }\end{array}$ & $\checkmark$ & $\checkmark$ & $\checkmark$ & $\checkmark$ & & $\checkmark$ & & $\checkmark$ & $\checkmark$ & $\checkmark$ & $\checkmark$ & $\checkmark$ & $?$ & $\checkmark$ & $\begin{array}{l}\text { ++ (Few weaknesses) } \\
\text { Nearly all criteria were } \\
\text { adequately met. The } \\
\text { study was conducted } \\
\text { rigorously to improve } \\
\text { validity and reliability. } \\
\text { However, could have } \\
\text { benefited from further } \\
\text { elaboration and } \\
\text { interpretation in the } \\
\text { discussion. }\end{array}$ \\
\hline
\end{tabular}




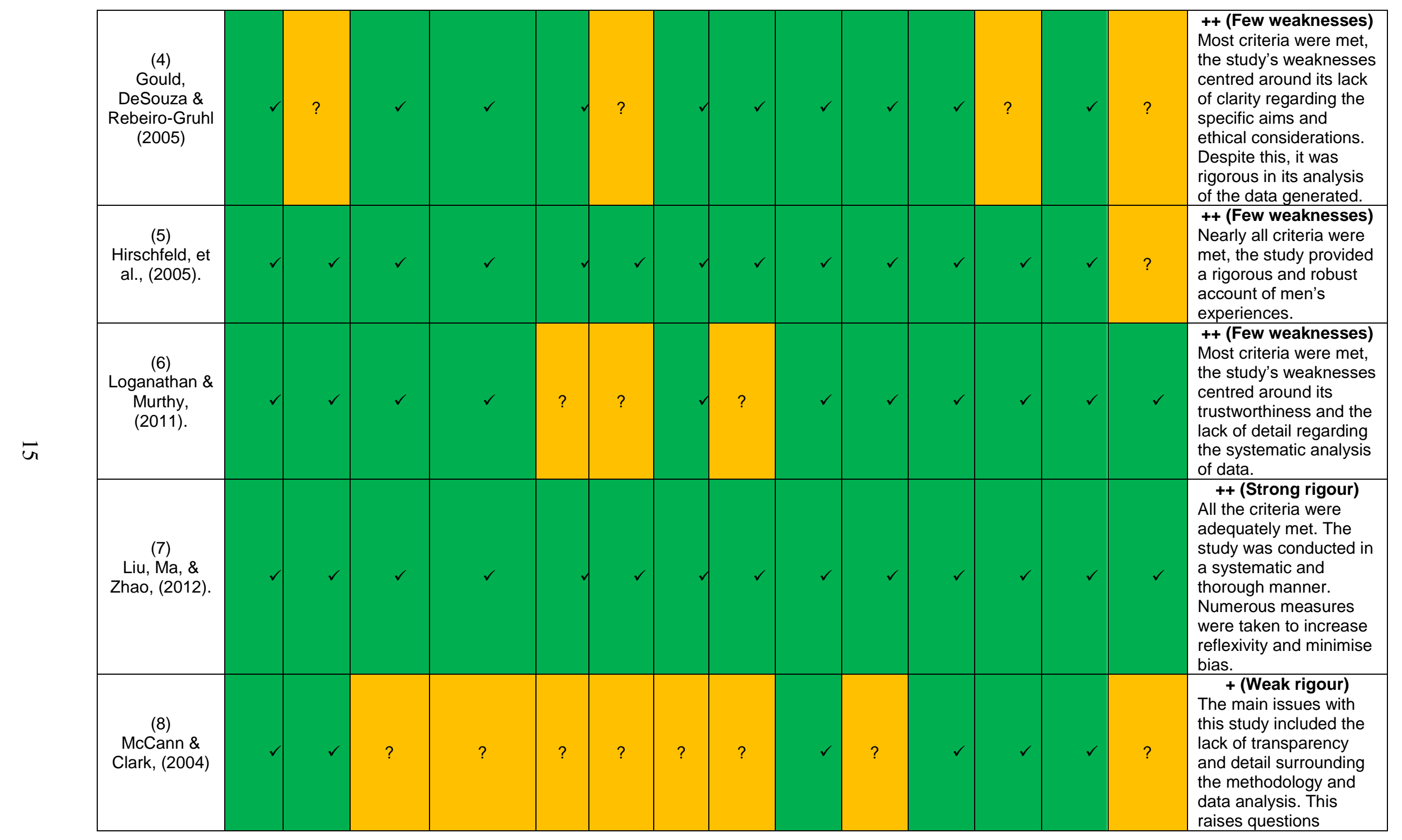




\begin{tabular}{|c|c|c|c|c|c|c|c|c|c|c|c|c|c|c|c|}
\hline & & & & & & & & & & & & & & & $\begin{array}{l}\text { regarding the overall } \\
\text { reliability of the findings } \\
\text { presented and to what } \\
\text { extent they were } \\
\text { influenced by the } \\
\text { researcher's } \\
\text { assumptions. }\end{array}$ \\
\hline $\begin{array}{l}\text { (9) } \\
\text { Oliviera et al., } \\
\quad(2013)\end{array}$ & $\checkmark$ & $\checkmark$ & $\checkmark$ & ? & ? & $\checkmark$ & ? & ? & ? & ? & $\checkmark$ & $\checkmark$ & $\checkmark$ & $\checkmark$ & $\begin{array}{l}\quad+\text { (Weak rigour) } \\
\text { This study was limited } \\
\text { by the lack of } \\
\text { procedures in place to } \\
\text { ensure the reliability of } \\
\text { the methodological } \\
\text { design and data } \\
\text { analysis, which was not } \\
\text { systematically or clearly } \\
\text { described. This impacts } \\
\text { on the overall } \\
\text { robustness of this } \\
\text { study. }\end{array}$ \\
\hline $\begin{array}{l}\text { (10) } \\
\text { Roe, Chopra } \\
\text { \& Rudnick, } \\
\text { (2004). }\end{array}$ & $\checkmark$ & $\checkmark$ & $\checkmark$ & $\checkmark$ & ? & $\checkmark$ & & $\checkmark$ & $\checkmark$ & ? & $\checkmark$ & $\checkmark$ & $\checkmark$ & $?$ & $\begin{array}{l}++ \text { (Few weaknesses) } \\
\text { Most criteria were met; } \\
\text { this study was limited } \\
\text { by the lack of } \\
\text { triangulation of findings } \\
\text { or use of other checks } \\
\text { to minimise bias. }\end{array}$ \\
\hline $\begin{array}{c}(11) \\
\text { Saneesha et } \\
\text { al. (2009) }\end{array}$ & $\checkmark$ & $\checkmark$ & $\checkmark$ & $\checkmark$ & & $\checkmark$ & & $\checkmark$ & $\checkmark$ & $\checkmark$ & $\checkmark$ & $\checkmark$ & $\checkmark$ & $\checkmark$ & $\begin{array}{l}\quad++ \text { (Strong rigour) } \\
\text { All the criteria were } \\
\text { adequately met. A } \\
\text { strength of the study } \\
\text { was the numerous } \\
\text { measures taken to } \\
\text { increase reflexivity and } \\
\text { minimise bias. }\end{array}$ \\
\hline
\end{tabular}


Table 1.4: Summary of studies included in review

\begin{tabular}{|c|c|c|c|c|c|c|c|c|}
\hline No. & Author \& Country & Aims of study & Participants & $\begin{array}{c}\text { Male } \\
\text { quotes } \\
\text { extracted }\end{array}$ & $\begin{array}{c}\text { Data } \\
\text { Collection }\end{array}$ & Analysis & Main Concepts/Themes & $\begin{array}{c}\text { Contribution to } \\
\text { synthesis }\end{array}$ \\
\hline 1 & $\begin{array}{c}\text { Alshowkan, Curtis \& } \\
\text { White, (2015). } \\
\text { Saudi Arabia }\end{array}$ & $\begin{array}{l}\text { The quality of } \\
\text { life of people } \\
\text { experiencing } \\
\text { schizophrenia }\end{array}$ & $\begin{array}{c}97 \text { males; } 62 \\
\text { females (18- } \\
65 \text { years) }\end{array}$ & 6 & $\begin{array}{c}\text { Semi-structured } \\
\text { interview }\end{array}$ & Thematic analysis & $\begin{array}{l}\text { Shame (keeping it secret } \\
\text { and media influence); } \\
\text { positive role of religion; } \\
\text { meaning of life }\end{array}$ & $\begin{array}{c}\text { Living with } \\
\text { psychosis; shock } \\
\text { followed by } \\
\text { understanding; } \\
\text { towards recovery }\end{array}$ \\
\hline 2 & $\begin{array}{l}\text { Gajwani, Larkin \& } \\
\text { Jackson, (2017) } \\
\text { United Kingdom }\end{array}$ & $\begin{array}{c}\text { Men's } \\
\text { experiences of } \\
\text { emerging } \\
\text { psychosis and the } \\
\text { meaning of } \\
\text { suicide attempts }\end{array}$ & $\begin{array}{c}7 \text { males } \\
\text { (18-35 years) }\end{array}$ & 38 & $\begin{array}{l}\text { Semi-structured } \\
\text { interview }\end{array}$ & $\begin{array}{c}\text { Interpretative } \\
\text { Phenomenological } \\
\text { Analysis }\end{array}$ & $\begin{array}{l}\text { Loss of self-identity; } \\
\text { critical father } \\
\text { relationship; unresolved } \\
\text { early experiences; social } \\
\text { isolation; hopelessness; } \\
\text { shared meaning and } \\
\text { burden }\end{array}$ & $\begin{array}{c}\text { Living with } \\
\text { psychosis; shock } \\
\text { followed by } \\
\text { understanding; } \\
\text { towards recovery }\end{array}$ \\
\hline 3 & $\begin{array}{l}\text { Gee, Pearce, \& } \\
\text { Jackson, (2003). } \\
\text { United Kingdom }\end{array}$ & $\begin{array}{c}\text { Impact of } \\
\text { schizophrenia on } \\
\text { quality of life }\end{array}$ & $\begin{array}{c}3 \text { males; } 3 \\
\text { females (30- } \\
55 \text { years) }\end{array}$ & 16 & Interview & Grounded Theory & $\begin{array}{l}\text { Barriers to relationships; } \\
\text { reduced behavioural } \\
\text { control; loss of } \\
\text { occupational opportunity; } \\
\text { financial constraints; } \\
\text { symptoms; side-effects; } \\
\text { labelling; concerns for } \\
\text { future; positive outcomes }\end{array}$ & $\begin{array}{c}\text { Living with } \\
\text { psychosis; shock } \\
\text { followed by } \\
\text { understanding; } \\
\text { towards recovery }\end{array}$ \\
\hline
\end{tabular}




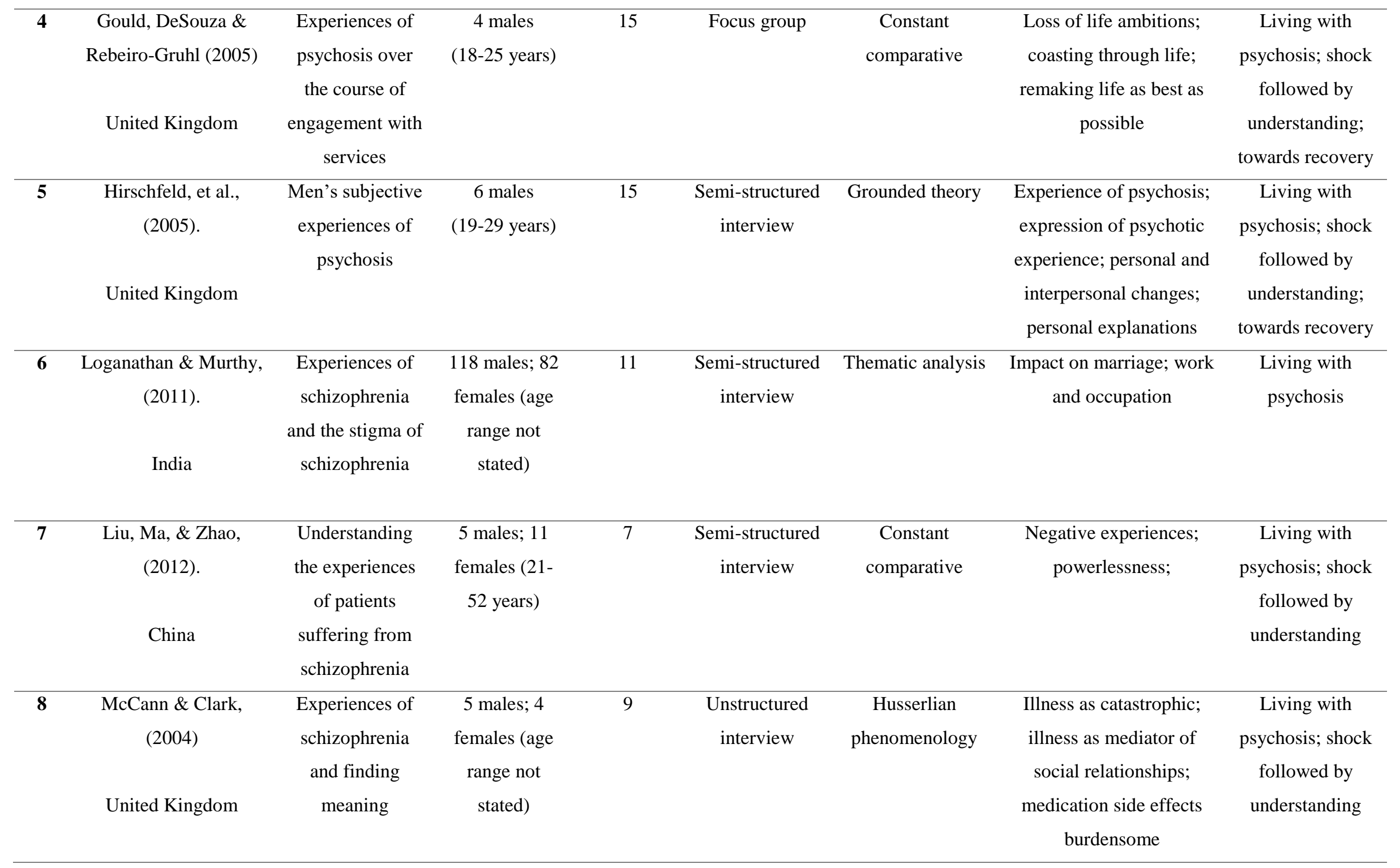




\begin{tabular}{|c|c|c|c|c|c|c|c|c|}
\hline 9 & Oliviera et al., (2013) & $\begin{array}{l}\text { Meaning and } \\
\text { implications of } \\
\text { having } \\
\text { schizophrenia }\end{array}$ & $\begin{array}{c}6 \text { males; } 4 \\
\text { females (21- } \\
66 \text { years) }\end{array}$ & 6 & Interview & $\begin{array}{l}\text { Thematic } \\
\text { Analysis }\end{array}$ & $\begin{array}{l}\text { Feelings experienced in } \\
\text { discovery and } \\
\text { acceptance; knowledge } \\
\text { about disorder; } \\
\text { Expectations for future }\end{array}$ & $\begin{array}{c}\text { Living with } \\
\text { psychosis; shock } \\
\text { followed by } \\
\text { understanding; } \\
\text { towards recovery }\end{array}$ \\
\hline 10 & $\begin{array}{c}\text { Roe, Chopra \& } \\
\text { Rudnick, (2004). } \\
\text { USA }\end{array}$ & $\begin{array}{l}\text { Exploring the } \\
\text { course of } \\
\text { schizophrenia } \\
\text { and change } \\
\text { processes }\end{array}$ & $\begin{array}{c}25 \text { males; } 18 \\
\text { females (20- } \\
39 \text { years) }\end{array}$ & 9 & $\begin{array}{l}\text { Semi-structured } \\
\text { interview, } \\
\text { longitudinal } \\
\text { design }\end{array}$ & $\begin{array}{l}\text { Open coding case } \\
\text { analysis }\end{array}$ & $\begin{array}{l}\text { Regulating activity; } \\
\text { controlling symptoms; } \\
\text { determination and hope; } \\
\text { change in attitude and } \\
\text { corrective experiences }\end{array}$ & $\begin{array}{c}\text { Living with } \\
\text { psychosis; } \\
\text { towards recovery }\end{array}$ \\
\hline 11 & $\begin{array}{c}\text { Saneesha et al. (2009) } \\
\text { Thailand }\end{array}$ & $\begin{array}{l}\text { Self-perceptions } \\
\text { of individuals in } \\
\text { relation to their } \\
\text { mental illness } \\
\text { (schizophrenia) }\end{array}$ & $\begin{array}{c}18 \\
\text { participants } \\
\text { (gender } \\
\text { breakdown } \\
\text { not provided) } \\
\text { (24-57 years) }\end{array}$ & 6 & $\begin{array}{c}\text { In-depth } \\
\text { interviews and } \\
\text { observations }\end{array}$ & $\begin{array}{c}\text { Heidegger's } \\
\text { hermeneutic } \\
\text { phenomenological } \\
\text { approach }\end{array}$ & $\begin{array}{l}\text { Perceptions of mental } \\
\text { illness; causes of illness; } \\
\text { discrimination; living } \\
\text { with schizophrenia }\end{array}$ & $\begin{array}{c}\text { Living with } \\
\text { psychosis; shock } \\
\text { followed by } \\
\text { understanding }\end{array}$ \\
\hline
\end{tabular}




\section{Data Extraction and Analysis}

The data extracted focused on the research findings pertaining to men's experiences, including quotations and the researcher's interpretations, plus themes and concepts where applicable. Only four of the studies were male-specific, whereas the remaining seven had a mixed sample. The challenge of including mixed sample studies was effectively deducing to what degree the male narratives contributed to the themes to ensure that the analysis was not solely restricted to de-contextualised data (Walsh \& Downe, 2005). Taking into account the context within which data emerged and the interpretations related to it, is reported to be important to a reliable synthesis of qualitative data (Sandelowski \& Barroso, 2006). As a way of overcoming this, the author extracted quotes alongside the original researcher's descriptions and interpretations of those specific quotes, while noting their relationship to the overall concepts or themes in the study.

A thematic synthesis (Thomas \& Harden, 2008) was deemed as the most appropriate method of analysis in this case, due to the lack of a gendered focus in most studies. As in Figure 1.1, the analysis involved line-by-line coding of the data (see appendix C) for each study to identify emerging 'descriptive' themes within and across the studies (see appendix D). These were then interpreted and transformed into 'analytical' themes (see appendix E) to move 'beyond' the original findings. During the coding stage, the author was mindful of their presumptions and biases regarding masculinity, to minimise the risk of imposing meanings onto the data. The themes were checked against the extracted data and discussed with an external researcher to enhance the reliability of findings. 


\section{Results}

The analysis revealed three superordinate themes: 'shock followed by understanding', 'living with psychosis' and 'towards recovery', with a combination of nine respective subthemes (see Figure 1.3). These themes combine the idiographic similarities and differences across studies (referred to by number) to provide an interpretative synthesis of the findings as depicted through men's narratives.

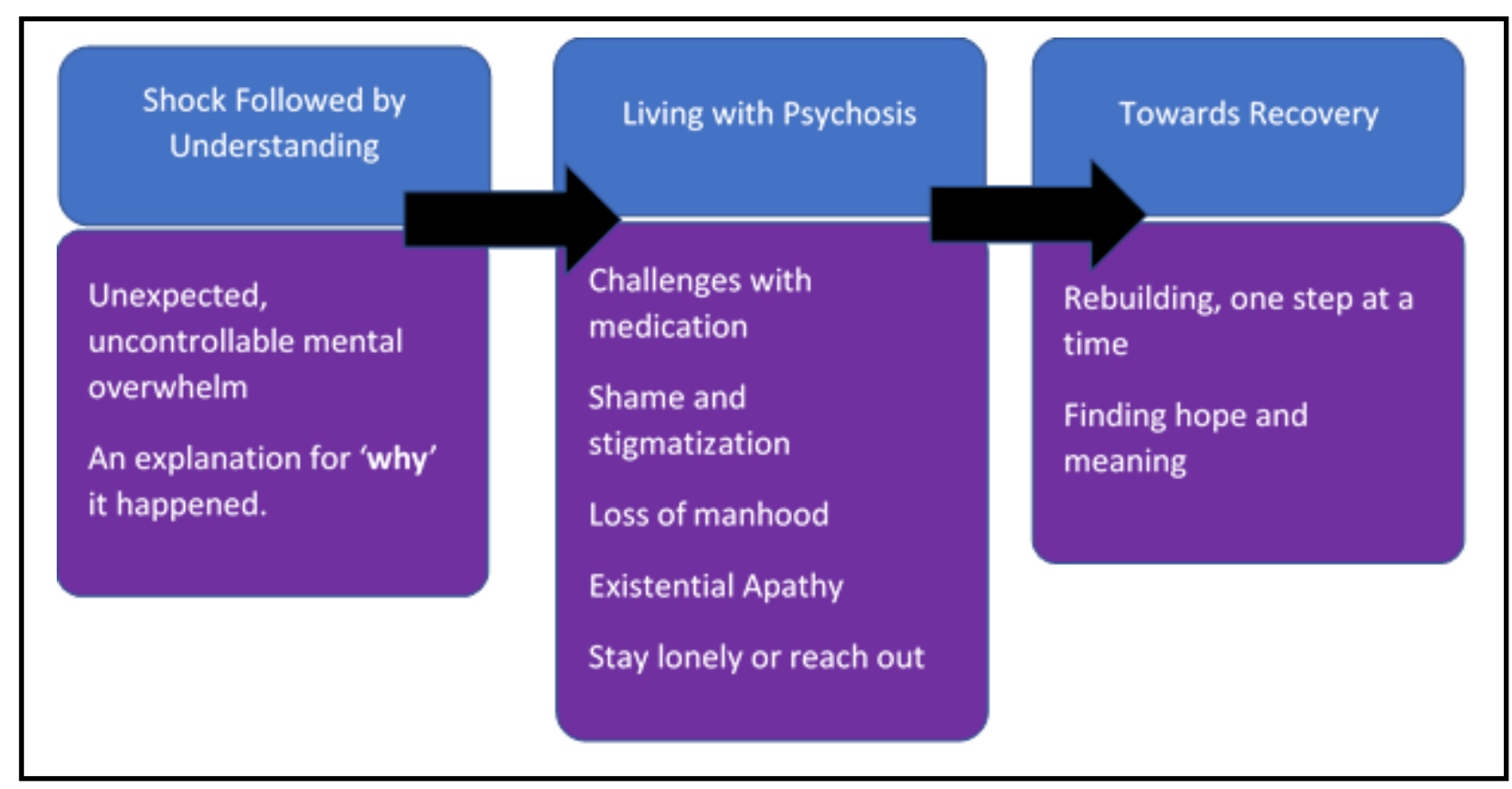

Figure 1.3: Summary of superordinate and subordinate themes.

\section{Theme 1: Shock followed by Understanding}

Nine of the eleven studies contributed to this theme which represented the initial disruption that occurred in the lives of men at the onset of their illness and was re-experienced at times when symptoms were overpowering $(1-5,7-9,11)$. The men attempted to understand the causes behind their illness and across the studies various reasons were expressed, each an attempt to make sense of why it happened $(1,2,5,8)$ and what contributed to the development of the illness. 


\subsection{Unexpected, Uncontrollable Mental Overwhelm}

The onset of illness marked a traumatic turning point in the lives of men, who described it as a 'sudden' event that caused drastic changes in their brain, perceptions and emotions, upturning their reality. The effects on the mind were most noticeable, experienced as a sense of being 'shut down', 'wiped clean', or struggling to concentrate or think due to the internal noise (4) that was all-consuming. They alluded to its uncontrollable $(2,3,5,11)$ and unexpected nature $(7,9)$. Feelings of fear accompanied the psychotic experience, including confusion and uncertainty $(7,8)$, expressed through the constant questioning, "Mom, what's going on?" (9, pg. 80) and bewilderment, "I have no idea what had happened" (7, pg. 1710).

Men reported experiencing 'un-normal things' (5), leading to distressing, intrusive thoughts and urges to behave in destructive ways that they would not have anticipated of themselves. One man stated, “it's this evil thing within you, that's gonna make you do something terrible" (2, pg. 3). Another described the command hallucinations he experienced: "I heard voices telling me to kill people" (5, pg. 256), forcing him to contend with his aggressive urges. Anger was a common experience across the studies $(2,5,6,7)$ in response to the emotional pain and overwhelm. Due to the impact that the experience had on the men's lives and the subsequent powerlessness that they experienced, there was a heightened anxiety relating to relapse $(7,8)$. Some men viewed their prognosis as 'unpredictable', seeing their illness as chronic and unchangeable (11). This often led to a sense of hopelessness regarding their future. 


\section{Example quotes for 'Unexpected, uncontrollable mental overwhelm':}

"I remember one day ... that everything crumbled ... It was probably one of the worst days of my life ... Before that I was just kinda complacent ... you know, not just coasting through life, you know, normally ... Then everything dormant and then all of a sudden ... it's like your whole mind just gets wiped clean and ... you gotta restart your whole life because all these negative things kinda get written on the blackboard.” (Gould, DeSouza, \& Rebeiro-Gruhl, 2005, pg. 470)

"Actually, I have no idea what had happened to me at that time [his psychotic episode]. I just felt as if there was fire in my breast. You know, that made me very anxious and [I] wanted to fight with other people. Everything could irritate me easily. The explanation of Chinese traditional medicine was that my organs were Shang huo [overactivated]. Anyway, I am very confused. How could this happen?” (Liu, Ma, \& Zhao, 2012, pg. 1710)

"The worst aspect of it is not being confident with your own mind. Knowing that you can lose it, as it happened before. I am conscious of the fact that it can happen again ... For me, that is the worst thing." (McCann \& Clark, 2004, pg. 788)

"It was a shock for me [...] was desperate with a too great anguish [...] It was difficult, when I remember, I remember the suffering I went through [...] I prayed and asked God in my prayers for that was nothing [...] I was suspicious, like a sixth sense. I asked, weeping for my mom [childish voice]: mom what's going on? " (Oliveira, Rodrigues, Furegato, \& Siqueira Júnior, 2013,pg. 82)

\subsection{An Explanation for 'Why' it Happened}

Following the upheaval to themselves and by extension their lives, when speaking about their illness the men contemplated how their life stories had led them to this point $(2,5,9,11)$ in attempt to make sense of the causes of illness, or identify what factors increased their vulnerability to it. Some considered the biological factors $(9,11,5)$, others social and psychological factors $(2,5)$, whilst others attributed it to supernatural causes $(11)$. For some a single adverse event stood out $(2,5,11)$ whereas for others it was the accumulation of multiple adverse experiences $(2,5)$. 
Biological factors were related to brain-injury when "[his] car overturned, so that accident caused [his] brain disorder" (11, pg. 308) or simply the result of a 'disease' (9) that was not fully understood. In addition, the use of substances was prevalent amongst the men, who admitted to using cannabis recreationally $(2,5,8)$ as a means of enjoyment, or for selfsoothing or self-medicating purposes. Hirschfield et al. (2005) described one young man "taking acid and feeling close to friends through that shared social experience but finding that the drug had disturbing mental effects" (5, pg. 261).

Others recalled unresolved past experiences of bullying or victimisation, "turbulent" relationships with their parents (mainly fathers), abuse, or loss and separation as being core factors in contributing to their difficulties $(2,5)$. For instance, in the Gajwani, Larkin, \& Jackson, (2017) study the loss of a caring parental figure left a void or absence in the men's lives, creating a sense of vulnerability and grief. Conversely, in the face of an abusive parent, it meant feeling belittled, criticized and devalued (2). Two men reported experiencing 'flashbacks', paranoia and anxiety related to specific traumatic events that they had encountered (2), whilst others described a cumulative effect of 'bottled up' emotions and increased isolation (5). Hirschfield et al., (2005) described one individual who resorted to self-blame, viewing his illness as a form of 'punishment' for his past behaviour. As a result, he internalised his distress, condemning himself and berating himself rather than focusing on external causes. The illness signified a form of retribution, 'something unforgivable catching up with him' (5, pg 262) that was now physically and visibly apparent.

In the study in Thailand (11) greater emphasis was placed on supernatural causes of illness, specifically the men viewing themselves as the victims of 'black magic' which had been performed on them by those harbouring malicious intent. There was an understanding that the effects of black magic were the same as those experienced in psychosis, such as confusion, 
distress and unusual cognitive and sensory perceptions. This is how the illness was understood on a cultural level.

\section{Example quotes for 'An explanation for why it happened':}

"I had a real big problem with eating and er, my dad use to like bully me about my eating, and take the piss out of me at the dinner table... dad was always very critical of me like, I wasn't very good at maths... And he'd shout at me, he'd shout at me, shout at me about not being able to do it." (Gajwani, Larkin, \& Jackson, 2017, pg. 4)

"I felt like I was being punished and in a way I thought yeah this is what you deserve, but then I thought, no because you have never been like this before...yeah, I have felt I need to be punished, throughout my life as well, things I have done throughout my life, I have thought well everyone knows now, you know, you got to be punished, and this is what they are doing to you, they are punishing you. (Hirschfeld, Smith, Trower, \& Griffin, 2005, pg. 262)

"My illness [was] caused by black magic. I believed that someone disliked me and envied me, so ... he would do this to me. Yes, I thought that my illness was affected by black magic. I worked . . . at a construction site on the border of Thailand where black magic was widely believed." (Sanseeha, Chontawan, Sethabouppha, Disayavanish, \& Turale, 2009, pg. 308)

“[...] this disease that I recently came to know, I don't know if I ever had it before and I didn't know [...] I was retracted, you know, because it's a disease that we don't know much [...] we are always in doubt, because actually we don't know the base of this disease [...] we're a bit goofy of having a disease like this." (Oliveira, Rodrigues, Furegato, \& Siqueira Júnior, 2013, pg. 82)

\section{Theme 2: Living with Psychosis}

This theme was apparent in all eleven studies that together, encapsulated the various facets of men's experiences of living with psychosis. It highlights the dilemmas they experienced in the process of coming to terms with their illness, whilst simultaneously managing their daily lives, captured in the five subthemes: challenges with medication, shame and stigmatization, loss of manhood, existential apathy and stay lonely or reach out. 


\subsection{Challenges with Medication}

Medication did not form a core part of the studies that were reviewed, however in five studies $(2,3,8,9,11)$ they were mentioned by the men. There seemed to be an on-going battle within themselves (9) and with healthcare professionals $(2,11)$, as to whether they should take medication, indeed whether they even wanted to. On the one hand, there were the debilitating effects of the illness and symptoms, whilst on the other being dependent on medication did not appeal to them. It was a contentious issue and the pressure to take medication came externally from family and services, sometimes coercively $(2,9)$.

Similarly, others doubted the effectiveness of medication and failed to understand the use for it, since it "[didn't] have an effect" (3,pg 7) and they were "not sure it had any benefits" (3, pg. 8). It led to a sense of despondency about the prognosis of the illness, and powerlessness and desperation in the face of its chronicity $(7,8,11)$. For others still, the side effects caused greater concern (8); McCann and Clark (2004) specifically noted that "only male participants reported that medications adversely affected their sexual relationships" (pg. 793). Thus, "there was a general sense that they continued to take their medication because of concern regarding what would happen if they didn't" $(3$, pg. 7$)$. In the end the men either conceded or accepted psychotropic intervention. 


\section{Example quotes for 'Challenges with medication':}

"It all seems like they want something else from what I want though which always puts me at loggerheads with my mum for instance... My mum was kind of campaigning for me to stay in hospital... I was given an ultimatum to either stop taking cannabis or to umm, be put back down on medication, forcefully...I don't believe in these, the power of prescription drugs to just heal, you know, mental, psychological trauma." (Gajwani, Larkin \& Jackson, 2017, pg. 6)

"I have taken medications for a long time, and never stopped them ... I asked and also begged my doctor to stop prescribing them but he advised that I need to take them because the symptoms may relapse. Some patients with 10 years of treatment had relapsed, and they needed to restart the medication. I can take it for my whole life as long as there are no side-effects. I have this illness until now because it cannot be cured in 10 years." (Sanseeha et al., 2009, pg. 307)

"Sexually, my medication affects my ability to ejaculate... I am on a dose now where it is okay ... But when I get above that threshold, I just can't do it." (McCann \& Clark, 2004, pg. 793)

"When I told my problems to the psychiatrist in the first hospitalization I decided to take the drugs naturally. I understood that the medicines made me calmer, that the world was not evil." (Oliveira et al., 2013, pg. 82)

\subsection{Shame and Stigmatization}

Men would not talk about their difficulties due to the fear of stigma that might be associated with the illness and subsequent feelings of shame $(1-3,6-8,11)$. In one case, the individual attempted to deal with the onset of their symptoms alone, unable to trust others, only to find that his condition worsened (2). Wary and fearful of 'discrimination' from others $(1,3$, $6,11,8)$ regarding how they or their behaviour would be perceived $(7,8)$, remaining silent was a protective measure employed by the men. They felt others would not understand them (8) and would seek to hospitalise them (7). This was associated with family member's apprehension regarding any strange or out of ordinary behaviour that may indicate possible destabilisation. In fact, the stigma associated with their illness often impacted on work and created 
complications in relationships $(1,3,6,8,11)$. One individual described how he was robbed of 'being human' and aspiring, as if in his condition this was inadvisable (7).

A deep sense of shame pervaded during their illness, which further reinforced the urge to 'hide' symptoms or knowledge regarding their illness. This was a particularly strong theme within those studies conducted in Asia $(1,6,7,11)$. In some cases, this sense of shame was further compounded by humiliation or ridicule faced by the men from friends and the wider community, in the form of abuse, victimisation, labelling or stereotypes that were attached to them $(3,6)$. This constant devaluation by others resulted in a subsequent loss of self-esteem, respect and status within the communities that they lived, causing them to feel inferior and isolated $(1,6,8)$.

\section{Example quotes for 'Shame and stigmatisation':}

"But because of my illness and negative view of people with mental illness as they are mentally ill. . . people will not allow me to get a job and to get married and to have a little dream like any other human being." (Alshowkan, Curtis, \& White, 2015, pg. 3)

"People throw stones at me. They tease me and call me names. I used to be a tailor. Now, I cannot do that and work as a waiter in a hotel. My friends too throw coconut shells at me." (Loganathan \& Murthy, 2011, pg. 575)

"I am like a timid dog every day. I dare not talk with other people, and dare not do what I want to do. I am always worried that I would say or do something wrong that would remind other people about whether or not I am going to relapse. Otherwise, my family will take me to the hospital again." (Liu, Ma, \& Zhao, 2012, pg. 1710)

"I try to avoid letting them know, because there is stigma associated with it. People are concerned and worried about you; what you might do. I can understand that; I can understand the concern employers probably have with people with mental illness. But if the person who has the mental illness is responsible, then it shouldn't be a problem. You see, I can understand that, but I don't let them know." (McCann \& Clark, 2004 pg. 791) 


\subsection{Loss of Manhood}

There was a marked sense of 'before and after' in the narratives of men, noticeable in the prominent and consistent feeling of loss in over half the studies (2-7). It appeared under several guises, sometimes in the form of concrete losses connected to relationships, occupational opportunities, skills and abilities, or the happy, normal life they had possessed (24, 6). Other times, these were more abstract: a loss of self-esteem, independence, status, autonomy, competence and respect (2-7), stripping them of not only their selfhood, but also their manhood.

With regards to occupation and relationships, the men frequently compared their capacity and ability to perform certain tasks prior to the onset of illness to their current state. They noticed that they were more tired, less able to maintain senior positions and appeared to demonstrate greater weakness in their working life $(6,4)$. Their confidence level dropped as a result of their observed lack of competence, which led to reduced autonomy and constrained independence.

Hirschfield et al. (2005) described how the men's illness interfered with their relationships. Specifically, she described how a participant's illness impacted on his confidence with 'pulling girls', never quite 'actualising his desire', resulting in a sense of dissatisfaction with himself (5). Others recognised that it impacted on their ability to socialise with others (2, 6). Being aware of these discrepancies likely contributed to a loss of self-esteem, resulting in internal feelings of inadequacy, 'worthlessness' and 'uselessness' $(2,3)$.

As a result of the illness, men were no longer viewed in the same way by others, nor did they view themselves in the same way. Thus, the subsequent devaluation they experienced was inflicted by others and self. Failure, deficit and impotence became commonplace for them as 
their functioning was impaired $(4,5)$ which meant they struggled to cope with the demands of life or achieve goals that they may have once envisioned for themselves $(3,4,6)$. Hence, either forced to limit themselves (7) or fall into a state of helplessness (3) leading to feelings of frustration, anger and depression at being 'thwarted' and 'stifled' (5).

As the impact of their illness penetrated several areas of their life, the men reported a pronounced loss of respect, status and value in their communities. They were rejected even by close family members (6), no longer as 'popular' (4) as they had once been. For those who did not 'self-identify as mentally disordered', there was a sense of feeling unheard or forced into treatment (7). This was indicative of an overall loss of personal power and perhaps influence.

\section{Example quotes for 'Loss of manhood':}

"I did very well in my work before I got sick. Sometimes I even felt working was so easy that I could handle it as I wished. However, I became so incompetent in my job after being ill. Sometimes I found that the only thing I could do was just to follow other people, without my own ideas and plan." (Liu, Ma, \& Zhao, 2012,pg. 1710)

“Can't get a job, can't get a girlfriend, can't get a car, can't get a telly, can't get nothing...it's just everything falls down into a big pit, and you can't get out." (Hirschfeld et al., 2005, pg. 249)

"The feeling of uselessness is one of the strongest things. Because you've got no self-esteem and I'm always sort of comparing myself with people who do work. There's no ........ you've got no respect in a way." (Gee, Pearce, \& Jackson, 2003, pg. 7)

"I was to marry my cousin, now, after my illness, my relatives have decided not to get her married to me and have given her hand elsewhere. At home also people don't give me importance, whatever I say has no value at all. " (Loganathan \& Murthy, 2011, pg. 572)

\subsection{Existential Apathy}

"Coasting through life" (4, pg. 470) depicted the periods where there was "nothing to do' $(2,4)$ and the frustration, despair or boredom that accompanied these states. During these 
periods, most men described feeling low in mood, demotivated and apathetic $(2-5,8)$. Everyday tasks such as getting up in the morning and attending college were 'arduous' (4), eroding the men's motivation (5) to participate in daily life, further exacerbated by the loss of self-efficacy. It left behind a sense of emptiness and meaninglessness about life, because "what's the point of life?" (2, pg.6) when there's "nothing to do" (4, pg. 470) and hope for the future has diminished $(2,3,8)$.

Some men sought to escape this overwhelming sense of 'nothingness', powerlessness, hopelessness and despair by either contemplating or actively attempting suicide $(2-5,8)$, or alternatively numbing themselves through substance use (8). For these men this was the only solution to an unfathomable, unbearable situation where they "did not know what to do or how to help themselves" (5, pg. 257). There was a feeling of 'entrapment' (8) or being stuck due to

\section{Example quotes for 'Existential apathy':}

'The days are empty, there's nothing to do but sleep' and 'I just want to go to sleep and never wake up'”' (Gould, DeSouza \& Rebeiro-Gruhl, 2005, pg. 470)

"Sometimes, when I am alone I just break down and cry for no reason at all. It just comes out on me that I just want to cry and I get down...I've even tried committing suicide once...I took three beers with 15-17 tablets. I ended up in the hospital and was unconscious for three days...It is very hard to see a future with this illness. ” (McCann \& Clark, 2004)

"What is the point of life. What is the point of life? What are you supposed to do every day? Just work, eat, drink, watch tv, that's what life is? Do you know what I mean? All I remember was that I was feeling low. I took some paracetamol. I wanted to die." (Gajwani, Larkin \& Jackson, 2017, pg. 6)

"It's just that I think there's not going to be anything good about the future and that I'm always going to be like this. Well, I think that things can't change and that things are going to stay the same." (Gee, Pearce, \& Jackson, 2003, pg. 8) 
their life circumstances, the losses they had suffered and the difficulties they experienced as a result of this.

\subsection{Stay Lonely or Reach out}

Another challenge faced by these men involved complications in interpersonal relationships and a struggle for belonging $(2-6,8,10)$. For one, the numerous biological and psychological effects of the illness underlined the men's difference from others, alienating them from those who had a 'normal life' (2). It promoted a feeling of exclusion that was further compounded by experiences of stigma (6) or a loss of close friendships $(2-4,8)$. The mistrust and paranoia they experienced strained their relationships $(2,3,5,8)$, particularly since others were unsure of how to respond or help them (3). At times the overprotectiveness of close others was perceived as more of a hindrance than a help (10).

Feelings of low mood and general apathy interfered with their capacity to socialise or maintain friendships $(2,5)$. As a means of managing this, the men employed self-isolating strategies, minimising or avoiding interaction altogether, which only served to increase their detachment from others. The loneliness of social withdrawal disconnected these men from their

wider community $(2,5,6,8)$. This lack of belonging could only be rectified through risking emotional intimacy and connection. However, the men found that the illness impacted on their social skills causing difficulties in their ability and confidence to build relationships $(2,6)$. One man expressed his conflict in communicating his emotional needs and deep yearning for closeness. Though he contemplated sharing his feelings, when confronted with the reality of it, he was unable to reveal his needs, automatically maintaining his 'hard' front (5).

Once this barrier towards seeking support and displaying vulnerability was overcome, the men acknowledged this process as vital to their recovery $(2-4,8)$. The peer support they 
received alongside the realisation that they were not 'alone', that others had similar experiences and the ability to share these experiences was in itself healing $(2,3)$. Some felt most comfortable revealing their difficulties to a female partner $(5,8)$ and experienced relief when their disclosure was met with acceptance and support. It instilled in them a renewed sense of hope, meaning and connectedness with others $(3,5)$, lessening the internal shame and stigma attached to their illness. For others, it helped them to transform their role in the community by offering support and mentoring to others who were also suffering, which in turn affirmed the progress they themselves had made.

\section{Example quotes for 'Stay lonely or reach out':}

"There were people in my family and other people that were saying, "You know, it's this way and that way and take it easy, I don't want you to get worked up." I'm like, "What do you mean worked up? People who had just suffered heart attacks can get worked up, it doesn't mean they are going to have another heart attack.” (Roe, Chopra, \& Rudnick, 2004, pg. 125)

"I'm quite a different person to the person I used to be. Umm, don't feel as confident, or as sociable... I feel like a bit of an outcast from the, from the rest of society. I just go through periods of feeling very, very low and lonely really." (Gajwani, Larkin \& Jackson, 2017, pg. 5)

"If I didn't have my parents and my family and friends ... I wouldn't be going nowhere ... I'd be stuck. (Gould, DeSouza \& Rebeiro-Gruhl, 2005, pg. 471)

"I told her [my girlfriend], so that she would know what she was getting in to. She did not mind. She said it was okay. If she is my girlfriend, we can share a secret with each other, I suppose. Not keep it bottled up." (McCann \& Clark, 2004, pg. 791)

\section{Theme 3: Towards Recovery}

Seven of the eleven studies pointed towards the beginnings of the recovery process (1$5,9,10)$. A point at which the men started employing coping strategies, re-establishing a daily routine and looking towards the future with meaning and hope. 


\subsection{Rebuilding, One Step at a Time}

Rebuilding marked the process of adjusting to life once the symptoms had sufficiently remitted $(2,4,5)$. "Going from actively getting up in the morning which [took] ages to master, all the way through to interactions with other people" (2, pg. 4). Thus, this began with small improvements in motivation which enabled the men to establish a daily routine and reintegrate themselves into familiar patterns of behaviour: "just return to normal things like before" $(4, \mathrm{pg}$. 471).

The emphasis was in accepting that the illness was a part of their life and developing new ways of managing their life. One that enabled them to fulfil their goals, whilst coping with the symptoms. Identifying realistic goals and taking active steps to meet these goals was an essential step in facilitating readjustment. It meant taking personal responsibility and encouraging oneself to keep moving forward (10), whilst acknowledging that setbacks could occur (5) that required re-initiating this process. By re-engaging in activities, the men regained a sense of pleasure and enjoyment from life (4).

\section{Example quotes for 'Rebuilding, one step at a time':}

"It's like rewriting the programmes or getting into the habits like you did before and building healthier habits to facilitate recovery... 'remaking' in the sense that you are rebuilding a new life... reconfiguring or writing a new programme ... one that is more suitable to living with schizophrenia." (Gould, DeSouza \& Rebeiro-Gruhl, 2005, pg. 471)

"I feel like it's time for me to get on my own two feet, and start taking care of myself and start being more responsible for myself...I am gonna try. This is a scary feeling you know but I got to get out there. I have to learn how to cook for one thing...it would be a big change, it would be a scary one." (Roe, Chopra \& Rudnick, 2005, pg. 126)

"Yeah, it is like it is easy, if any thing college is like easier for me in a way, I dunno why but it seems...before, I mean I went to college before and I could not deal with it before, and I left, and then my mum wrote a letter. But I really wanted to give it a go, but my motivation went then, you got to have motivation all the time. Since I have been at college this last year my motivation has just gone up and up, I want to be there, I make sure I am there early for everything." (Hirschfield et al., 2005, pg. 259) 


\subsection{Finding hope and meaning}

Finally, restoration was supported by finding hope and meaning in the experience in comparison to the shock and ambiguity present at the onset of illness $(1-5,9,10)$. This meant moving out of a state of fear, shame, despair, isolation and blame towards control, optimism, acceptance and hope. There was a sense of comfort and ease as opposed to struggle. The experiencing of symptoms was no longer frightening but manageable, indicative of increased confidence and self-belief.

The men found outlets for expressing themselves that helped them create personal meaning for themselves $(1,5)$. As such, the men were able to work towards building a renewed sense of purpose. In Saudi Arabia men utilised spiritual means to facilitate healthy adjustment, offering them "peace of mind" and "comfort" (pg. 4). This enabled them to maintain hope for the future by finding a 'reason' for their illness. The question of "will life always be this way?" (9, pg. 82) was transformed into gratitude for an experience that had enabled the men to "value life" $(2,3)$. It changed their perspective about themselves and their life purpose through greater wisdom and maturity (5).

\footnotetext{
Example quotes for 'Finding hope and meaning':

"It's funny but I don't fight back with my illness like when I hear voices. I don't try to do something to hurt the voices, I don't try to do something that the voices are going to hurt me. I'm just...fine. I'm bothered by certain voices, fine. I just keep doing...I know I am getting stronger and more positive, and if I'm laying in bed and if I'm at work or if I'm driving a car or if I'm in an area with people or no people, fine. I don't even bother any more if somebody else hears this or I hear this. I just know that what I'm doing, I'm doing." (Roe, Chopra \& Rudnick, 2004)

"But my faith in God Almighty is strong, and I believe that what happens to me was decided by God. He decided that I would be sick; I am not mentally ill by chance." (Alshowkan, Curtis \& White, 2015, pg. 4)

"Yeah, you could say, you know I have matured a lot more. You become more aware of what is around you, and you understand illnesses and all the ins and outs. So obviously, yah, you change a lot." (Hirschfield et al., 2005, pg. 260)
} 


\section{Discussion}

Overall, the themes identified are in line with the general literature on psychosis, including the traumatic nature of the illness itself (Tarrier, Khan, Cater, \& Picken, 2007), its association with past childhood trauma or maltreatment (Read, Os, Morrison, \& Ross, 2005), its close link with suicide and depression (Birchwood, Mason, MacMillan, \& Healy, 1993; Radomsky, Haas, Mann, \& Sweeney, 1999), its subsequent impact on interpersonal relationships and occupational functioning (Thornicroft et al., 2004), increase in spiritual affiliation (Fortune, Smith, \& Garvey, 2005) and the recovery process (Andresen, Oades, \& Caputi, 2003). Nonetheless, the aim of this review was not to singularly affirm previous findings relating to service-users' experiences of psychosis, but to explore whether salient gender-specific matters were apparent in the men's narrative accounts. When put together, the findings across studies suggest the possibility of certain common experiences specific to men with psychosis. The emerging patterns appear to support the quantitative literature relating to gender differences in psychosis (Barajas, Ochoa, Obiols, \& Lalucat-Jo, 2015). Furthermore, two studies using a mixed sample (Longanathan \& Murthy, 2011; McCann \& Clark, 2004) made reference to the gender differences they observed in the narrative accounts of men and women.

\section{Is there a link to male identity?}

Synthesis of the individual narratives and researcher's interpretations, identified certain themes which both explicitly and implicitly referred to specific conflicts arising from gender role expectations that may have influenced men's perceptions of their experiences (Mahalik, Good, \& Englar-Carlson, 2003). In particular the themes 'shame and stigmatisation', 'loss of manhood' and 'stay lonely or reach out' highlighted common conflicts which men may 
particularly experience in revealing vulnerability, initiating emotional intimacy and facing the shame of being 'less than a man' (Addis \& Cohane, 2005).

Socially higher demands are placed on men to adhere to norms for low emotional expression (Levant \& Richmond, 2008), emotional control (Addis, 2011), and restrictive emotionality (Snell, 1989). This often inhibits men from sharing their distress and interferes with their ability to seek help from services (Addis \& Mahalik, 2003), evidenced in the narratives of men who attempted to deal with difficulties alone (Gajwani, Larkin \& Jackson, 2017) or bottled them up (Hirschfield et al., 2005). It may also increase the likelihood of social withdrawal and isolation, promoting the use of self-medicating strategies via substance use (Magovcevic \& Addis, 2008), occurrences which have been found to be higher in men with psychosis (Barajas et al., 2015). Conversely women, are more amenable to help and appear to experience improved positive outcomes (Cotton et al., 2009). This poses questions regarding men's engagement with early intervention services and whether the more severe levels of psychopathology and higher rates of institutionalization observed (Cotton et al., 2009; Ochoa et al., 2012) can be accounted for by this general pattern of help-seeking behavior in men (Kingerlee, 2011).

Within 'shame and stigmatisation', ultimately the risk of rejection or devaluation from family members and the wider community (Alshowkan et al., 2015; Loganathan \& Murthy, 2011; McCann \& Clark, 2004) triggered feelings of shame that were associated with a loss of respect, power or status (Gee, Pearce, \& Jackson, 2003; Liu et al., 2012; Loganathan \& Murthy, 2011; Sanseeha et al., 2009). Exposure to further ridicule, humiliation and the need to "hide" their mental illness was a particular theme in men from Eastern cultures (Alshowkan, Curtis \& White, 2015; Loganathan \& Murthy, 2011; Saneesha et al., 2009). This may be representative of the collectivist culture and influence of relationships on self-identity and experiences of 
shame (Ha, 1995). Stigma is also more highly reported in men than women (Vogel, Wade, \& Hackler, 2007). Even an internal perception of one's weaknesses may be sufficient to trigger feelings of shame in men who find that they are unable to fulfil specific duties or obligations, resulting in a loss of self-esteem, feelings of 'worthlessness', inadequacy or inferiority (Mahalik et al., 2003b). Such a psychological state could lead to the profound demotivation, depression and hopelessness (Good \& Mintz, 1990) experienced by men with psychosis which may influence their subsequent adjustment and impact on the recovery process.

Typically, autonomy is reinforced and valued in men in comparison to their female counterparts (Kahn, 2009). Men's self-esteem is closely tied to success and achievement in both social, occupational and family life (Levant \& Pollack, 1995). As evidenced, the onset of psychosis was severely debilitating, robbing these men of their previous capabilities. They found themselves "coasting" through life, "stuck" or unable to fulfil their previous roles (e.g. Gajwani, Larkin \& Jackson, 2017; Gould, DeSouza \& Rebeiro-Gruhl, 2005; Loganathan \& Murthy, 2011). When comparing their situation pre and post illness, and when comparing themselves to other healthy individuals, these men experienced a strong sense of failure from being all too aware of their limitations socially, occupationally and sexually (e.g. Gajwani, Larkin \& Jackson, 2017; McCann \& Clark, 2004). 'Loss of manhood' was associated with an inability to initiate romantic encounters (Hirschfield et al., 2005), marriage proposals were rejected (Loganathan \& Murthy, 2011), some thought about abdicating leaderships positions (Liu, Ma, \& Zhao, 2012), whilst others lost jobs and stopped attending college (Gee, Pearce, \& Jackson, 2003; Gould, DeSouza \& Rebeiro-Gruhl, 2005). A loss of key roles has been associated with high rates of suicide in older men (Apesoa-Varano, Barker, \& Hinton, 2017), as these formed a key part of their identity. Similarly, Sajatovic et al. found that men with psychosis identified less with male gender roles, which may be associated with a loss of male 
identity. As a result of this loss, across the studies men identified a sense of meaninglessness from having 'nothing to do'. They were unable to see a purpose or 'way out' of their current circumstances, rendering them hopeless and powerless; a state that men find difficult to tolerate (Krugman, 1995).

Feeling supported and connected with others is a core human need. Another dominant theme across the narratives included the loneliness and social isolation experienced by men during their illness, which conflicted with their need for support from others (e.g. Gajwani, Larkin \& Jackson, 2017) as evidenced in 'stay lonely or reach out'. This could be further juxtaposed by their reluctance to talk about their distress for fear of rejection or humiliation. Men's sensitivity to social rejection and relational dread (Levant \& Pollack, 1995), coupled with their reluctance to admit to vulnerability can make both of these positions difficult for them (Krugman, 1995) as it requires emotional honesty. Being able to support and encourage men to access the necessary support when experiencing psychosis in the early stages of onset and building these therapeutic relationships with them, may have implications for future treatment adherence and recovery (Lecomte et al., 2008).

\section{What is missing?}

There appeared to be no gender-specific distinguishing elements in the remaining themes: the reaction to psychosis ('shock and understanding') and overcoming the negative changes it brought about ('existential apathy', 'challenges with medication' and 'towards recovery'). These aspects may be universal to both males and females who experience psychosis including the profound psychological disruption that overwhelms their perceptions and emotions, conflict regarding medication (Coldham, Addington, \& Addington, 2002), depression and suicidal ideation (Tarrier et al., 2014). Although suicide in general, has been reported to be three times more likely in men (Scowcroft, 2017). In relation to 'towards 
recovery', the theme was in line with the recovery process identified by Andresen, Oades and Caputi (2003) relating to (1) finding hope, (2) finding meaning in life and (3) taking responsibility for recovery.

Men's relationship with their fathers and early experiences of bullying or traumatic violent incidents were identified as contributing to the onset of illness in the Gajwani, Larkin and Jackson's (2017) study. Considering the role of fathers in boys' development contrasted against the absence of fathers, may help shed light on later-life functioning in men (Lewis \& Lamb, 2003). However traumatic experiences are widely acknowledged to increase vulnerability to psychosis in men and women (Read et al., 2005).

Additionally, anger and aggressive urges were alluded to in men's narratives (e.g. Hirschfield et al., 2005). Research indicates that men predominantly expressed their emotional difficulties using anger, possibly due to a combination of the urge to suppress authentic emotion (Levant et al., 2008) and the use of anger and aggression as a socially acceptable means of men expressing themselves (Levant \& Pollack, 1995). This pattern was tentative and not sufficiently supported by the data, the researcher's interpretations or the subsequent emerging concepts, possibly due to the gender-less perspective of seven studies.

\section{Limitations of Review}

As the data was not extracted exclusively from studies with male participants alone, it is difficult to state whether the themes identified are conclusively gender-specific. Directly comparing the narratives of males and females would have provided an opportunity to better distinguish the presence or absence of salient gender-specific themes or concepts. This review is also limited in terms of the studies included and the scope of the literature reviewed in combination with the low level of homogeneity across the various studies, which may have 
influenced the quality of the themes produced. Further methodological and analytical constraints within the studies are likely to have impacted on the quality of data available for review. The eleven articles included are unlikely to have captured the totality of people's experiences of psychosis, especially men's. This places limits on the generalisability of these results, although they offer a valid case for extending research into this area (Sajatovic et al., 2005).

\section{Clinical Relevance}

The review poses an interesting question regarding the unique experiences of men with psychosis in light of gender role socialisation. The need for further research in deducing men's understanding of psychosis and to gain an insight into their subjective experiences as male members of society. It suggests focusing on an additional layer of need (beyond the 'clinical presentation') that could improve the way in which services engage male sufferers of psychosis. Clinicians working with men would be encouraged to be more sensitive to the challenges that men face, which may hinder their ability to ask for help and remain engaged in services. In addition to addressing cross-cultural needs and how the experience of shame in collectivist cultures may further impact on men's views of psychosis and its treatment. Therefore, improving the chances of men, including those from minority ethnic groups, being able to access support in the early stages of their illness to avoid the need for hospitalisation.

Furthermore, services may need to utilise alternative strategies that support help-seeking behaviour in men, such as raising awareness through popular events and reducing the stigma associated with illness for men. This would include working with outside agencies such as Mind, the Movember Foundation and CALM (Campaign Against Living Miserably). 


\section{Future Research}

Further research directly comparing the narratives of male and female participants would help to gain a better understanding of the gender differences that may exist, and whether there are qualitative differences in the manner both genders conceptualise or manage their experience of psychosis. The search revealed only four qualitative studies specific to men's experiences, further studies like these would add to the evidence base and perhaps shed light on the gender differences reported in quantitative studies. Additionally, this would provide a stronger base from which a more systematic synthesis that prioritises interpretations, such as meta-ethnography (Noblit \& Hare, 1988) could be performed. These findings could then be contrasted against studies exploring females' experiences of psychosis (Chernomas et al., 2017). 


\section{References}

Addis, M. (2011). Invisible men: Men's inner lives and the consequences of silence. New York: Macmillan.

Addis, M. E., \& Cohane, G. H. (2005). Social scientific paradigms of masculinity and their implications for research and practice in men's mental health. Journal of Clinical Psychology, 61(6), 633-647.

Addis, M. E., \& Mahalik, J. R. (2003). Men, masculinity, and the contexts of help seeking. American Psychologist, 58(1), 5-14.

Alshowkan, A., Curtis, J., \& White, Y. (2015). Factors affecting the quality of life for people with schizophrenia in Saudi Arabia: a qualitative study, 18(4), 1-6.

Andresen, R., Oades, L., \& Caputi, P. (2003). The experience of recovery from schizophrenia: towards an empirically validated stage model. Australian \& New Zealand Journal of Psychiatry, 37(5), 586-594.

Barajas, A., Ochoa, S., Obiols, J. E., \& Lalucat-Jo, L. (2015). Gender differences in individuals at high-risk of psychosis: a comprehensive literature review. The Scientific World Journal, 1, 1-13.

Birchwood, M., \& Fiorillo, A. (2000). The Critical Period for Early Intervention. Psychiatric Rehabilitation Skills, 4(2), 182-198.

Birchwood, M., Mason, R., MacMillan, F., \& Healy, J. (1993). Depression, demoralization and control over psychotic illness: a comparison of depressed and non-depressed patients with a chronic psychosis. Psychological Medicine, 23(2), 387-395.

Birchwood, M., Todd, P., \& Jackson, C. (1998). Early intervention in psychosis. The critical period hypothesis. The British Journal of Psychiatry. Supplement, 172(33), 53-59. 
Chernomas, W. M., Rieger, K. L., Karpa, J. V., Clarke, D. E., Marchinko, S., \& Demczuk, L. (2017). Young women's experiences of psychotic illness: a systematic review of qualitative research. JBI Database of Systematic Reviews and Implementation Reports, 15(3), 694-737.

Coldham, E., Addington, J., \& Addington, D. (2002). Medication adherence of individuals with a first episode of psychosis. Acta Psychiatrica Scandinavica, 106(4), 286-290.

Connell, R. W., \& Messerschmidt, J. W. (2005). Hegemonic Masculinity: Rethinking the Concept. Gender \& Society, 19(6), 829-859.

Conus, P., Lambert, M., Cotton, S., Bonsack, C., McGorry, P. D., \& Schimmelmann, B. G. (2010). Rate and predictors of service disengagement in an epidemiological firstepisode psychosis cohort. Schizophrenia Research, 118(1-3), 256-263.

Cotton, S. M., Lambert, M., Schimmelmann, B. G., Foley, D. L., Morley, K. I., McGorry, P. D., \& Conus, P. (2009). Gender differences in premorbid, entry, treatment, and outcome characteristics in a treated epidemiological sample of 661 patients with first episode psychosis. Schizophrenia Research, 114(1-3), 17-24.

Deegan, P. E. (1988). Recovery: The lived experience of rehabilitation. Psychosocial Rehabilitation Journal, 11(4), 11-19.

Doyle, R., Turner, N., Fanning, F., Brennan, D., Renwick, L., Lawlor, E., \& Clarke, M. (2014). First-Episode Psychosis and Disengagement From Treatment: A Systematic Review. Psychiatric Services, 65(5), 603-611.

Englar-Carlson, M., \& Kiselica, M. S. (2013). Affirming the Strengths in Men: A Positive Masculinity Approach to Assisting Male Clients. Journal of Counseling \& Development, 91(4), 399-409. 
Finfgeld, D. L. (2003). Metasynthesis: The state of the art—so far. Qualitative Health Research, 13(7), 893-904.

Fortune, D. G., Smith, J. V., \& Garvey, K. (2005). Perceptions of psychosis, coping, appraisals, and psychological distress in the relatives of patients with schizophrenia: An exploration using self-regulation theory. British Journal of Clinical Psychology, 44(3), 319-331.

Fraguas, D., del Rey-Mejías, Á., Moreno, C., Castro-Fornieles, J., Graell, M., Otero, S., ... Parellada, M. (2014). Duration of untreated psychosis predicts functional and clinical outcome in children and adolescents with first-episode psychosis: A 2-year longitudinal study. Schizophrenia Research, 152(1), 130-138.

Gajwani, R., Larkin, M., \& Jackson, C. (2017). "What is the point of life?”: An interpretative phenomenological analysis of suicide in young menwith first-episode psychosis. Early Intervention in Psychiatry.

Galdas, P. M., Cheater, F., \& Marshall, P. (2005). Men and health help-seeking behaviour: literature review. Journal of Advanced Nursing, 49(6), 616-623.

Gee, L., Pearce, E., \& Jackson, M. (2003). Quality of life in schizophrenia: A grounded theory approach. Health and Quality of Life Outcomes, 1(31), 1-11.

Good, G. E., \& Mintz, L. B. (1990). Gender Role Conflict and Depression in College Men: Evidence for Compounded Risk. Journal of Counseling \& Development, 69(1), 17-21.

Gough, D. (2015). Qualitative and mixed methods in systematic reviews, 4(181), 1-3.

Gould, A., DeSouza, S., \& Rebeiro-Gruhl, K. L. (2005). And Then I Lost That Life: A Shared Narrative of Four Young Men with Schizophrenia. British Journal of Occupational Therapy, 68(10), 467-473. 
Ha, F. I. (1995). Shame in Asian and Western cultures. American Behavioral Scientist, 38(8), $1114-1131$.

Hirschfeld, R., Smith, J., Trower, P., \& Griffin, C. (2005). What do psychotic experiences mean for young men? A qualitative investigation. Psychology and Psychotherapy: Theory, Research and Practice, 78(2), 249-270.

Kahn, J. S. (2009). An introduction to masculinities. John Wiley \& Sons.

Kessler, R. C., Amminger, G. P., Aguilar-Gaxiola, S., Alonso, J., Lee, S., \& Ustun, T. B. (2007). Age of onset of mental disorders: a review of recent literature. Current Opinion in Psychiatry, 20(4), 359-364.

Kingerlee, R. (2012). Conceptualizing men: A transdiagnostic model of male distress: A transdiagnostic model of male distress. Psychology and Psychotherapy: Theory, Research and Practice, 85(1), 83-99.

Kingerlee, R., Precious, D., Sullivan, L., \& Barry, J. (2014). Engaging with the emotional lives of men. The Psychologist, 27(6), 418-421.

Krugman, S. (1995). Male Development and the Transformation of Shame. In R. F. Levant \& W. S. Pollack (Eds.), A New Psychology of Men (pp. 91-126). New York: Basic Books.

Lecomte, T., Spidel, A., Leclerc, C., Macewan, G., Greaves, C., \& Bentall, R. (2008). Predictors and profiles of treatment non-adherence and engagement in services problems in early psychosis. Schizophrenia Research, 102(1-3), 295-302.

Levant, R. F., \& Pollack, W. S. (1995). A New Psychology of Men. New York: Basic Books. Lincoln, C. V., \& McGorry, P. (1995). Who cares? Pathways to psychiatric care for young people experiencing a first episode of psychosis. Psychiatric Services. 
Liu, L., Ma, X., \& Zhao, X. (2012). What Do Psychotic Experiences Mean to Chinese Schizophrenia Patients? Qualitative Health Research, 22(12), 1707-1716.

Loganathan, S., \& Murthy, R. S. (2011). Living with schizophrenia in India: Gender perspectives. Transcultural Psychiatry, 48(5), 569-584.

Magovcevic, M., \& Addis, M. E. (2008). The Masculine Depression Scale: development and psychometric evaluation. Psychology of Men \& Masculinity, 9(3), 117.

Mahalik, J. R., Aldarondo, E., Gilbert-Gokhale, S., \& Shore, E. (2005). The Role of Insecure Attachment and Gender Role Stress in Predicting Controlling Behaviors in Men Who Batter. Journal of Interpersonal Violence, 20(5), 617-631.

Mahalik, J. R., Good, G. E., \& Englar-Carlson, M. (2003b). Masculinity scripts, presenting concerns, and help seeking: Implications for practice and training. Professional Psychology: Research and Practice, 34(2), 123-131.

Mahalik, J. R., Good, G. E., Tager, D., Levant, R. F., \& Mackowiak, C. (2012). Developing a taxonomy of helpful and harmful practices for clinical work with boys and men. Journal of Counseling Psychology, 59(4), 591-603.

Mahalik, J. R., Locke, B. D., Ludlow, L. H., Diemer, M. A., Scott, R. P., Gottfried, M., \& Freitas, G. (2003a). Development of the conformity to masculine norms inventory. Psychology of Men \& Masculinity, 4(1), 3-25.

Malla, A. (2005). First-Episode Psychosis: Psychopathology, Quality of Life, and Functional Outcome. Schizophrenia Bulletin, 31(3), 650-671.

Mansfield, A., Addis, M., \& Mahalik, J. (2003). 'Why Won't He Go to the Doctor?': The Psychology of Men's Help Seeking. International Journal of Men's Health, 2(2), 93109. 
McCann, T. V., \& Clark, E. (2004). Embodiment of Severe and Enduring Mental Illness: Finding Meaning in Schizophrenia. Issues in Mental Health Nursing, 25(8), 783-798. McDonell, M. G., Short, R. A., Berry, C. M., \& Dyck, D. G. (2003). Burden in schizophrenia caregivers: impact of family psychoeducation and awareness of patient suicidality. Family Process, 42(1), 91-103.

McFarlane, W. R. (2011). Prevention of the First Episode of Psychosis. Psychiatric Clinics of North America, 34(1), 95-107.

Nasser, E. H., Walders, N., \& Jenkins, J. H. (2002). The experience of schizophrenia: what's gender got to do with it? A critical review of the current status of research on schizophrenia. Schizophrenia bulletin, 28(2), 351.

National Audit Office. (2017). Mental Health in Prisons.

NICE. (2012). Methods for the development of NICE public health guidance (third edition). National Institute for Health and Care Excellence.

Ochoa, S., Usall, J., Cobo, J., Labad, X., \& Kulkarni, J. (2012). Gender Differences in Schizophrenia and First-Episode Psychosis: A Comprehensive Literature Review. Schizophrenia Research and Treatment, 1, 1-9.

Oliveira, R. M., Rodrigues, P. C. B., Furegato, A. R. F., \& Siqueira Júnior, A. C. (2013). The meaning and implications of schizophrenia from the perspective of people who experience it. Acta Scientiarum. Health Science, 35(1), 77-84.

O’Neil, J. M. (2008). Summarizing 25 Years of Research on Men's Gender Role Conflict Using the Gender Role Conflict Scale: New Research Paradigms and Clinical Implications. The Counseling Psychologist, 36(3), 358-445. 
Penn, D. L., Waldheter, E. J., Perkins, D. O., Mueser, K. T., \& Lieberman, J. A. (2005). Psychosocial Treatment for First-Episode Psychosis: A Research Update. American Journal of Psychiatry, 162(12), 2220-2232.

Radomsky, E. D., Haas, G. L., Mann, J. J., \& Sweeney, J. A. (1999). Suicidal behaviour in patients with schizophrenia and other psychotic disorders. American Journal of Psychiatry, 156(10), 1590-1595.

Read, J., Os, J. van, Morrison, A. P., \& Ross, C. A. (2005). Childhood trauma, psychosis and schizophrenia: a literature review with theoretical and clinical implications. Acta Psychiatrica Scandinavica, 112(5), 330-350.

Roe, D., Chopra, M., \& Rudnick, A. (2004). Persons with Psychosis as Active Agents Interacting with their Disorder. Psychiatric Rehabilitation Journal, 28(2), 122-128.

Sajatovic, M., Jenkins, J. H., Strauss, M. E., Butt, Z. A., \& Carpenter, E. (2005). Gender identity and implications for recovery among men and women with schizophrenia. Psychiatric Services, 56(1), 96-98.

Sandelowski, M., \& Barroso, J. (2006). Handbook for synthesizing qualitative research. New York: Springer Publishing Company.

Sanseeha, L., Chontawan, R., Sethabouppha, H., Disayavanish, C., \& Turale, S. (2009). Illness perspectives of Thais diagnosed with schizophrenia. Nursing \& Health Sciences, 11(3), 306-311.

Scowcroft, E. (2017). Samaritans suicide statistics report 2017. Retrieved from https://www.samaritans.org/sites/default/files/kcfinder/files/Suicide_statistics_report_ 2017_Final.pdf

Seidler, V. J. J. (1997). Man enough: Embodying masculinities. London: Sage. 
Shaw, R. L., Booth, A., Sutton, A. J., Miller, T., Smith, J. A., Young, B., ... Dixon-Woods, M. (2004). Finding qualitative research: an evaluation of search strategies. BMC Medical Research Methodology, 4(1), 1-5.

Shepard, D. S., \& Rabinowitz, F. E. (2013). The power of shame in men who are depressed: Implications for counselors. Journal of Counseling \& Development, 91(4), 451-457.

Smith, B. (1999). The Abyss: Exploring Depression Through a Narrative of the Self. Qualitative Inquiry, 5(2), 264-279.

Spencer, E., Birchwood, M., \& McGovern, D. (2001). Management of first-episode psychosis. Advances in Psychiatric Treatment, 7(02), 133-140.

Tarrier, N., Kelly, J., Maqsood, S., Snelson, N., Maxwell, J., Law, H., ... Gooding, P. (2014). The cognitive behavioural prevention of suicide in psychosis: a clinical trial. Schizophrenia Research, 156(2), 204-210.

Tarrier, N., Khan, S., Cater, J., \& Picken, A. (2007). The subjective consequences of suffering a first episode psychosis: trauma and suicide behaviour. Social Psychiatry and Psychiatric Epidemiology, 42(1), 29-35. 0127-2

Thomas, J., \& Harden, A. (2008). Methods for the thematic synthesis of qualitative research in systematic reviews. BMC Medical Research Methodology, 8(1), 1-10.

Thornicroft, G., Tansella, M., Becker, T., Knapp, M., Leese, M., Schene, A., \& VazquezBarquero, J. L. (2004). The personal impact of schizophrenia in Europe. Schizophrenia Research, 69(2), 125-132.

Vogel, D. L., Wade, N. G., \& Hackler, A. H. (2007). Perceived public stigma and the willingness to seek counselling: The mediating roles of self-stigma and attitudes toward counselling. Journal of Counselling Psychology, 54(1), 40-50. 
Walsh, D., \& Downe, S. (2005). Meta-synthesis method for qualitative research: a literature review. Journal of Advanced Nursing, 50(2), 204-211.

Warren, L. W. (1983). Male intolerance of depression: A review with implications for psychotherapy. Clinical Psychology Review, 3(2), 147-156.

Wedgwood, N. (2009). Connell's theory of masculinity - its origins and influences on the study of gender1. Journal of Gender Studies, 18(4), 329-339.

Wright, N., Callaghan, P., \& Bartlett, P. (2011). Mental health service users' and practitioners' experiences of engagement in assertive outreach: a qualitative study: Engagement in assertive outreach. Journal of Psychiatric and Mental Health Nursing, $18(9), 822-832$.

Wright, F. (1987). Men, shame and antisocial behavior: A psychodynamic perspective. Group, 11(4), 238-246.

Yung, A. R., \& McGorry, P. D. (1996). The Prodromal Phase of First-episode Psychosis: Past and Current Conceptualizations. Schizophrenia Bulletin, 22(2), 353-370.

Yung, Alison R, Phillips, L. J., Yuen, H. P., \& McGorry, P. D. (2004). Risk factors for psychosis in an ultra high-risk group: psychopathology and clinical features. Schizophrenia Research, 67(2), 131-142. 


\section{EMPIRICAL PAPER}

Men's Experiences of Engaging in Psychological Therapy in a Forensic Mental Health Setting 


\begin{abstract}
Background: The Multifactor Offender Readiness Model (MORM) acknowledges the importance of gender-sensitive interventions in enhancing engagement in the rehabilitation of offenders. However, to date, little attention has been paid to the role of gender identity in psychological therapy. Even though men in forensic settings are likely to endorse hypermasculine attitudes, such as promoting aggression and restricting emotional expression, which run counter to therapeutic ideals.
\end{abstract}

Aims and objectives: The present study aimed to explore men's experiences of engaging in psychological therapy to develop a better understanding of the barriers and facilitators to engagement, as well as the role of the therapeutic relationship.

Methodology: Nine men residing in medium-secure forensic mental health hospitals were interviewed. Interpretative Phenomenological Analysis (IPA) was used to obtain first-person accounts of the men's lived experiences to gain an insight into the subjective meanings they attached to their experiences of psychological therapy.

Results: An analysis of the individual transcripts highlighted the men's journey over the course of therapy, marked by an internal struggle against the external pressures. Three superordinate themes were identified: 'shifting self', 'relationship with other' and 'therapeutic journey', alongside their subsequent sub-themes.

Discussion: A gradual, non-linear process of change was evident in the men's narratives, who at the various phases of psychological therapy were faced with the challenge of questioning and redefining their identity. This involved lowering their guard, learning to become comfortable with vulnerability and face their past in the presence of a supportive 'other', in order to move towards building a new or better future for themselves. 


\section{Introduction}

Men's mental health took centre stage in 2015 when the Samaritans report revealed that suicide rates were the highest in middle-aged men (aged 40 - 44 years), with men being three times more likely to commit suicide in comparison to females (Scowcroft, 2017). It brought to light the overwhelming degree to which men's mental health needs had perhaps been neglected by public health organisations, naturally fuelling the subsequent socio-political movement to better understand the unique challenges men face in managing stress, identifying and dealing with mental health problems. Charity organisations such as CALM (Campaign Against Living Miserably), Men's Health Forum, Mind and the Movember Foundation gained impetus to raise awareness with the aim to reach out to men through the media, in the effort to engage them in alternative discourses to breakdown the stigma associated with mental health conditions or indeed seeking 'help' as a man. Simultaneously, mental health systems have been forced to confront their gender-blindness and consider whether adaptations are needed to better appeal to men (Seidler, Rice, River, Oliffe, \& Dhillon, 2018).

\section{Theories of Gender Identity}

In this postmodern era characterised by pluralism, gender continues to be a key organising principle in social-relational contexts (Risman, 2004) influencing many aspects of life including access to resources (Hausmann, 2009), styles of interpersonal interaction (Govender \& Penn-Kekana, 2008), methods of coping (Matud, 2004), self-evaluation (Ruble, Greulich, Pomerantz, \& Gochberg, 1993), self-identity and expectations of others (Ridgeway \& Correll, 2004). Researcher's vary on their perspectives of the extent to which gender is understood as a product of biological, neurochemical (Dabbs, Riad, \& Chance, 2001; Galligani, Renck, \& Hansen, 1996) and evolutionary (Cocks, 2010) mechanisms (i.e. a result of nature) 
versus gender as a social and cultural construct (Connell \& Messerschmidt, 2005) shaped by the environmental context (i.e. a result of nurture).

Conversely, a holistic standpoint would propose that once a biological male or female is born, social labelling and differential treatment interact with biological factors to steer development (Bargh \& Huang, 2014; Eagly, 2009). This supports the current movement away from viewing gender as exclusively binary or solely related to biological sex, but rather as a socially constructed concept to which certain attributes, behaviours and roles are associated (Glenn, 1999). In this respect masculinity and femininity may be viewed as a set of personality traits that can be exhibited by either sex, accounting for the broad variation in the behavioural expression of traditional gender roles (Schippers, 2007) across and with-in cultures.

For the purposes of this thesis an outline of three key theories will be briefly explored which explain the emergence of gendered attitudes, beliefs and behaviours from alternative philosophical perspectives. Each theory takes into account the unique impact of the individual's interaction with their social environment.

\section{Hegemonic Masculinity (Connell \& Messerschmidt, 2005)}

Connell's theory of 'hegemonic masculinity' which has its origins in feminist and social constructionist schools of thought, is one of the most commonly cited in the literature to conceptualise "maleness" at a macro-level. Hegemonic masculinity refers to a dominant idealised position of men in a social or cultural hierarchy achieved through certain 'acts of manhood' which involve claiming privilege, eliciting deference and resisting exploitation (Schrock \& Schwalbe, 2009). Thus, men position themselves in relation to the hegemonic ideal, internalising personal codes of behaviour that contribute to its reproduction (Coles, 2009). Certain characteristics may include the rejection of femininity, emotional invulnerability, 
toughness, competitiveness, success, sexual prowess, violence and aggression (Mahalik et al., 2003a).

The theory proposes the presence of multiple competing masculinities within the social hierarchy that are continuously being constructed and contested (Connell \& Messerschmidt, 2005; Wedgwood, 2009). As a result, masculinity is not construed as a stable, definitive set of personality traits but instead as a dynamic entity which finds specific forms of expression in interactions within a socio-cultural, economic and historical context. This helps account for the variation that exists amongst men in their demonstration of 'manliness', giving rise to the notion of multiple masculinities. At any given time, certain masculinities may be subordinated in favour of dominant masculinities (Mike Donaldson, 1993). Hence gender identity is constructed and influenced by one's position in the social hierarchy, such that individuals are afforded different opportunities and so grow to view themselves in particular ways (Hearn, 2004).

\section{Gender Schema Theory (Bem, 1981)}

Social learning and cognitive behavioural paradigms are typically used in psychological literature to understand the development of subjective gendered ideals at a micro-level (Eckes \& Trautner, 2000). Although there are a variety of frameworks, the underlying theoretical assumptions are that gendered behaviours, beliefs, and attitudes are learned from social environments through basic processes of reinforcement, punishment, modelling, and the acquisition of gendered schemas or belief systems (Kahn, 2009; Levant, 1996).

Bem (1981) stipulated that all human beings have a basic template for gender which acts as a lens through which they interpret their experience of the world, identified as the gender schema. Information for gender schemas comes from interactions within the social context. Individuals draw their interpretation from the cultural norms exhibited, however subjective 
differences exist in how gender norms are internalised by the individual on the basis of their unique experiences (Kahn, 2009). Therefore, depending on the information an individual has been exposed to (and hence is able to assimilate) regarding gender, will inevitably form their gender self-schema. This can differ from another individual's gender self-schema. Furthermore, the degree to which individuals rely on their gender schema to interpret the world will create additional variation referred to as gender-schematic processing.

\section{Psychoanalytic Perspective (Chodorow, 1999; Pollack, 1995)}

Psychoanalytic approaches operate on the underlying assumption that men's early attachment-related interactions are critical in shaping their subsequent emotional and interpersonal development (Diamond, 2004, 2006). The relationship between mothers and their sons becomes a key feature in determining boys' capacity for relatedness and sensitivity to their own and other's emotions as adult men (Kahn, 2009).

Given the social context in how gender is defined and its subsequent impact on individuals' interpretations as well as the sex of the baby, mothers are likely to form different relationships with their sons in comparison to their daughters (Chodorow, 1999; Pollack, 1995). Eventually boys reach a stage in life where they must separate and dis-identify with their mothers (Mahler, 1972) to individuate and develop a differentiated gendered self. Recognising their difference from their mothers, boys seek counter-identification with their fathers (Bergman, 1995; Diamond, 2004). As such the mother who was once viewed as the primary love object, responsible for nurturing is experienced as 'pushing away' when facilitating this process. Pollack (1995) described this as a 'traumatic loss' for boys who face subsequent rejection and disconnection (Bergman, 1995). For those whose fathers are absent this necessary transition is not adequately supported and the loss is further magnified. Boys inadvertently learn 
to value autonomy and 'doing', over emotional connection and social intimacy from which they remain separated (Levant \& Pollack, 1995).

These theories are important to developing an understanding of men's relationships with their social context and inner lives to inform successful treatment interventions and to better engage men in mental health services. "Clinicians who develop awareness of how socialization experiences may constrain men's lives and affect their well-being are likely to be more effective in working clinically with men" (Englar-Carlson \& Shepard, 2005, p. 384).

\section{Gender Identity and Psychological Distress}

Given that men are socialised from an early age to subscribe to prevailing views of masculinity, there is huge pressure amongst men to sustain society's expectations (Pleck, 1995). Any perceived violation may lead to cultural condemnation and negative psychological consequences, like poor self-esteem and negative self-judgments (Addis \& Cohane, 2005). In order to protect against the shame of this (Krugman, 1995) men can adopt a rigid adherence to masculine ideology. Pleck (1995) referred to this as gender role strain which leads to men overcompensating through hypermasculine behaviours.

O’Neil, (1990) proposed that gender role strain is directly linked to gender role conflict. It suggests that men's underlying unconscious fears of femininity result in four key areas of conflict: (1) power, success and competition, (2) restrictive emotionality, (3) restrictive affectionate behaviour between men and (4) conflict between work and family relations (O'Neil, 2008). Men with higher levels of gender role conflict may be at greater risk for maladaptive behaviours including abandonment of children and families, addictive behaviours, obsessions with work, power and control, sexual harassment, and violence (O’Neil, Glenn, \& Holmes, 1995). 
Mahalik et al. (2003a) argued that the degree to which men conformed to specific masculine gender norms varied. Masculine norms were categorised as follows: 'winning', 'emotional control', 'risk-taking', 'violence', 'dominance', 'playboy', 'self-reliance', 'primacy of work', 'power over women', 'disdain for homosexuals', 'physical toughness', and 'pursuit of status (Mahalik, et al, 2003a). Thus, one individual may adhere more firmly to 'risk-taking', whilst another to 'self-reliance'. Cognitive distortions in any one domain (e.g. 'winning is everything') could hold implications for the individual's ability for psychological adjustment (Gordon et al., 2013).

Additionally, Kingerlee (2012) proposed the transdiagnostic model of male distress to explain how men's affiliation to masculine norms could impact on their perception and management of psychological distress. He formulated the male-specific profile (MSP) which consisted of four primary constituents: (1) status-seeking, (2) empathic potential, (3) emotional potential and (4) shame-avoiding. This postulates that men are evolutionarily primed to seek rank and status, therefore any threat to their status may result in the exposure of their psychological fragility. Empathic potential relates to men's intolerance of their own vulnerability (Addis, 2011) and limited capacity to self-sooth (Gilbert, 2007). Furthermore, men are less skilled in identifying and managing negative emotions (Sullivan, Camic, \& Brown, 2015) which determines their emotional potential. Men have a strong aversive response to shame increasing their tendency to withdraw or isolate (Berger, Levant, McMillan, Kelleher, \& Sellers, 2005). This MSP has a top-down influence activating specific meta-cognitive beliefs (e.g. 'I mustn’t appear weak') during times of psychological distress. These subsequently impact on the men's expression of distress and the coping strategies they employ. 


\section{Men in the Criminal Justice System}

As of $201795 \%$ of the UK prison population consisted of male inmates (Ministry of Justice, 2017). These men are likely to be of low socio-economic status groups, often from impoverished and abusive backgrounds (Reavis, 2013) who present with complex mental health problems (National Audit Office, 2017). Having discussed the development of gender identity, the multiplicities of masculinity and the stress created by gender-role strain, one might consider the unique position and challenges faced by men in the criminal justice system. Plus, the additional complications services and professionals may be confronted with when attempting to engage these individuals in rehabilitative programmes.

'Manhood' in the forensic population is precarious (Bosson \& Vandello, 2011), arising from a complex interplay between the individual male characteristics and institutional dynamics (Kupers, 2005). Hypermasculinity is a common occurrence in prison environments where domination, anger expression, physical strength, aggression and sexuality are exaggerated (Mosher \& Sirkin, 1984; Toch, 1998). This may function to ward off the masculine anxiety (collapse in self-identity as a man) that is likely to create a state of tension and cognitive dissonance, when the individual is faced with the reality of the impossibility of reaching his 'ideal masculine self' under conditions of imprisonment (Whitehead, 2005). Thus, he is placed in a position whereby he must protect against his fear of being exposed as 'less than a man' (Kimmel, 1994).

One way in which this is achieved is through aggression and intimidation. Prisoner's described their use of violence as arising due to self-defence, wishing to avoid disrespect, alcohol or drug use, to gain or maintain dominance, protect others, an innate drive or as a last resort to dealing with conflict (Dagirmanjian et al., 2017). Men who endorse traditional masculine norms are more interpersonally hostile (Amato, 2012), perpetrate more intimate 
partner violence (Moore \& Stuart, 2005), and report getting into more physical fights (Mahalik, Aldarondo, Gilbert-Gokhale, \& Shore, 2005). Violence and aggression may serve as an avenue to achieve masculinity, albeit fragmented (Messerschmidt, 2000). As a result, in such settings talking about feelings and distress is likely to be associated with "a loss of masculine power" (Evans \& Wallace, 2008, p. 486).

\section{Rehabilitation}

What does this mean for the day-to-day therapeutic interactions with men in forensic mental health settings? One of the biggest challenges forensic services encounter when working with mentally disordered offenders is establishing and maintaining engagement in psychological therapy (McMurran \& McCulloch, 2007). Across forensic services and depending on the type of therapeutic programmes, non-completion rates vary from $20 \%$ to $50 \%$ where individuals either fail to commence therapy or drop-out prematurely (McMurran, Huband, \& Overton, 2010; Olver, Stockdale, \& Wormith, 2011). Treatment non-completion is associated with higher rates of criminal recidivism when compared to untreated individuals and those who had completed treatment (McMurran \& Theodosi, 2007). Cann and colleagues (2005) found that reconviction at one-year follow-up was higher for treatment non-completers in comparison to untreated individuals.

Moreover, the negative implications for non-engagement in psychotherapeutic interventions further extend to issues of cost-effectiveness and the financial burdens for services. "On average, in the first 10 years following admission, those who do not complete treatment go on to incur $£ 52,000$ more in costs to the National Health Service and criminal justice system than those who complete treatment" (Sampson, James, Huband, Geelan, \& McMurran, 2013, p. 321). Thus, much research has focused on improving treatment efficacy 
through the 'Risk, Need, Responsivity' principles to identify 'what works' for specific groups of offenders (Andrews \& Dowden, 2007; Bonta \& Andrews, 2007).

The development of the Multifactor Offender Readiness Model (MORM; Ward, Day, Howells, \& Birgden, 2004) outlines both internal, client-specific factors and external, contextual and systemic factors that may influence an offender's motivation and readiness to change. They suggest that only when the individual possesses "certain cognitive, emotional, volitional, and behaviour properties, and lives in an environment where such changes are possible and supported" can change occur (Ward et al., 2004, p. 650). Therefore, greater emphasis is being placed on enhancing treatment readiness using techniques such as motivational interviewing (McMurran, 2009) and developing a strong therapeutic alliance (Ross, Polaschek, \& Ward, 2008). Identity has been identified as a significant factor associated with treatment readiness in this model. Therefore, exploring how men's gender identity may impact on the way men engage in therapy or with their psychologist, may offer some insight into the therapeutic process and development of a therapeutic alliance.

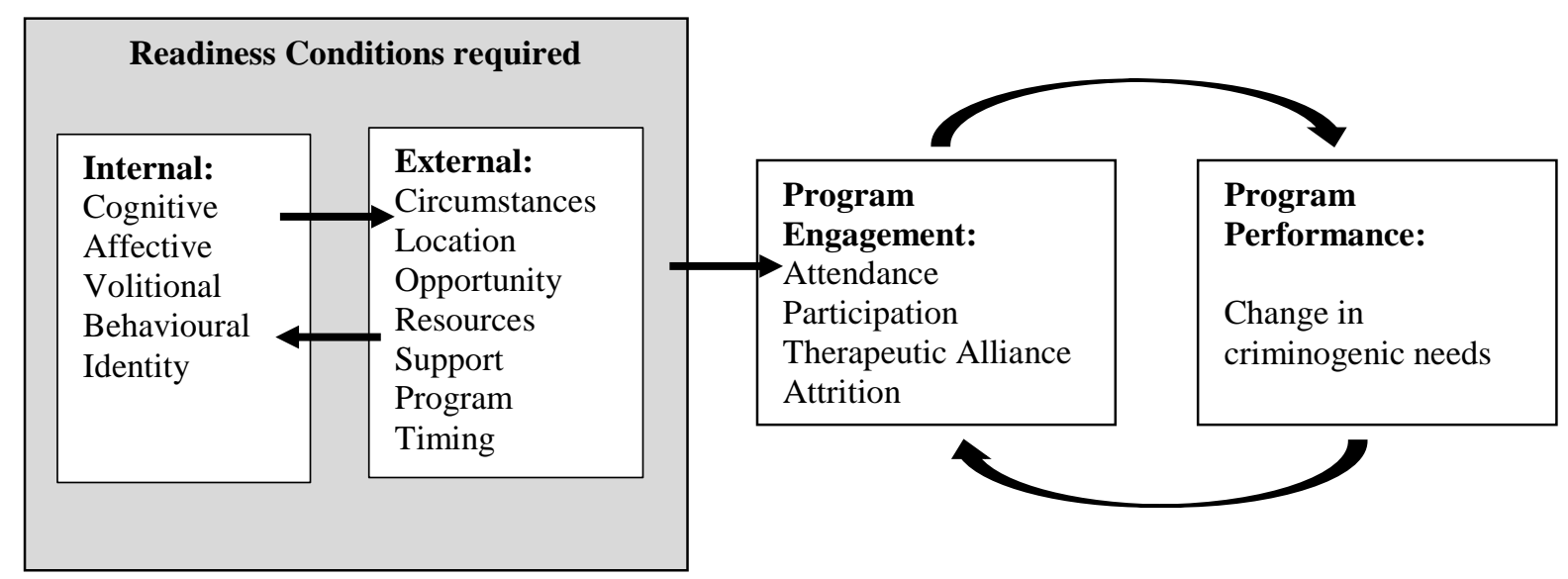

Figure 2.1: Multi-factor Offender Readiness Model (Ward et al., 2004) 


\section{Aims and Objectives}

Across sociological, psychological, mental health and forensic literature there is a strong opinion that gender-identity plays a dominant role in shaping an individual's conceptualisation of the world which in turn reciprocally influences their manner of interacting with the world, a process that is both dynamic and interdependent. Thus, taking a gender-sensitive approach and examining the role of gender identity on engagement in psychological therapy, may help shed light on the unique experiences of men in forensic mental health services. With the hope of developing a deeper understanding of what can be done to facilitate change in this population.

This study's primary objective is to explore men's experiences of engaging in psychological therapy in a forensic mental health setting. To gain an understanding of the role of gender identity in men's engagement in therapy, potential barriers and facilitators to engagement, and the development of the therapeutic relationship. 


\section{Methodology}

\section{Ethics}

This study was approved by the West Midlands-South Birmingham Research Ethics Committee (16/WM/0482) and the Research and Development Department of the participating NHS Trust (appendix F \& G).

\section{Design}

A qualitative design based on Interpretative Phenomenological Analysis (Smith, Flowers, \& Larkin, 2009) was used. Grounded in phenomenology, this approach aims to explore personal experiences and perceptions of an object or event to gain an 'insider's perspective'. This is facilitated by the double-hermeneutic process whereby the researcher makes sense of the participants' meaning-making. Participants were interviewed to collect an account of their personal experiences of psychological therapy within a forensic mental health context. These interviews were guided by four key open-ended questions (appendix H) formulated in collaboration with the Clinical Research Supervisor to support disclosure and were elaborated upon during interview. The interviews lasted for an average of 33 minutes (range 22-45) and explored topics surrounding men's perceptions of psychological therapy, the content of sessions, the therapeutic relationship, and barriers and facilitators to engaging in psychological therapy. The researcher prompted participants to consider their gender identity in the context of psychological therapy but was predominantly guided by the personal narratives. 


\section{Recruitment \& Setting}

Participants were recruited from across two Medium-Secure Forensic Mental Health Hospitals within the West Midlands. The interviews took place within a treatment room or consulting room, which was either based on the ward or located elsewhere in the hospital. Interviews were conducted between November 2017 and January 2018.

Initially, information regarding the research study was presented to service users via the ward community meetings or ad-hoc visits to the ward by sharing a leaflet (appendix I) and participant information sheet (appendix J) with them. For those who declared their initial interest with the researcher and met the specified inclusion criteria (Table 2.1), the researcher contacted the clinical team to identify whether there were any issues relating to capacity or risk that needed to be considered prior to obtaining informed consent. Once the service users had been deemed to have capacity to engage in the research interview, they were approached a second time to check their understanding of the research, whether they still wanted to participate in the study and to schedule a time for the interview.

Prior to commencing the interview, the aims of the study were explained to the service user by the researcher and informed consent (appendix K) was obtained in the presence of a healthcare professional. This was to confirm that the service user had indeed understood the purpose of the study and had capacity to participate in the interview. Interviews were all recorded on an encrypted digital voice recorder.

To ensure anonymity of the quotes reported, all identifiable information was altered or removed. Due to the nature of the research, participants were informed that there could be a possibility that their quotes could be recognised by those familiar to the organisation, however the risk of this was limited since data was collected across two different sites. Participants were 
contacted two weeks after the interview to identify whether their data could be used for the research or if there was anything they wished to be removed. No amendments were requested to the transcripts.

Table 2.1: Criteria for participant suitability

\section{Inclusion criteria $\quad$ Exclusion criteria}

- $\quad$ Male $\geq 18$ years

- Under the care of a forensic mental health team

- Received a minimum of six face-to-face sessions of psychological therapy (group or individual)

- Deemed to have capacity

- English speaker.
- Males <18 years

- Females

- Not under the care of a mental health team

- Received less than six face-toface sessions of psychological therapy (group or individual)

- Deemed to lack capacity

- Non-English speaker

\section{Participants}

Table 2.2 lists the demographic characteristics of the men who completed the interviews. A total of nine men aged 30 to 48 years (mean age $=37$ years) agreed to be interviewed out of the 16 that initially declared their interest. Five individuals who were not interviewed had chosen to opt out when they were approached on a second occasion to plan for the interview. This was either due to having changed their mind, external stressors they were experiencing at the time, complications that had arisen in their care, or due to their worries about the interview being audio recorded. One individual was discharged prior to the interview taking place and another individual was deemed unsuitable to take part by the team psychologist.

The nine participants who completed the interview were based on the rehabilitation wards within the hospitals, which meant that they were further along in their care pathway and 
their mental health was relatively stable. They were under varying degrees of restriction based on their individual treatment care pathways and current level of risk to the public. Due to the extended length of time individuals can spend in forensic services (Rutherford \& Duggan, 2008), the multiple admissions (Coid, Kahtan, Gault, Cook, \& Jarman, 2001) and the transfers that occur between forensic services (e.g. prison, high-secure hospital to low-secure hospitals), the current length of admission was recorded, which averaged to 3 years. Three participants had been admitted from step-down services (i.e. transferred from a high-secure hospital to medium secure hospital), four participants had been transferred directly from prison, and two participants had been admitted due to needing a higher level of security (i.e. moving from a low-secure hospital to medium-secure hospital).

Psychological therapy in a forensic mental health setting is usually diverse, often utilising a tiered and multi-dimensional approach due to the severity and complexity of presentations (Davies \& Nagi, 2017). As such, the definition for psychological therapy was kept broad rather than limited to specific therapeutic models or modalities of interventions to encapsulate an accurate representation of the participants' experience. In terms of exposure to psychological therapy, the men were asked to provide an approximate estimate of the length of time they had been in therapy, and the degree to which this involved group therapy versus individual psychological therapy, to formulate an understanding of the intensity of intervention they had received, since it was difficult to obtain an exact quantitative measure. With regards to individual psychological therapy, two men had participated in short-term individual psychological therapy, which meant they had received less than 3 months of individual psychological therapy. The remaining seven men had received long-term individual psychological therapy and thus had undertaken extensive psychological therapy both previously 
and currently. Finally, two men had completed some group psychological interventions, whilst seven had received intensive group intervention.

\section{Data analysis}

IPA was used to analyse the data collected from the interviews with participants to gain an understanding of how the men with-in this context made sense of their experience and the meanings they attributed to them (Larkin \& Thompson, 2011). Each transcript was transcribed verbatim and then read and re-read by the researcher. For each individual transcript, line-byline coding was undertaken whereby exploratory comments were initially noted focusing on linguistic, descriptive and conceptual comments (appendix L). Following this, emerging themes for each transcript were noted so that the analysis could move from descriptive to interpretive (Smith, Flowers, \& Larkin, 2009). Once the emergent themes had been identified within and across transcripts, the researcher followed a continuous process of mapping the connections between the themes so these could be represented in a diagrammatic format (appendix M). This included the process of identifying patterns across cases and distinguishing between superordinate and subordinate themes (Figure 2.2).

To ensure the findings and themes identified were consistent with the data collected and to reduce the degree of researcher bias, the clinical supervisor linked to the research was involved in exploration, identification, and naming. Further input from IPA support groups and academic supervisor experienced in IPA analysis (external to the research) was sought whereby alternative perspectives were considered. A final quality check corroborated the researcher's themes and interpretations were credible and grounded in the data. 


\section{Step-by-step process of analysis}

Reading and re-reading: Each transcript was read initially prior to coding. It was then re-read and revisited at several stages of the analysis to refine coding and emergent themes.

Initial coding: Initial thoughts were noted about the participants claims and concerns.

Development of emerging themes: These individual codes were then grouped together based on common patterns or concepts to formulate themes. Input sought from research supervisors.

Connections across emerging themes and identifying common patterns across transcripts: The emergent themes from individual cases were grouped and a table of common themes was created as well as a diagram of how those themes were connected. Input sought from research supervisors and IPA support group.

Developing superordinate and subthemes: This meant frequently revisiting the emergent themes, codes and transcripts to distinguish the main themes and sub-themes, as well as in naming the themes. Followed by a process of constant revision supported by input from research supervisors and IPA support group.

Figure 2.2: Analysis process as indicated by Smith, Flowers \& Larkin (2009)

\section{Reflective Statement}

As the researcher I was aware of being a female who had worked in forensic mental health settings. Thus I was aware of my own preconceived notions of men's experiences, as well as the expectations I held of the possible themes that could arise through the interviews. For this reason, in the first interviews I noticed my frustration and disappointment when the participant's narrative did not appear to overtly link with the research themes I was interested in, or if the participant's responses appeared to be tangential and irrelevant to the question I had posed. Having worked within the field I was aware of the challenges of obtaining a comprehensive and rich narrative from the participants due to the nature of their mental health difficulties and willingness to speak to an unknown professional regarding such a potentially emotive experience, which could trigger feelings of vulnerability. 
Having undertaken personal therapy, myself, I was conscious of my positive bias towards the benefits of therapy but also the challenges inherent in opening up to another person and sharing intimate details about one's life. At times this led me to feel disheartened about the quality of the data that I collected, as well as the struggle I experienced in encouraging the participants to open up about their experiences. Towards the latter interviews, I noticed I was better able to manage these tensions and more willing to explore the narrative shared by the participants, whilst prompting for information specific to the aims of the study without leading the participants. The use of a reflective diary and supervision enabled me to deal with my own reactions to the experiences shared by the participants which often left me with a deep sense of sadness and hopelessness for the pain they had suffered. On occasion however, I was also dubious about the responses that were given and the potential for participants to respond to myself (as a trainee psychologist) in a socially desirable manner, and thus being reluctant to share negative aspects of their experience. In completing IPA, I was aware of the parallel processes and used others' coding of the data to ensure that I was not being too focused on my own experiences and feelings and missing alternative interpretations. 
Table 2.2: Demographic characteristics of participants ( $n=9)$

\begin{tabular}{|c|c|c|c|c|c|c|c|c|}
\hline $\begin{array}{l}\text { Participant } \\
\text { pseudonym }\end{array}$ & $\begin{array}{c}\text { Age } \\
(\text { years })\end{array}$ & Ethnicity & $\begin{array}{l}\text { Level of } \\
\text { education }\end{array}$ & $\begin{array}{l}\text { Primary ICD-10 } \\
\text { Diagnosis \& Other } \\
\text { identified presenting } \\
\text { problems }\end{array}$ & $\begin{array}{l}\text { Length of } \\
\text { current } \\
\text { admission }\end{array}$ & $\begin{array}{l}\text { Approximate } \\
\text { length of } \\
\text { psychological } \\
\text { therapy }\end{array}$ & $\begin{array}{c}\text { Type of psychological } \\
\text { input }\end{array}$ & Index offence \\
\hline Mark & 32 & $\begin{array}{l}\text { Mixed } \\
\text { Ethnicity }\end{array}$ & $\begin{array}{l}\text { Secondary } \\
\text { School }\end{array}$ & $\begin{array}{l}\text { Diagnosis: Paranoid } \\
\text { Schizophrenia } \\
\text { Presenting problems: } \\
\text { substance use }\end{array}$ & 0.5 years & 0.5 years & $\begin{array}{l}\text { - Short-term } \\
\text { individual } \\
\text { psychological therapy } \\
\text { - Some group } \\
\text { psychological therapy }\end{array}$ & Theft/robbery \\
\hline Jacob & 32 & $\begin{array}{l}\text { Black } \\
\text { African }\end{array}$ & $\begin{array}{l}\text { Secondary } \\
\text { school }\end{array}$ & $\begin{array}{l}\text { Diagnosis: Paranoid } \\
\text { Schizophrenia } \\
\text { Presenting problems: } \\
\text { substance use, past } \\
\text { trauma }\end{array}$ & 4 years & 8 years & $\begin{array}{l}\text { - Long-term } \\
\text { individual } \\
\text { psychological therapy } \\
\text { - Intensive group } \\
\text { psychological therapy }\end{array}$ & Manslaughter \\
\hline Phillip & 30 & White Irish & College & $\begin{array}{l}\text { Diagnosis: } \\
\text { Emotionally Unstable } \\
\text { Personality Disorder } \\
\text { Presenting problems: } \\
\text { antisocial, substance } \\
\text { use, anxiety, childhood } \\
\text { trauma }\end{array}$ & 4 years & 6 years & $\begin{array}{l}\text { - Long-term } \\
\text { individual } \\
\text { psychological therapy } \\
\text { - Intensive group } \\
\text { psychological therapy }\end{array}$ & $\begin{array}{l}\text { Grievous } \\
\text { Bodily Harm }\end{array}$ \\
\hline Craig & 33 & $\begin{array}{l}\text { Mixed } \\
\text { White \& } \\
\text { Caribbean }\end{array}$ & $\begin{array}{l}\text { Secondary } \\
\text { school }\end{array}$ & $\begin{array}{l}\text { Diagnosis: Bipolar } \\
\text { Affective Disorder } \\
\text { Presenting problems: } \\
\text { substance use }\end{array}$ & 3 years & 3 years & $\begin{array}{l}\text { - Long-term } \\
\text { individual } \\
\text { psychological therapy } \\
\text { - Intensive group } \\
\text { psychological therapy }\end{array}$ & Theft/robbery \\
\hline
\end{tabular}




\begin{tabular}{|c|c|c|c|c|c|c|c|c|}
\hline Jason & 35 & $\begin{array}{l}\text { Mixed } \\
\text { White \& } \\
\text { Caribbean }\end{array}$ & $\begin{array}{l}\text { Secondary } \\
\text { school }\end{array}$ & $\begin{array}{l}\text { Diagnosis: } \\
\text { Unspecified non- } \\
\text { organic Psychosis } \\
\text { Presenting Problems: } \\
\text { self-harm, substance } \\
\text { use }\end{array}$ & 1.5 years & 3 years & $\begin{array}{l}\text { - Short-term } \\
\text { individual } \\
\text { psychological therapy } \\
\text { - Intensive group } \\
\text { psychological therapy }\end{array}$ & $\begin{array}{l}\text { Theft with } \\
\text { grievous } \\
\text { bodily harm }\end{array}$ \\
\hline Jermaine & 34 & $\begin{array}{l}\text { African- } \\
\text { Caribbean }\end{array}$ & $\begin{array}{l}\text { Secondary } \\
\text { school }\end{array}$ & $\begin{array}{l}\text { Diagnosis: Paranoid } \\
\text { Schizophrenia } \\
\text { Presenting problems: } \\
\text { substance use, trauma }\end{array}$ & 10 weeks & 7.5 years & $\begin{array}{l}\text { - Long-term } \\
\text { individual } \\
\text { psychological therapy } \\
\text { - Intensive group } \\
\text { psychological therapy }\end{array}$ & $\begin{array}{l}\text { Theft/robbery; } \\
\text { Assault and } \\
\text { wounding }\end{array}$ \\
\hline Sean & 42 & $\begin{array}{l}\text { Mixed } \\
\text { White \& } \\
\text { Asian }\end{array}$ & $\begin{array}{l}\text { Masters } \\
\text { level }\end{array}$ & $\begin{array}{l}\text { Diagnosis: Paranoid } \\
\text { Schizophrenia } \\
\text { Presenting problems: } \\
\text { childhood trauma. }\end{array}$ & 4.5 years & 4.5 years & $\begin{array}{l}\text { - Long-term } \\
\text { individual } \\
\text { psychological therapy } \\
\text { - Some group } \\
\text { psychological therapy }\end{array}$ & Wounding \\
\hline Terry & 45 & $\begin{array}{l}\text { White } \\
\text { British }\end{array}$ & $\begin{array}{l}\text { Secondary } \\
\text { school }\end{array}$ & $\begin{array}{l}\text { Diagnosis: Paranoid } \\
\text { Schizophrenia } \\
\text { Presenting problems: } \\
\text { depression, substance } \\
\text { use }\end{array}$ & 3 years & 3 years & $\begin{array}{l}\text { - Long-term } \\
\text { individual } \\
\text { psychological therapy } \\
\text { - Intensive group } \\
\text { psychological therapy }\end{array}$ & $\begin{array}{l}\text { Attempted } \\
\text { Murder }\end{array}$ \\
\hline Dan & 48 & $\begin{array}{l}\text { White } \\
\text { British }\end{array}$ & $\begin{array}{l}\text { Secondary } \\
\text { school }\end{array}$ & $\begin{array}{l}\text { Diagnosis: Paranoid } \\
\text { Schizophrenia } \\
\text { Presenting problems: } \\
\text { anxiety, panic attacks, } \\
\text { substance use, self- } \\
\text { harm }\end{array}$ & 4.5 years & 4 years & $\begin{array}{l}\text { - Long-term } \\
\text { individual } \\
\text { psychological therapy } \\
\text { - Intensive group } \\
\text { psychological therapy }\end{array}$ & Manslaughter \\
\hline
\end{tabular}




\section{Results}

At the time of the study it was apparent that the men differed in their ability to express and articulate their thoughts coherently. As evidenced in Table 2.2, a majority of the individuals were from minority ethnic backgrounds, with a diagnosis of Schizophrenia who had received long-term treatment for chronic and enduring mental health difficulties, which may have likely impacted upon their cognitive capacity overtime. A number of these individuals may have low levels of cognitive functioning compared to the general population as indicated by their level of education. In some cases, the narratives were fragmented and non-linear, interspersed with 'I don't know' responses. This may be attributable to a general reluctance to elaborate further as a means of avoiding further disclosure or due to a lack of understanding about what was being asked. In the latter case, questions were rephrased, simplified or broken down to support the participant. These factors are likely to have impacted on their introspective capacity during the interview.

The men's narratives highlighted their individual conflicts in undertaking psychological therapy. Effectively, sharing the arduous journey of sifting through their life-story, challenging and re-defining aspects of themselves to various degrees, to make it through with the hope of building a new life for themselves. The analysis revealed three key superordinate themes: 'shifting self', 'relationship with other' and 'therapeutic journey'. Each of these included a cluster of sub-themes (Figure 2.3). The themes were both convergent and divergent, which is consistent with the IPA process (Larkin \& Thompson, 2011) ensuring that the diversity of men's experiences were captured. A summary of the men's contributions to each of the themes can be found in appendix N. Despite the themes being presented separately there was invariably some overlap across themes. Minor changes have been introduced to the verbatim extracts to improve readability and maintain anonymity (Table 2.3). 

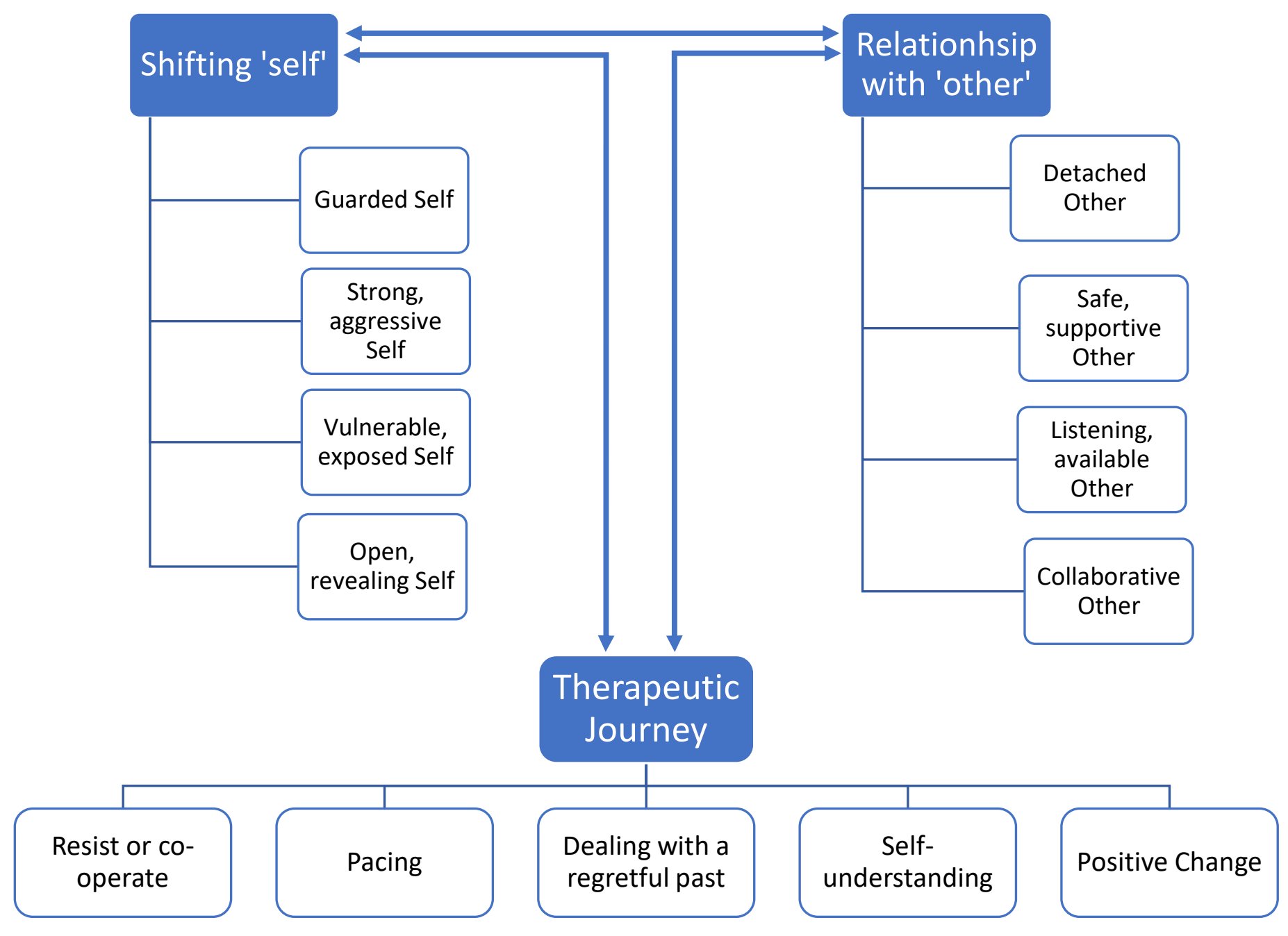

Figure 2.3: Diagrammatic representation of links between superordinate themes and sub-themes. 
Table 2.3: Annotation of changes introduced to verbatim script.

- (...) Indicates pause in speech

- [...] Indicates missing text and where information has been condensed

- $[\mathrm{xxxx}]$ Explanatory text inserted by researcher

- Utterances such as 'erm', 'you know what I mean?' or 'I don't know' where used repetitively, have been removed

\section{Theme 1: Shifting 'Self'}

Men reflected on several time points in their therapeutic journey, from the very beginning to the current time. Two of the men referred to specific experiences as young boys, whilst four others referred to themselves as 'old', signifying their evolving identity. Collectively they recalled the incessant to-ing and fro-ing as they experienced fear, paranoia and anger at the threat of being exposed as ' $b a d$ ' or 'weak'. All too aware of the pervasive social expectations and archetypes relating to men ('the breadwinners'(Terry), 'stronger of the species' (Mark), 'alpha males' (Phillip), 'macho' personalities (Jermaine), 'nice guys finish last' (Dan)) that persisted throughout their life via gender socialisation and the media. In subtle ways, past experiences and social messages influenced the self-image they projected in psychological therapy. This was dynamic and changeable, dependent on circumstances, mood, acuteness of mental health, institutional setting and time in therapy.

\subsection{Guarded Self: 'I don't wanna talk about how I'm feeling.'}

A common tendency to refuse to talk about difficulties was exhibited in the men, with some demonstrating a greater propensity to keep people at a distance than others. In the early stages talking to a psychologist was experienced as intrusive and threatening, fuelling paranoid thoughts and anxiety regarding the intentions of the psychologist who was seen in a sinister light: 
For myself and mates right, I had mates over here and they wasn't willing to open up. They were, 'Nah I'm not doing it'. I'm like, 'Why?' They were like 'I'm not doing it man'... getting information about me or building a profile on me. [...] Some people think it will be deep, don't they? (Mark)

Mark recalled a shared experience within forensic settings of an aversion to speaking for fear of what would happen with the information that was revealed, along with the insight that could be gleaned by the psychologist through this process. Often the fear related to two aspects: (1) probable negative consequences of criminal disclosures and (2) maintaining privacy of intimate details regarding their inner world. In a sense the men were not simply avoiding talking but were avoiding deeper exploration of potentially traumatic experiences or incriminating information. Avoidance was a common way of suppressing the accompanying pain associated with this:

As for me, I'm happy not seeing problems. I don't see them I'm happy, brush them under the carpet, put them in a box, hide them away and don't open the box - that's the easy way to deal with things. (Terry)

Hiding pain was the norm in this group of men who felt unable to show their feelings. Being 'too vulnerable' was ill advised as 'people can take advantage of that' (Dan), especially in environments like prison. Phillip identified that putting up a 'front' or 'smokescreen' was his solution. This defense had been instilled in childhood, whereby crying was met with humiliation and ridicule:

We're looking up to people from an early age to like act and behave in a masculine way, and like expressing emotions, if you like cry a lot well I did personally myself - if I cried a lot as a child I tried to express emotional feelings to [parents], I tried to tell them how I was feeling, I was made to feel like shit for it, I was put down for it, and I was made 
to feel like I was being stupid. [...] Yeh, so I quickly learnt to keep things to myself and not wear my heart on my sleeve. (Phillip)

This protectiveness meant that men isolated themselves or resisted therapy. It placed a barrier between them and the psychologist. Even if they were attending therapy, they would remain silent, dismiss questions and avoid certain topics:

It's like having a bubble. You don't wanna let no one in. And when they finally do, you think, 'Why the hell do they wanna get in my bubble for?' (Jermaine)

Men recognised that this deep-seated need to exercise emotional control or defend themselves was easily triggered around other males due to not wanting to be seen 'as weaker than another male’ (Phillip).

\subsection{Strong, aggressive self: 'Men are supposed to be the stronger of the species.'}

The affiliation to strength in several forms was a prominent feature of the men's narratives. Their motivation to present themselves as invulnerable and to not appear 'weak' or 'broken' was intensified. Especially when they felt they were being evaluated by other men on the merit of their strength. Only to be juxtaposed against their current reality where they were labelled mentally unwell and detained. Being in a state where they needed help from others placed them in a deprived, powerless position.

Everyone wants to be like, no one wants to be seen as someone who is vulnerable. And going into a room with a doctor, like, they can't disclose what you discuss but still you're in that kind of mindset aren't you? That I'm the alpha male, I'm not vulnerable, I'm not anything, I'm top dog. (Phillip)

Reputation equated with strength which could only be maintained through a position of power. In Phillip's mind there were implications for attending psychological therapy and what this 
implied about his ability to cope with stress. It would potentially have signified a sense of defeat or loss of control, the antithesis of 'top dog'. As such, 'bravado' and aggression protected oneself from the scrutiny of others, to avoid being labelled as 'soft'. Something Terry mentioned was learnt from his adolescence:

When I was 15 I went out looking for a fight. [...] And it was like image you know, reputation and you're trying to make yourself viewed in a certain way, like don't mess with him kind of thing. [...] Things like that is bravado. Like I want to be known as the strong, tough guy. (Terry)

Jermaine frequently mentioned problems with anger and its impact on his therapy, ' $I$ used to have arguments and walk off'. He discovered that his 'macho' attitude affected professionals' perceptions of him and his receptivity to interventions. Consequently, his treatment was extended by his team:

\section{People thought because of that attitude that I weren't taking it seriously. But it depends, because obviously I was macho, if someone is macho, then someone is macho. [...] Taking it seriously, like you know, they thought I weren't ready for it, or I was just doing it for the fun of it or pratting around. (Jermaine)}

For Jermaine this was intrinsic to his personality, a means of self-expression that he felt was misconstrued as resistance.

In one case, strength was conveyed with greater subtlety. Sean compared his state of functioning relative to others on his ward as an expression of his superiority over other men in his circumstances. He emphasised that he did not require the acute facilities of the hospital as other men did, highlighting not only his better coping but also making a case for his misplacement in services: 
I was only downstairs [acute ward] for a week. I come straight upstairs [rehab ward] more or less, so I wasn't bouncing off any walls, I was very well-adjusted, calm and normal. [...] Some people spend months down there, even years down there, I spent 5 days okay. (Sean)

\subsection{Vulnerable, exposed self: 'I've gone back to my cell and cried'}

Despite the uncertainty regarding what therapy involved, the men anticipated that it would inevitably entail lowering their guard, opening up and getting in touch with their emotions. This is exactly what they were most hesitant to do. Therefore, being confronted in a therapeutic situation which threatened to expose their inherent sense of vulnerability, created discomfort for five men. Sharing their emotions in therapy led to a heightened awareness of the psychologist's presence, further increasing their self-consciousness which was experienced as unpleasant:

I'd be embarrassed. I'd think you know they're looking at me thinking ... I don't know, I just, I just wouldn't like it, I wouldn't like it, that feeling. [...] I just don't like the thought of it, I just don't like the thought of someone sitting across from me and pitying me. I don't like the thought of that. [...] No, just makes me wanna get out of there. (Mark)

I feel un- I do feel kinda uncomfortable, even when I speak to her obviously I don't look at her, I look down innit, like, I feel uncomfortable. (Jason)

The unnamed shame is evident in Mark and Jason's experience of wanting to avoid being seen. Though they struggled to comprehensively articulate this emotion with words, it was portrayed in their obvious intolerance and aversion towards 'that feeling'. 
Exposing their inner-most feelings involved stripping away the strong front that had been developed from boyhood. This brought alongside it a fear of displaying one's weaknesses in front of others, due to how these would be received and responded to:

\begin{abstract}
It's kinda hard because if, what do you call it, we believe that we're meant to be strong and that we're not supposed to be broken or whatever so, it can be-it can be difficult. [...] I worry if I'm being perceived as being weak when I say what I say or whatever. (Jason)

You don't want to be seen as vulnerable or you don't want to seem like you're inferior, or you don't want to feel like, especially in psychology as well because sometimes you can feel - well in any setting, in any relationship really, exposing secrets about yourself, can expose weaknesses can't it? Like if you expose secrets, you expose weaknesses and you don't want to be seen as weak. No one wants to be seen as weak. (Phillip)
\end{abstract}

Phillip emphasised an overwhelming need not be seen as 'weak' and to avoid this at all costs, since vulnerability led to feelings of subordination associated with a loss of power.

Establishing a sense of safety was important to the men, who described that not being pushed or pressured into sharing their stories had been helpful. This safety was particularly felt with female psychologists, who symbolised a maternal figure, someone who would be accepting of their feelings without being dismissive, illustrated in the men's stories regarding close relationships with their mothers or partners:

Yeah obviously raised- well my dad weren't about, I was raised [by] my mum innit so, I've always been brought up by a woman, my mum, and I know that I can tell my mum anything. [...] Any person that I've been around like girlfriend wise or whatever, they get in touch with your softer side then. You just relate to women differently than you do a man. That's how it's been all my life. (Jason) 
The strength is from the men like, 'Come man, I've been through worse than you, grow up and do it, stop like-' [...] With a female in the family you'll be like, 'Yo sis, can I come and see ya?', 'Yo mum I'm feeling like this today'. 'Ah come round'. (Jermaine)

\subsection{Open, revealing self: 'You can't keep it bottled up'}

As their time in therapy progressed and they developed a trusting therapeutic alliance, the men were able to risk vulnerability. However, this was an intentional step, one they had to build up to. Jermaine described the active effort that was required for him to be able to face his difficulties. The process required him to 'jump' to the 'bottom of the sea' where his difficulties were buried, and 'bring up' his issues in order for them to be dealt with.

I used to just sit there and like throw them at the bottom of the seas, but I jumped down, picked them up, brought them up with me, said this is an issue, threw the box away empty. (Jermaine)

Similarly, other men came to the realisation that moving forward required them to overcome the barrier to self-disclosure:

I like to open up with the psychologist because I feel like when you open up you're gonna get the work done. That's what they're there for. You need to open up to them, to talk to them, to let them know if you're having hard times, to let them know if something's bugging ya, to let them know if you're worried about something. (Craig)

Here, Craig stressed that the degree to which the psychologist could help would be dependent on the amount of insight they had, and the responsibility of providing that lay with the individual. It underlined the bi-directional nature of therapy and the self-ownership inherent in taking a step towards sharing one's difficulties.

For two men, this involved a cognitive shift where they took a position of 'I've got nothing to hide', which spurred them forward in their attempts to receive the help that was being 
offered to them. This confidence to open up manifested differently in the men, who provided contrasting rationalisations:

I'm not ashamed to talk about my past, about my experiences because I know, if I don't talk about it, it might eat me up inside and I wanna talk about it to professional psychologists. (Craig)

I ain't got nothing to hide, [it's] not like I'm a sex offender or anything like that. (Jason)

Craig expressed his concern regarding the negative impact holding things in would have on his psychological well-being, thus he was focused on his internal state. In contrast Jason drew a comparison between himself and others on the basis of a criminal act. He implied that the nature of his offence was not as horrific against the crimes of others, which lessened the internal conflict between staying quiet and opening up.

Part of this process of opening up also meant reappraising their attitude to help-seeking and placing less importance on projecting an image for others. Both Terry and Jason reflected this in their statements of 'I don't care what anyone else thinks' and 'I've got nothing to prove'.

As I said I'm old I've been in the worsest situation possible yeah, I ain't bothered what anyone else thinks anymore like that, or if they think I'm weak. If they think I'm strong, I ain't got no point to prove. I'm just here and I'm doing my thing and I wanna get better and go innit. (Jason)

This move to a position of accepting and recognising the need for help was facilitated by the men lowering their guards and letting go of 'pride' (Dan). Sometimes this shift arose as a function of maturity ('I'm too old for that game' - Dan), necessity ('Do what I need to progress and get out' - Jacob), trust, or a desire to improve ('trying to better myself' - Terry). Underneath, it required the men to become comfortable enough to express their vulnerability. 


\section{Theme 2: Relationship with 'other'}

Due to the length of time these men were detained in services the therapeutic relationship was central to their engagement in therapy. Psychologists changing and leaving was common. With each change the process of building trust and establishing rapport started afresh. Thus, the quality of previous therapeutic relationships served as a blueprint for future experiences.

Understandably, the men had reservations about the psychologist, born out of the experiences that they had elsewhere in the criminal justice system. This was accurately portrayed by a couple of the men's fears that the psychologist might 'stitch them up'. Effectively triggering a defensiveness resulting in heightened anxiety, mistrust and paranoia. The men's fear of whether or how the information would be shared, being judged and misunderstood was palpable. Hence, their relief and surprise when they discovered psychologists were unlike their expectations only strengthened the therapeutic relationship. Here the term 'other' has been used to be inclusive of group facilitators and group members.

\subsection{Detached-other: 'I don't know her that well'}

For three of the men there was a sense of separateness from the psychologist. An acknowledgement that despite the level of disclosure required in the relationship, this relationship was unlike other close relationships. Phillip commented on its one-sided nature and the unequal levels of self-disclosure, with the psychologist volunteering merely superficial details. For him, this was a barrier in his relationship with his psychologist:

They might tell me what music they like or what football team they like but they're not going to tell me about their sex life or like their childhood. And I've got to expose really deep-rooted things to them, it's one way. (Phillip) 
Two men had only engaged in short-term individual psychological therapy, one of whom was Mark. He referred to the unknown quality of the psychologist. His perception of the psychologist as an outsider increased his chances of being misunderstood. In his eyes the psychologist's knowledge was limited to scientific facts from a 'textbook' as opposed to real experience, creating a sense that the psychologist was simply a trained professional, lacking in human qualities:

I don't feel comfortable sitting there with someone I don't know, you know, talking about things that are probably mentally scarring. (Mark)

\subsection{Safe, Supportive-other: 'Very genuinely nice people'}

This was a predominant theme for all the men who valued specific qualities within their psychologist that helped foster a strong therapeutic alliance. These ranged from being 'genuine', 'caring', 'non-judgemental', 'helpful' and 'friendly'. In a setting where the men's power and control were challenged due to the nature of their detention, the psychologist represented an ally with whom they could share their difficulties.

It comes down to trust. You know, you can trust that person, you know what you're saying isn't going to backfire up in your face blow up in your face and keep you here longer. (Mark)

Overtime the men developed confidence that the psychologist's intention was not to be an impediment to their progress, but rather to facilitate and enhance rehabilitation. Often the men's disclosures were received with understanding and encouragement. The psychologist's 'tactful' (Terry) manner in communicating created a sense of ease. For the men who had experienced others as hostile and abusive, their experience of their psychologist stood out in stark contrast.

But it's like everyone got together in the group and we all wouldn't judge each other. [...] We all felt comfortable with each other, we 
all listened, we all felt comfortable in talking about our experiences. (Craig)

That they wouldn't erm judge me for what I was saying. Hopefully you know they thought that erm I'm on the right road to recovery. (Dan)

The gratitude and respect the men felt for the work that their psychologist had put into their therapy was clearly expressed throughout the men's narratives. As their relationship developed, the psychologist became the equivalent of a confidante, problem-solver, helper and nurturer. Some men revealed that they had shared things with their psychologist that they had not shared with others. In this respect it was a unique relationship to other professional and personal relationships.

\subsection{Listening, available other: 'Take her time to talk to me'}

Listening was a key component identified by all men as helpful to the therapeutic relationship. Many referred to their sessions as having a 'chat', highlighting the informal, nonthreatening nature of the interactions with their psychologist, indicative of a level of comfort. They felt valued that someone had 'taken the time' (Jacob) to be available to them. The listening capacity of the psychologist was experienced as characteristically unique, an active, engaged form of listening that was beyond 'listening for the sake of listening' (Jermaine).

But listening to me, that was one of the best things ever. Not a lot of people listen to people nowadays. (Jermaine)

It communicated to the men that this form of listening was purposeful and meaningful. The experience of feeling heard offered a form of catharsis, either due to the relief experienced or the realisation that the solutions they sought would be provided:

Ifelt she was a listening ear that without speaking my backstory - and sometimes it was difficult to with it all being cooped in your head - 
that talking to someone about it and releasing it to her was a way of unburdening. (Sean)

\subsection{Collaborative-other: 'We're a team'}

Having been faced with experiences that reinforced their defensiveness, discovering that there were others working with them rather than against them was encouraging. It facilitated the men's therapeutic progress and transferred control and power back to them. Giving them a sense of agency as the therapeutic relationship transformed into a partnership where there was mutual influence. Craig described the active process of creating a 'bond' through talking, sharing ideas and problem-solving together. He would put forward his problem and the psychologist would help him delve deeper whilst putting forward suggestions:

I would be like, 'Oh well this is a problem, this is a problem'. He would work round that problem and bring up many ideas and say, 'Look is that?' and I'd be like, 'Yeah, that's where it comes from'. And we'd work together and we'd create that relationship talking. (Craig)

He recognised that 'if I was on my own I might not solve that problem I might be stuck, but with them, we work together as a team and then we've solved the problem'. Whereas Mark viewed the psychologist as a devil's advocate warning him against harmful behaviours and identifying his pitfalls to discourage him from making poor decisions:

You've gotta have someone there to say look these are your triggers, you know if you go back and hanging around with the same people...the more time you're gonna start using again. (Mark)

Working alongside the psychologist in this way improved the men's recovery outcomes, since they were dependent on a favourable opinion from their psychologist: 
I always take on board what they say because I know I need some help. And they gotta make a decision whether I'm able to go on the outside or stay in. (Dan)

\section{Theme 3: Therapeutic Journey}

Alongside the changing relationship with themselves and others, the men's narratives captured the various phases of their journey. Therapy was thrust upon them as an important part of their rehabilitation, something they had limited understanding of and struggled to adjust to. It necessitated the revelation of their life story to learn the lessons they needed to prevent reoffending. In turn they developed a stronger sense of self and improved psychological wellbeing.

\subsection{Resist or co-operate: 'If you don't engage you just won't progress'}

The forensic mental health system prioritises the therapeutic environment. Regardless, due to the hospitals' medium-secure nature there is a duty of care to safeguard the public from potential risk of harm which warrants a degree of restriction. As such, the men struggled with the lack of autonomy and choice available. They found that they had limited options in the face of these circumstances: they could choose not to engage in therapy and risk a longer period of detention, or they could engage in therapy and progress through the system. The men's reactions to this position varied overtime, impacting on their approach to therapy:

I found it was something the team had decided for me. I wasn't consulted or asked, do you want to do psychology or not? It was basically my psychologist and her student at the time who come and saw me and said, 'We will be having sessions with you'. [...] I figured whether I want to or not it's part of the process, so I was quite amenable to doing what I needed to advance. (Sean) 
Sean felt he had no input into the decision-making and experienced therapy as an external imposition forced upon him. His acquiescence was a form of submission to the system's method of operating in favour of his own advancement. For him therapy represented a treatment demand that needed to be fulfilled. Phillip on the other hand, demonstrated an aggressive resistance to psychological therapy being 'thrown' his way. Similarly, experiencing it as an incessant, intrusive demand that triggered a provocative response:

Because it's thrown at you and it's not your option or your choice to go and engage with a psychologist - it would be in the community it throws you back and puts up your defenses. You feel like, 'Why the fuck should I go and see you? Why should I tell you about my life? What can you do to help me? (Phillip)

Mark was also reluctant, his dubiousness triggered by past experiences within a prison system, where he felt helpless, abused and powerless. This impacted on the level of trust he placed in the system to support him:

I know I need help in certain things and in certain parts of my life because otherwise I wouldn't be in a mental hospital. But erm, I also know that the system can be twisted and [...] in prison the staff and that can be very dark people. (Mark)

Jacob and Sean's motivation for engagement in therapy was externally driven. Therapy held little intrinsic value to them and was simply a means of facilitating their progress towards discharge. These men opted for a passive compliance, hoping to achieve a favourable view from their psychologist and by extension their multidisciplinary team by doing what they ' $h a d$ to do':

At the end of the day she has to write a report clearly saying, he's done psychology, I don't believe he's a risk anymore, we can let him out now. And that is in the back of your head that that is the ultimate goal. (Sean) 
Pretty much every group they've asked me to do since I've been here,

I've done it. [...] To get some leave, get out. (Jacob)

Others' motivations switched to being internally driven as they observed positive changes from the therapy and started to value the therapeutic relationship. These men demonstrated self-responsibility. For them the desire to reintegrate into the community outweighed everything else.

It's a service, if you use it right it will help you. Because then people that are laying things off and don't want the help it's only gonna drag them back longer, and I wanna get out in the community to start with my life again. (Craig)

When I do my courses I put all into it, I don't go half-hearted. I put my all into it. [...] I'm here to learn, to get better and to hopefully get out. (Jason)

As indicated, a shift in their perception of the system, the act of seeking help and the purpose of therapy, eventually enhanced the men's capacity to meaningfully engage in the work. Further facilitated by the strength of the therapeutic relationship, the men's willingness to risk exposure and accept the psychologist's or group's influence.

\subsection{Pacing: 'It was slow'}

Considering the men began their therapeutic journey in a place of reluctance with an underlying sense of threat, six valued a gentler approach to therapy where they did not feel pressured to discuss contentious topics or traumatic experiences. An essential part of their experience was the time it required to develop trust to feel safe enough to explore areas of their lives that brought about intense, painful emotions:

Taking it at my own pace. If I didn't want to talk about the offences then, say, 'Okay that's enough for today'. Come back next week and 
pick it back up. It's not like going straight into it, the deep end. (Jacob)

'This is what I've been through', and they'll be like, 'yeah', and you think alright their listening. Then after they're listening you start talking about it. Then um you gain that trust and then you just slowly let it out and then like um it takes baby steps though, you can't just jump from the worst thing. (Jermaine)

The severity and chronicity of their difficulties warranted a 'slow and gradual process' (Phillip) to overcome the several barriers to revealing themselves, before any change could be initiated.

Whilst recognising this need, the men were simultaneously frustrated by the intensity, frequency and length of the treatment. All men described the numerous groups they had attended throughout their detention. These were focused on skills development or psychoeducation regarding substances, mental health, coping, anger management, offending behaviour and victim empathy. Clearly indicative of the multiple psychological needs that were targeted for treatment. The individual therapy sessions were experienced as personalised and emphasised the building of a therapeutic alliance. They promoted self-reflection, problemsolving and emotional expression.

Jason expressed that despite completing numerous groups the learning was not permanent. He found himself repeatedly falling into destructive behaviours:

Erm, it was good, it was good man to learn more-new skills and stuff and then like at the end of it as times gone by, I did slip into drugs again. [...] When I did the course I don't know, I wasn't on drugs then. I weren't on drugs and I did feel better for it, I felt like I learnt a lot and it was only after time that I ended up taking drugs again. (Jason) 
Correspondingly, other men recounted the cyclical nature of their recovery and the time they required to appreciate, utilise and internalise the support that was offered to them, which often occurred 'down the line':

You might not like it at first, but down the line you'll see the difference within yourself. Because I've seen the difference within myself in being here, from my personal experience and my understanding and my work with the teams and that. (Craig)

\subsection{Dealing with a regretful past: 'Facing all through your life'}

The gradual process readied the men to explore their past. Something they had hoped to avoid as it required them to reveal their vulnerabilities and face their 'mistakes'. It meant opening themselves up to re-experiencing long suppressed feelings of guilt, fear, shame, disappointment and grief:

I was talking about my past and that time, what age I got on drugs and that. It brought be back to that and I thought if I didn't hang around with them olders and that generation, I would never have got into it. It was only because I was young and naïve. (Mark)

There was many things I could've done differently in the past with the offences, with the relationships, if I could turn back the time I'd like to change a lot of things but... (Craig)

It was difficult to look back on that, see what I've done and paid for. (Terry)

Regret was a shared experience for seven men, originating from the long-standing consequences of their actions and past destructive behaviours. It required them coming to terms with an unchangeable past whilst acknowledging the loss of what could have been, had they made different decisions in life. Dan attempted to reconcile his feelings by separating his present-self from his past-self with 'it wasn't me really'. 
In contrast, two men shared narratives of victimhood where they blamed external circumstances for their current predicament:

As I see myself as the victim and not [them], I just cannot complete that in all consciousness. Saying that, 'Oh they're the victims and I'm the aggressor'. My philosophy is, [the victims] had it coming [...] and they brought it all on themselves, so I can't finish that course. (Sean)

Sean asserted his justification for his actions and felt wrongly accused. This increased his resistance to aspects of therapy. Jason was unable to comprehend or make sense of his mental health as he continued to attribute it directly to the mistreatment and deceptive ploys of the prison officers. Thus, maintaining his confusion and disbelief regarding his illness:

Yeah. I don't know, I really don't know, but I've never ever in all my time had that problem before. When I was at [prison] I had that problem. It was drug-induced, they were drugging me with some shit. I don't know what it was, but like I said, since I've been here I've been doing my detox and I've not had a single problem. At [prison] I wasn't even detoxing, so it just goes to show. (Jason)

Even though all men went through the process of recounting their story, the regret they experienced manifested differently: for some it invoked a sense of remorse, for others it was the loss to themselves, and for others still, it was the lack of compensation.

\subsection{Self-understanding: 'You understand what you done.'}

Therapy offered a space for the men to learn about themselves. It encouraged them to reflect on their past to understand 'why' and 'how' particular circumstances had arisen in their lives. The men developed deeper insight into problematic behaviours, such as substance use, anger and impulsivity, which was portrayed through their psychological reasoning: 
I could smoke a spliff but I'm on medication and it could send me paranoid and wary, unwell. But someone [else] could smoke it and be fine. But it's a depressant and I learnt, when I was smoking I was always feeling low and down and lazy, and I learnt so much about all these different drugs. (Craig)

In my household it was praised to be angry as a man because my dad was really angry. So I quickly learnt to internalise everything else and all the other emotions, but the only emotion I could externalise was anger, because that was praised. (Phillip)

Here the men made links between their behaviour and how it impacted on their feelings or thoughts. They thought about their behaviour given the context of their current circumstances (i.e. being on medication) or past experiences (i.e. family life). As such they could 'prevent this from happening' (Craig) in future by 'dealing with it differently' (Jacob). Subsequently, therapy presented an opportunity for exploring the underlying mechanisms that shaped them as people, helping them to obtain a clearer, balanced view of themselves through increased self-awareness:

Yeah, I really get a better understanding of my strengths and my weaknesses and er the things that can frustrate me. And the things that I enjoy and is good. [...] It helps, writing about your feelings helps hold a mirror to yourself. (Sean)

Through this enhanced self-understanding the men were able to generate greater selfcompassion by reframing their behaviour based on the newfound self-knowledge they had acquired. This facilitated their recovery and enhanced their resolve to build a different future for themselves:

You regret what you done. You've done work to prevent this from happening and hopefully have a good future when you're out there. (Craig) 


\subsection{Positive Change: 'I became a new man'}

Six men noticed the positive social and psychological benefits they had gained. Phillip specifically noticed how his ability to communicate with others had changed due to his ability to exercise control over his anger and express himself authentically:

It helped me with relationships in that sense, because now I'm able to like talk to people on a level and not become angry, and I'm able to express emotions and thoughts and things freely. (Philip)

Likewise, Jermaine spoke extensively about how therapy had enabled him to work through distressing emotions, specifically linked to his past. He found that these emotions were no longer as overwhelming. This opened him up to experiencing positive, uplifting emotions that improved his general well-being. Jermaine could finally leave his past behind him:

You realise you're not really so angry, so you're not really so grieving, you're not really so lonely, you know you let off the steam and you try thinking, 'No shit, I've left that for so long and now I know it's over and I feel better about myself'. (Jermaine)

Dan who described himself as anxious, developed a greater sense of self-efficacy. He was able to reclaim his personal power, giving him the strength to 'tackle' life's circumstances and restoring his sense of pride in himself:

Self-belief. Yeah, I've got me mojo back. Yeah, Ifeel like I can tackle things now, things I can do. (Dan)

Overall, the men went through a process of redefining themselves in light of their criminal offending and mental health issues. In some cases, this involved confronting the selfcriticism they experienced at the realisation of their 'flaws' or 'weaknesses': 
I just thought I was a nasty, bad person. Now I don't see it like that. [...] I've done something bad but I'm not a bad person I was unwell. (Terry)

I'm here I've done psychology courses and I see things differently now. I'm not worried about having a reputation and being the tough guy. [...] I don't want a certain image to be portrayed as, I just wanna be a valued member of society now. I hope I can settle back into society, make me feel worthwhile. (Terry)

This allowed them to reframe the parts of their lives characterised by adversity and crime to move into the future with the hope of being better men in the community. 


\section{Discussion}

The present study explored men's experiences of psychological therapy in a forensic mental health setting, providing much needed insight into the therapeutic process within this specialist clinical population who are typically considered 'difficult to treat' (Bartlett \& McGauley, 2009). It encapsulates men's experiences of being in and doing therapy. This is captured in the three superordinate themes: (1) 'shifting self' portrays the dynamic nature of men's perception of and response to therapy, (2) 'relationship with other' highlights the men's experience of the psychologist's or group's attributes that facilitated the development of a therapeutic alliance, and (3) 'therapeutic journey' represented the distinct phases of psychological therapy. Though presented as separate and discreet, the potential overlap across the themes is arguably inevitable in light of the complex, interdependent interactions that occur within psychological therapy (Prochaska \& Norcross, 2018).

Several researchers have corroborated the multiplicity of self (Lester, 2012; Rowan, 2013) and how certain sub-selves or sub-personalities find expression in specific situations. Likewise, men's multiple masculine-selves will no doubt be expressed differently under different circumstances (Wedgwood, 2009). The diversity of masculinities is well-established in the literature, as not all men will align with hegemonic masculine principles (Seidler et al., 2018). This was evident in the sample of men who took part in the study, whereas some were more comfortable opening up and sharing their difficulties others remained guarded and at a distance. 'Shifting self' captured the conflicting parts of the men's identity live in therapy at any given moment, highlighting the men's struggle in allowing themselves to be seen and known by the psychologist. 
Psychological therapy required them to move from their original defensive position, characterised by the protective elements of the 'guarded-self' and 'strong, aggressive-self', to a more forthcoming position as evidence by the 'open, revealing-self'. To successfully achieve this the men had to risk vulnerability and exposure ('vulnerable, exposed-self'), usually accompanied by feelings of fear and shame (Kimmel, 1994; Krugman, 1995). Specific selfstates were experienced at different timepoints in therapy, influenced by the individual's personality, the severity of mental illness and other external circumstances that may have impacted on the individual's mood or perceived sense of safety. The shifting nature of these self-states was associated with a loosening of internalised (often conflicting) gender ideals related to emotional expression, strength, power and control (Mahalik et al., 2003b) that the men had adopted from their early childhood and adolescence.

Mahalik et al. (2003b) conceptualised specific masculinity scripts that men are likely to endorse to varying degrees which interfere with their capacity to engage with psychological therapy. Of these the 'tough guy' script is most clearly linked to the sub-themes of 'guardedself' and 'strong, aggressive-self'. It elicits the suppression of emotions and epitomises aggressiveness, fearlessness and invulnerability. Engaging in psychological therapy or needing psychological therapy implies dependence, vulnerability and submission, thus posing a threat to the men's internalised standards relating to male identity and masculinity (Schaub \& Williams, 2007), who may view this as a personal failure (Addis \& Mahalik, 2003). As such, men either choose to remain silent about difficulties through avoidance (Pederson \& Vogel, 2007), minimise or deny their difficulties by projecting a dominant persona (Johnson et al., 2013; O’Brien, Hunt, \& Hart, 2005) rather than confessing vulnerability (Mansfield et al., 2003). This pattern has been apparent in men's discourses related to help-seeking in the form of self-reliance and guarded vulnerability (Johnson et al., 2012). Men's fears of being judged 
negatively by others (Komiya, Good, \& Sherrod, 2000) further strengthens these defences. An aspect especially heightened in the forensic population where there is a higher prevalence of trauma (Reavis, 2013) and disorganised attachment styles (Adshead, 2002).

Feelings of fear and shame were the dominant forces that created a barrier to opening up. Kimmel (1994) attributed this to an intrinsic fear within men of being 'unmasked', 'not measuring up' and being viewed as 'less than a man'. Since from a young age, men are taught to repress their yearnings for love and connection and build a wall of toughness around themselves to be accepted as men (Pollack, 1995). This is reinforced through shaming processes during gender socialisation to shape acceptable behaviour leaving men to become shamephobic or shame-sensitive (Krugman, 1995). As a result, shame becomes the core organising principle in men's gender identity, easily triggered by feelings of inadequacy, inferiority, insecurity or emotional neediness. Thus, despite recognising their need for help, the men maintained a sense of aversiveness to sharing their difficulties with others and at times struggled to find the words.

Plus, the relationship between shame and disclosure is likely to be two-fold in this population. Shame may be experienced not only as a result of 'spoiled identity' but in response to the offending behaviour (Howells \& Day, 2007). As a result, it is not unlikely for individuals to experience shame in relation to their offending (Tangney, Stuewig, \& Hafez, 2011) and fall into denial (Adshead, 1998; Bouffard \& Piquero, 2010). This, compounded by the fear of rejection from others and limited ability for emotional expressiveness, make it difficult for men to expose their inner selves (Seidler, 1992).

Only after overcoming these fears, were the men able to appreciate the benefits of opening up. This was primarily precipitated by a reappraisal of their current circumstances and 
desire to progress. It fits in line with Johnson et al.'s (2012) discourse pattern of desperation whereby men often delayed seeking treatment until it reached a point where the issues were too serious to ignore. In forensic services after long periods of resistance the men often decided that it was in their best interest to co-operate and work with the system rather than against it. Increased comfort with emotional expression ('I wear my heart on my sleeve') and freedom from the judgement of others facilitated better engagement. This softening of masculine ideals was similarly observed in a qualitative study exploring men's ideas of masculinity in a prison setting (Evans \& Wallace, 2008). It suggested that self-definitions of masculinity or one's male identity were "ongoing and open to change". With maturity the men moved from an external locus of evaluation to an internal locus of evaluation giving less precedence to the opinions of other men (Evans \& Wallace, 2008).

In the men's journey, their 'relationship with other' (namely the psychologist) played a key role in facilitating change through a strong therapeutic alliance that emphasised 'doing with' rather than 'doing to' (Marshall \& Serran, 2004). The psychologist as a 'safe, supportiveother' and 'listening, available-other' exhibited specific qualities that allowed the men to feel heard, creating a space perceived to be unique to that therapeutic relationship (Bion, 1985; Winnicott, 1969). Perhaps it provided a space where they could be "known" by the psychologist (Seidler, Rice, Oliffe, Fogarty, \& Dhillon, 2017) which they valued (Mezey, Kavuma, Turton, Demetriou, \& Wright, 2010).

In forensic mental health settings therapist attributes such as being flexible, honest, respectful, trustworthy, confident, warm, interested, sensitive and open were found to contribute positively to the alliance (Ackerman \& Hilsenroth, 2003). Likewise, a firm but caring relational style was found to be the most effective in creating change in high risk offenders (Frost, 2004). The men used words such as 'genuine', 'non-judgemental', 'helpful' and 
'understanding'. They were sensitive to the micro, non-verbal aspects of the psychologist's style, frequently referring to the importance of eye-contact, tone of voice, body language, demeanour and tact. Extremely reminiscent of the Rogerian principles at the centre of humanistic psychotherapy: empathy, congruence and unconditional positive regard (Rogers, 1957).

Attempting to equalise power dynamics is of a greater importance in forensic settings due to the inherent legal constraints the men are often under (Livingston, Nijdam-Jones, \& Brink, 2012) which are likely to trigger feelings of helplessness, powerlessness and a loss of control. When the men experienced the psychologist as a 'collaborative-other' they felt they had greater autonomy and mutual influence within the relationship. This meant they were able to actively engage and take ownership of their recovery. Something Seidler (2017) discovered was an important aspect of the therapeutic relationship in men seeking treatment for Depression in the community. Such a stance is even more necessary when considering the dual purpose of therapy in a forensic mental health setting of supporting psychological well-being, whilst challenging and confronting maladaptive patterns of behaviour and identity (Adshead, 1998).

As part of their 'therapeutic journey', these men commented on their compromised capacity to exercise choice over their treatment. This placed them in a double-bind, whereby co-operation would mean risking vulnerability and exposure, a state deemed too intolerable, versus the reality of resistance which would invariably lengthen their stay in hospital and limit their chances of progress. The Multifactor Offender Readiness Model (MORM) clearly discusses the adverse impact of external factors on individual's readiness to change, resulting in greater levels of non-completion (Ward et al., 2004). Perhaps for this reason, the men emphasised the length of time required to meet their treatment goals. Although it was described 
as a hindrance, on the other hand the men expressed how the 'pacing' was required to ease them into telling their story, establishing trust and not exploring traumatic experiences prematurely.

'Self-understanding' and 'positive change' conveyed the overall positive experience of therapy for these men, despite the variable future outcomes that were expected for them. It was suggestive of a Recovery Model (Deegan, 1988) and in line with the Good Lives Model (Ward \& Brown, 2004), where the men developed greater insight into their difficulties to consider building a new future, emphasising a sense of empowerment, greater affinity for selfmanagement and the reclaiming of identity and hope. As in other studies, the men reported psychoeducation regarding their illness helped recovery by providing them with strategies to understand, monitor, and control their mental state (Mezey et al., 2010), as well as preventing future reoffending. A key aspect of this was admitting to their offences, "moving away from denial and hopelessness towards a story of regret and hope as the men started to come to terms with their 'badness' and 'madness"' (Adshead, 1998, p. 10).

A study by Laithwaite and Gumley (2007) using grounded theory identified similar themes for men with psychosis in a forensic mental health setting, which emphasised safety, developing trust, learning about self, sense of achievement and gaining confidence as the cornerstones of their experiences within services. In fact, men receiving treatment have been shown to exhibit pro-social masculine norms, greater acceptance of emotions and none antifeminine views (Searle, Hare, Davies, \& Morgan, 2018). Suggesting that treatment could support these men to view positive aspects of their masculinity (Englar-Carlson \& Kiselica, 2013) and leverage these to move forward in their recovery. 


\section{Strengths \& Limitations}

This study provides an important insight into the therapeutic processes when working with men in a forensic mental health setting, alongside aspects that are supportive of a strong therapeutic alliance. It helps bring to light how men's internalised attitudes regarding emotional expression and strength can pose challenges for them at various stages in therapy, but also demonstrates that these can be redefined and reshaped to facilitate successful therapeutic change. Not only this, the diversity of masculinities observed in the study demonstrated that not all forensic men absolutely align themselves with hypermasculine ideals.

It was noticeable however that some men tended to distance themselves from their experience, evident in their use of the pronoun 'you'. They were more comfortable talking about other men and their observations of other men, reluctant to attribute similar behaviours to themselves. There appeared to be an element of social desirability, especially when the men expressed few or no difficulties in their relationships with their psychologist, alternatively this may have been reflective of their stage of recovery. At times, it appeared the men identified less with their gender identity and more so with being a 'patient' or an 'offender'. For certain individuals it appeared that they had never contemplated or discussed what it meant to be a man in such a setting.

IPA analysis is reliant on rich, in-depth personal narratives of lived experiences in order for the researcher to elicit an understanding of the individual's perception of a particular phenomenon and the subjective meanings attached to it (Smith, Flowers, \& Larkin, 2009). It should be noted that in certain cases the narrative accounts of men were at times fragmented, lacking in elaborative introspection due to the men's limited ability to adequately express their internal emotional world (Adshead, 2012; Laithwaite \& Gumley, 2007), which may have impacted on the richness of the data. Furthermore, due to its interpretive nature, the meanings 
derived from the text will be limited to researcher's interpretative stance. Although steps were taken to "bracket off" personal assumptions and perceptions, the intersubjective nature of IPA lends itself to greater influence from the researcher's knowledge and personal experiences.

In addition, despite the sample being culturally diverse, the men who opted to take part were in the latter stages of their treatment pathway and so may represent the views of a particular cohort of men who are more willing to engage in therapy. Thus, these findings do not capture the experiences of those who are less likely to engage in therapy or refuse to engage in therapy altogether.

\section{Clinical implications}

Self-narrative is what individuals utilise to make sense of their lives. Psychological therapy allows individuals to contextualise their behaviour and psychological distress to develop a deeper understanding of themselves and their identity. Deconstructing men's gendered narratives in therapy to better understand their origins and influences can support men to critically evaluate the helpfulness of their gendered schemas (Addis, 2011; Seidler et al., 2018). Clinicians working in these settings could work towards promoting discourses that emphasise positive masculinity (Englar-Carlson \& Kiselica, 2013) and challenge hypermasculine ideals.

Reframing men's behaviours in the context of gender identity conflict may enable clinicians to take a more empathetic stance to the difficulties they face in engaging men. Incorporating the role of gender identity within psychological formulations, as demonstrated in the transdiagnostic model of male distress (Kingerlee, 2012), would allow clinician's to be cognizant of these aspects when providing psychological intervention or attempting to engage men. Like for example, men's tendency to avoid dependence may lead to avoiding emotional 
engagement in psychological therapy and higher levels of dismissiveness. A perceived loss of power and control may be exhibited through aggression or bravado. In such instances measures could be taken to establish safety, provide opportunities for collaboration and autonomy to reinstil a positive sense of self-efficacy (Seidler et al., 2018). Service providers could consider whether other forms of engagement with men who are unable to attend psychological therapy could be utilised to establish a therapeutic rapport in a gender-sensitive manner.

\section{Future Research}

This study sets the stage for further exploration of whether the concepts identified in this study are in fact unique to men or indeed simply related to psychological therapy or individuals under the care of forensic mental health settings. Exploring the narratives of women in forensic mental health settings could help shed light on this, as well as extending the possibility of distinguishing factors that may be unique to either gender. It has already been acknowledged that women in forensic mental health settings have different treatment needs (Dowden \& Andrews, 1999). It may be worth considering whether their experiences of psychological therapy are also as specific.

Furthermore, comparing narratives of men at different stages of psychological therapy may provide an enhanced insight into the specific challenges faced by them at specific timepoints, including pre-therapy and post therapy. It may help identify how men's gender identity is transformed from one phase of therapy to the next. Alternative methodologies like the Q-sort could be utilised to obtain an explicit understanding of the masculine ideologies endorsed by men in forensic mental health services and how these subsequently impact on men's psychological rehabilitation more broadly. Using similar creative strategies to explore the stories of those who choose not to engage or disengage would significantly add to the literature. 


\section{References}

Ackerman, S. J., \& Hilsenroth, M. J. (2003). A review of therapist characteristics and techniques positively impacting the therapeutic alliance. Clinical Psychology Review, 23(1), 1-33.

Addis, M. (2011). Invisible men: Men's inner lives and the consequences of silence. New York: Macmillan.

Addis, M. E., \& Cohane, G. H. (2005). Social scientific paradigms of masculinity and their implications for research and practice in men's mental health. Journal of Clinical Psychology, 61(6), 633-647.

Addis, M. E., \& Mahalik, J. R. (2003). Men, masculinity, and the contexts of help seeking. American Psychologist, 58(1), 5-14.

Adshead, G. (1998). The heart and its reasons: Constructing explanations for offending behaviour. The Journal of Forensic Psychiatry, 9(2), 231-236.

Adshead, G. (2002). Three degrees of security: Attachment and forensic institutions: Attachment and forensic institutions. Criminal Behaviour and Mental Health, 12(S2), $31-45$.

Adshead, G. (2012). Their Dark Materials: Narratives and Recovery in Forensic Practice, Royal College of Psychiatrists, 1-11.

Amato, F. J. (2012). The Relationship of Violence to Gender Role Conflict and Conformity to Masculine Norms in a Forensic Sample. The Journal of Men's Studies, 20(3), 187208. 
Andresen, R., Oades, L., \& Caputi, P. (2003). The experience of recovery from schizophrenia: towards an empirically validated stage model. Australian \& New Zealand Journal of Psychiatry, 37(5), 586-594.

Andrews, D. A., \& Dowden, C. (2007). The risk-need-responsivity model of assessment and human service in prevention and corrections: Crime-prevention jurisprudence. Canadian Journal of Criminology and Criminal Justice, 49(4), 439-464.

Apesoa-Varano, E. C., Barker, J. C., \& Hinton, L. (2017). "If You Were Like Me, You Would Consider It Too": Suicide, Older Men, and Masculinity. Society and Mental Health.

Bargh, J. A., \& Huang, J. Y. (2014). The evolutionary unconscious: From selfish genes to selfish goals (pp. 35-54). Presented at the Motivation and its Regulation: The Sydney symposium on social cognition.

Bartlett, A., \& McGauley, G. (2009). Forensic mental health: concepts, systems, and practice. United Kingdom: Oxford university press.

Bem, S. L. (1981). Gender schema theory: A cognitive account of sex typing. Psychological Review, 88(4), 354.

Berger, J. M., Levant, R., McMillan, K. K., Kelleher, W., \& Sellers, A. (2005). Impact of Gender Role Conflict, Traditional Masculinity Ideology, Alexithymia, and Age on Men's Attitudes Toward Psychological Help Seeking. Psychology of Men \& Masculinity, 6(1), 73-78.

Bergman, S. J. (1995). Men's psychological development: A relational perspective. In R. F. Levant \& W. S. Pollack (Eds.), A New Psychology of Men (pp. 68-90). New York: Basic Books.

Bion, W. R. (1985). Container and contained. Group Relations Reader, 2(8), 127-133. 
Bonta, J., \& Andrews, D. A. (2007). Risk-need-responsivity model for offender assessment and rehabilitation. Rehabilitation, 6(1), 1-22.

Bouffard, L. A., \& Piquero, N. L. (2010). Defiance theory and life course explanations of persistent offending. Crime \& Delinquency, 56(2), 227-252.

Cann, J., Falshaw, L., \& Friendship, C. (2005). Understanding 'what works': accredited cognitive skills programmes for young offenders. Youth Justice, 5(3), 165-179.

Chodorow, N. J. (1999). The reproduction of mothering: Psychoanalysis and the sociology of gender. University of California Press.

Cocks, H. (2010). The History of Sexuality Meets Evolutionary Psychology. Contemporary British History, 24(1), 109-129.

Coid, J., Kahtan, N., Gault, S., Cook, A., \& Jarman, B. (2001). Medium secure forensic psychiatry services: comparison of seven English health regions. The British Journal of Psychiatry, 178(1), 55-61.

Coles, T. (2009). Negotiating the field of masculinity: The production and reproduction of multiple dominant masculinities. Men and Masculinities, 12(1), 30-44.

Connell, R. W., \& Messerschmidt, J. W. (2005). Hegemonic Masculinity: Rethinking the Concept. Gender \& Society, 19(6), 829-859.

Dabbs, J. M., Riad, J. K., \& Chance, S. E. (2001). Testosterone and ruthless homicide. Personality and Individual Differences, 31(4), 599-603.

Dagirmanjian, F. B., Mahalik, J. R., Boland, J., Colbow, A., Dunn, J., Pomarico, A., \& Rappaport, D. (2017). How Do Men Construct and Explain Men's Violence? Journal of Interpersonal Violence, 32(15), 2275-2297.

Davies, J., \& Nagi, C. (2017). Individual Psychological Therapies in Forensic Settings: Research and Practice. New York: Taylor \& Francis. 
Deegan, P. E. (1988). Recovery: The lived experience of rehabilitation. Psychosocial Rehabilitation Journal, 11(4), 11.

Diamond, M. J. (2004). The shaping of masculinity: Revisioning boys turning away from their mothers to construct male gender identity. The International Journal of Psychoanalysis, 85(2), 359-379.

Diamond, M. J. (2006). Masculinity Unraveled: The Roots of Male Gender Identity and the Shifting of Male Ego Ideals Throughout Life. Journal of the American Psychoanalytic Association, 54(4), 1099-1130.

Dowden, C., \& Andrews, D. A. (1999). What Works for Female Offenders: A Meta-Analytic Review. Crime and Delinquency, 45(4), 438-452.

Eagly, A. H. (2009). The his and hers of prosocial behavior: An examination of the social psychology of gender. American Psychologist, 64(8), 644-658.

Eckes, T., \& Trautner, H. M. (2000). The developmental social psychology of gender. Sussex: Psychology Press.

Emslie, C., Ridge, D., Ziebland, S., \& Hunt, K. (2006). Men's accounts of depression:

Reconstructing or resisting hegemonic masculinity? Social Science \& Medicine, 62(9), $2246-2257$.

Englar-Carlson, M., \& Kiselica, M. S. (2013). Affirming the Strengths in Men: A Positive Masculinity Approach to Assisting Male Clients. Journal of Counseling \& Development, 91(4), 399-409.

Englar-Carlson, M., \& Shepard, D. S. (2005). Engaging men in couples counseling: Strategies for overcoming ambivalence and inexpressiveness. The Family Journal, 13(4), 383391. 
Evans, T., \& Wallace, P. (2008). A Prison within a Prison?: The Masculinity Narratives of Male Prisoners. Men and Masculinities, 10(4), 484-507.

Frost, A. (2004). Therapeutic engagement styles of child sexual offenders in a group treatment program: A grounded theory study. Sexual Abuse: A Journal of Research and Treatment, 16(3), 191-208.

Galdas, P. M., Cheater, F., \& Marshall, P. (2005). Men and health help-seeking behaviour: literature review. Journal of Advanced Nursing, 49(6), 616-623.

Galligani, N., Renck, A., \& Hansen, S. (1996). Personality profile of men using anabolic androgenic steroids. Hormones and Behavior, 30(2), 170-175.

Gilbert, P. (2007). Evolved minds and compassion in the therapeutic relationship. In P. Gilbert \& R. Leahy (Eds.), The therapeutic relationship in the cognitive behavioural psychotherapies (pp. 106-142). New York: Routledge.

Glenn, E. N. (1999). The social construction and institutionalization of gender and race. In M. M. Ferree, J. Lorber, \& B. B. Hess (Eds.), Revisioning Gender (pp. 3-43). Oxford: Atamira Press.

Good, G. E., \& Mintz, L. B. (1990). Gender Role Conflict and Depression in College Men: Evidence for Compounded Risk. Journal of Counseling \& Development, 69(1), 17-21.

Gordon, D. M., Hawes, S. W., Reid, A. E., Callands, T. A., Magriples, U., Divney, A., ... Kershaw, T. (2013). The many faces of manhood: Examining masculine norms and health behaviors of young fathers across race. American Journal of Men's Health, 7(5), 394-401.

Govender, V., \& Penn-Kekana, L. (2008). Gender biases and discrimination: a review of health care interpersonal interactions. Global Public Health, 3(S1), 90-103.

Hausmann, R. (2009). The global gender gap report 2009. World Economic Forum. 
Hearn, J. (2004). From Hegemonic Masculinity to the Hegemony of Men. Feminist Theory, $5(1), 49-72$.

Howells, K., \& Day, A. (2007). Readiness for treatment in high risk offenders with personality disorders. Psychology, Crime \& Law, 13(1), 47-56.

Johnson, J. L., Oliffe, J. L., Kelly, M. T., Galdas, P., \& Ogrodniczuk, J. S. (2012). Men's discourses of help-seeking in the context of depression. Sociology of health \& illness, 34(3), 345-361.

Kahn, J. S. (2009). An introduction to masculinities. John Wiley \& Sons.

Kimmel, M. S. (1994). Masculinity as Homophobia: Fear, Shame and Silence in the Construction of Gender Identity. In H. Brod \& M. Kaufman (Eds.), Theorising Masculinities (pp. 119-143). London: Sage.

Kingerlee, R. (2012). Conceptualizing men: A transdiagnostic model of male distress: A transdiagnostic model of male distress. Psychology and Psychotherapy: Theory, Research and Practice, 85(1), 83-99.

Kingerlee, R., Precious, D., Sullivan, L., \& Barry, J. (2014). Engaging with the emotional lives of men. The Psychologist, 27(6), 418-421.

Komiya, N., Good, G. E., \& Sherrod, N. B. (2000). Emotional openness as a predictor of college students' attitudes toward seeking psychological help. Journal of Counseling Psychology, 47(1), 138-143.

Krugman, S. (1995). Male Development and the Transformation of Shame. In R. F. Levant \& W. S. Pollack (Eds.), A New Psychology of Men (pp. 91-126). New York: Basic Books.

Kupers, T. A. (2005). Toxic masculinity as a barrier to mental health treatment in prison. Journal of Clinical Psychology, 61(6), 713-724. 
Laithwaite, H., \& Gumley, A. (2007). Sense of self, adaptation and recovery in patients with psychosis in a forensic NHS setting. Clinical Psychology \& Psychotherapy, 14(4), $302-316$.

Larkin, M., \& Thompson, A. R. (2011). Interpretative phenomenological analysis in mental health and psychotherapy research. In Qualitative research methods in mental health and psychotherapy: A guide for students and practitioners. (pp. 99-116). Chichester, UK: John Wiley \& Sons, Ltd.

Lester, D. (2012). A Multiple Self Theory of the Mind. Comprehensive Psychology, 1, 212232

Levant, R. F. (1996). The new psychology of men. Professional Psychology: Research and Practice, 27(3), 259.

Levant, R. F., \& Pollack, W. S. (1995). A New Psychology of Men. New York: Basic Books.

Levant, R. F., \& Richmond, K. (2008). A review of research on masculinity ideologies using the Male Role Norms Inventory. The Journal of Men's Studies, 15(2), 130-146.

Livingston, J. D., Nijdam-Jones, A., \& Brink, J. (2012). A tale of two cultures: examining patient-centered care in a forensic mental health hospital. Journal of Forensic Psychiatry \& Psychology, 23(3), 345-360.

Magovcevic, M., \& Addis, M. E. (2008). The Masculine Depression Scale: development and psychometric evaluation. Psychology of Men \& Masculinity, 9(3), 117.

Mahalik, J. R., Aldarondo, E., Gilbert-Gokhale, S., \& Shore, E. (2005). The Role of Insecure Attachment and Gender Role Stress in Predicting Controlling Behaviors in Men Who Batter. Journal of Interpersonal Violence, 20(5), 617-631. 
Mahalik, J. R., Good, G. E., \& Englar-Carlson, M. (2003b). Masculinity scripts, presenting concerns, and help seeking: Implications for practice and training. Professional Psychology: Research and Practice, 34(2), 123-131.

Mahalik, J. R., Good, G. E., Tager, D., Levant, R. F., \& Mackowiak, C. (2012). Developing a taxonomy of helpful and harmful practices for clinical work with boys and men. Journal of Counseling Psychology, 59(4), 591-603.

Mahalik, J. R., Locke, B. D., Ludlow, L. H., Diemer, M. A., Scott, R. P., Gottfried, M., \& Freitas, G. (2003a). Development of the conformity to masculine norms inventory. Psychology of Men \& Masculinity, 4(1), 3-25.

Mahler, M. (1972). On the first three subphases of the separation-individuation process. The International Journal of Psycho-Analysis, 53, 333-338.

Mansfield, A., Addis, M., \& Mahalik, J. (2003). 'Why Won't He Go to the Doctor?': The Psychology of Men's Help Seeking. International Journal of Men's Health, 2(2), 93109.

Marshall, W. L., \& Serran, G. A. (2004). The role of the therapist in offender treatment. Psychology, Crime \& Law, 10(3), 309-320.

Matud, M. P. (2004). Gender differences in stress and coping styles. Personality and Individual Differences, 37(7), 1401-1415.

McMurran, M. (2009). Motivational interviewing with offenders: A systematic review. Legal and Criminological Psychology, 14(1), 83-100.

McMurran, M., Huband, N., \& Overton, E. (2010). Non-completion of personality disorder treatments: A systematic review of correlates, consequences, and interventions. Clinical Psychology Review, 30(3), 277-287. 
McMurran, M., \& McCulloch, A. (2007). Why don't offenders complete treatment? Prisoners' reasons for non-completion of a cognitive skills programme. Psychology, Crime \& Law, 13(4), 345-354.

McMurran, M., \& Theodosi, E. (2007). Is treatment non-completion associated with increased reconviction over no treatment? Psychology, Crime \& Law, 13(4), 333-343.

Messerschmidt, J. W. (2000). Becoming "real men" adolescent masculinity challenges and sexual violence. Men and Masculinities, 2(3), 286-307.

Mezey, G. C., Kavuma, M., Turton, P., Demetriou, A., \& Wright, C. (2010). Perceptions, experiences and meanings of recovery in forensic psychiatric patients. Journal of Forensic Psychiatry \& Psychology, 21(5), 683-696.

Mike Donaldson. (1993). What Is Hegemonic Masculinity? Theory and Society, 22(5,), 643657.

Ministry of Justice. (2017). Prison population figures: 2017. Retrieved from https://www.gov.uk/government/statistics/prison-population-figures-2017.

Moore, T. M., \& Stuart, G. L. (2005). A Review of the Literature on Masculinity and Partner Violence. Psychology of Men \& Masculinity, 6(1), 46-61.

Mosher, D. L., \& Sirkin, M. (1984). Measuring a macho personality constellation. Journal of Research in Personality, 18(2), 150-163.

National Audit Office. (2017). Mental Health in Prisons.

NICE. (2012). Methods for the development of NICE public health guidance (third edition). National Institute for Health and Care Excellence.

O’Brien, R., Hunt, K., \& Hart, G. (2005). 'It's caveman stuff, but that is to a certain extent how guys still operate': men's accounts of masculinity and help seeking. Social Science \& Medicine, 61(3), 503-516. 
Olver, M. E., Stockdale, K. C., \& Wormith, J. S. (2011). A meta-analysis of predictors of offender treatment attrition and its relationship to recidivism. Journal of Consulting and Clinical Psychology, 79(1), 6-21.

O’Neil, J. M. (1990). Assessing men's gender role conflict. In D. Moore \& F. Leafgren (Eds.), Problem solving strategies and interventions for men in conflict (pp. 23-38). Alexandria: American Association of Counselling and Development.

O’Neil, J. M. (2008). Summarizing 25 Years of Research on Men's Gender Role Conflict Using the Gender Role Conflict Scale: New Research Paradigms and Clinical Implications. The Counseling Psychologist, 36(3), 358-445.

O’Neil, J. M., Glenn, E. G., \& Holmes, S. (1995). Fifteen years of theory and research on men's gender role conflict: New paradigms for empirical research. In R. F. Levant \& W. S. Pollack (Eds.), A New Psychology of Men (pp. 184-206). New York: Basic Books.

Paesen, L., Vervaeke, G., Claes, L., Stroobants, R., \& Vertommen, H. (2013). Hard to treat forensic patients: the development and initial validation of the Mind-scale. Journal of Forensic Psychiatry \& Psychology, 24(6), 740-755.

Pederson, E. L., \& Vogel, D. L. (2007). Male gender role conflict and willingness to seek counseling: Testing a mediation model on college-aged men. Journal of Counseling Psychology, 54(4), 373-384.

Pleck, J. H. (1995). The gender role strain paradigm: An update. In R. F. Levant \& W. S. Pollack (Eds.), A New Psychology of Men (pp. 11-32). New York: Basic Books.

Pollack, W. S. (1995). Deconstructing dis-identification: Rethinking psychoanalytic concepts of male development. Psychoanalysis \& Psychotherapy. 
Prochaska, J. O., \& Norcross, J. C. (2018). Systems of psychotherapy: A transtheoretical analysis. New York: Oxford University Press.

Reavis, J. (2013). Adverse Childhood Experiences and Adult Criminality: How Long Must We Live before We Possess Our Own Lives? The Permanente Journal, 17(2), 44-48.

Rice, S. M., Fallon, B. J., Aucote, H. M., Möller-Leimkühler, A., Treeby, M. S., \& Amminger, G. P. (2015). Longitudinal sex differences of externalising and internalising depression symptom trajectories: Implications for assessment of depression in men from an online study. International Journal of Social Psychiatry, 61(3), 236-240.

Ridgeway, C. L. (2006). Gender as an Organizing Force in Social Relations: Implications for the Future of Inequality. In F. D. Blau, M. C. Brinton, \& D. B. Grusky (Eds.), The Declining Significance of Gender? (pp. 265-288).

Risman, B. J. (2004). Gender As a Social Structure: Theory Wrestling with Activism. Gender $\&$ Society, 18(4), 429-450.

Rogers, C. R. (1957). The necessary and sufficient conditions of therapeutic personality change. Journal of Consulting Psychology, 21(2), 95.

Ross, E. C., Polaschek, D. L., \& Ward, T. (2008). The therapeutic alliance: A theoretical revision for offender rehabilitation. Aggression and Violent Behavior, 13(6), 462-480.

Rowan, J. (2013). Subpersonalities: The people inside us. London: Routledge.

Rowan, J., \& Cooper, M. (1998). The plural self: Multiplicity in everyday life. London: Sage.

Ruble, D. N., Greulich, F., Pomerantz, E. M., \& Gochberg, B. (1993). The role of genderrelated processes in the development of sex differences in self-evaluation and depression. Journal of Affective Disorders, 29(2), 97-128. 
Rutherford, M., \& Duggan, S. (2008). Forensic mental health services: facts and figures on current provision. The British Journal of Forensic Practice, 10(4), 4-10.

Sampson, C. J., James, M., Huband, N., Geelan, S., \& McMurran, M. (2013). Cost implications of treatment non-completion in a forensic personality disorder service: Costs of non-completion in personality disorder. Criminal Behaviour and Mental Health, 23(5), 321-335.

Schaub, M., \& Williams, C. (2007). Examining the relations between masculine gender role conflict and men's expectations about counseling. Psychology of Men \& Masculinity, $8(1), 40-52$

Schippers, M. (2007). Recovering the feminine other: Masculinity, femininity, and gender hegemony. Theory and Society, 36(1), 85-102.

Schrock, D., \& Schwalbe, M. (2009). Men, masculinity, and manhood acts. Annual Review of Sociology, 35, 277-295.

Scowcroft, E. (2017). Samaritans suicide statistics report 2017. Retrieved from https://www.samaritans.org/sites/default/files/kcfinder/files/Suicide_statistics_report_ 2017_Final.pdf

Searle, R., Hare, D., Davies, B., \& Morgan, S. L. (2018). The impact of masculinity upon men with psychosis who reside in secure forensic settings. The Journal of Forensic Practice, 20(2), 69-80.

Seidler, V. J. J. (1992). Masculinity, violence and emotional life. In G. Bendelow \& S. J. Williams (Eds.), Emotions in Social Life: Critical Themes and Contemporary Issues (pp. 191-208). London: Routledge.

Seidler, V. J. J. (1997). Man enough: Embodying masculinities. London: Sage. 
Seidler, Z. E., Rice, S. M., Oliffe, J. L., Fogarty, A. S., \& Dhillon, H. M. (2017). Men In and Out of Treatment for Depression: Strategies for Improved Engagement: Engaging men in treatment for depression. Australian Psychologist.

Seidler, Z. E., Rice, S. M., River, J., Oliffe, J. L., \& Dhillon, H. M. (2018). Men’s Mental Health Services: The Case for a Masculinities Model. The Journal of Men's Studies, 26(1), 92-104.

Shaw, R. L., Booth, A., Sutton, A. J., Miller, T., Smith, J. A., Young, B., ... Dixon-Woods, M. (2004). Finding qualitative research: an evaluation of search strategies. $B M C$ Medical Research Methodology, 4(1), 1-5.

Smith, J. A., Flowers, P., \& Larkin, M. (2009). Interpretative phenomenological analysis: theory, method and research. Los Angeles: SAGE.

Snell, W. E. (1989). Development and validation of the Masculine Behavior Scale: A measure of behaviors stereotypically attributed to males vs. females. Sex Roles, 21(11-12), $749-767$.

Sullivan, L., Camic, P. M., \& Brown, J. S. L. (2015). Masculinity, alexithymia, and fear of intimacy as predictors of UK men's attitudes towards seeking professional psychological help. British Journal of Health Psychology, 20(1), 194-211.

Tangney, J. P., Stuewig, J., \& Hafez, L. (2011). Shame, guilt, and remorse: Implications for offender populations. Journal of Forensic Psychiatry \& Psychology, 22(5), 706-723.

Toch, H. (1998). Hypermasculinity and prison violence. In L. H. Bowker (Ed.), Masculinities and violence (pp. 168-178). USA: Sage Publications.

Ward, T., \& Brown, M. (2004). The good lives model and conceptual issues in offender rehabilitation. Psychology, Crime \& Law, 10(3), 243-257. 
Ward, T., Day, A., Howells, K., \& Birgden, A. (2004). The multifactor offender readiness model. Aggression and Violent Behavior, 9(6), 645-673.

Wedgwood, N. (2009). Connell's theory of masculinity - its origins and influences on the study of gender1. Journal of Gender Studies, 18(4), 329-339.

Whitehead, A. (2005). Man to Man Violence: How Masculinity May Work as a Dynamic Risk Factor. The Howard Journal of Criminal Justice, 44(4), 411-422.

Winnicott, D. W. (1969). The use of an object. The International Journal of Psycho-Analysis, $50,7-11$.

Wright, F. (1987). Men, shame and antisocial behaviour: A psychodynamic perspective. Group, 11(4), 238-246. 
PUBLIC DOMAIN BRIEFING PAPER 
This chapter gives an outline of the literature review and empirical paper carried out by Shazia Hussain as part of the Doctorate in Forensic Clinical Psychology program at the University of Birmingham.

\section{Literature Review: Men's Experiences of Psychosis}

\section{Introduction}

Psychosis is a common symptom of various mental health disorders (e.g. Schizophrenia, Shizoaffective Disorder, Bipolar Affective Disorder, Delusional Disorder) where an individual loses touch with reality. Those who suffer from psychosis experience problems in their social and occupational functioning (Malla, 2005). Not to mention the huge effect it has on someone's psychological functioning (Penn et al., 2005), increasing chances of suicide (Power, 2010).

Recently, researchers are recognising that there are differences in how men and women experience psychosis, how they manage psychosis and their outcomes of treatment. Men are said to be more severely unwell, more likely to be isolated, use substances and have less positive outcomes to treatment in the long-term (Barajas et al., 2015). Services in the community that hope to prevent psychosis can struggle to engage young men (Lincoln \& McGorry, 1995), which means they do not get adequate support.

Research into men's mental health has looked into the impact of masculinity on helpseeking behaviour in depressed men. It has been found that men who conform to gender role norms such as not showing feelings, being in control, self-reliant and strong, are less likely to seek support (Addis \& Mahalik, 2003). These men view their depression differently and may struggle with vulnerability. The literature review aimed to bring together all the research on 
men's experiences of psychosis to explore whether masculine identity impacted on how men viewed and managed their psychosis.

\section{Methodology}

A systematic literature search uncovered 11 relevant studies. The findings from these studies that related specifically to men's experiences were brought together and analysed using a Thematic Synthesis. This involved identifying common themes across the papers.

\section{Results}

During the analysis three key themes were discovered: (1) shock followed by understanding, (2) living with psychosis and (3) towards recovery. Each of these themes had corresponding subthemes which captured the diverse experiences of men.

Shock followed by understanding captured the initial disruption that happened in the lives of men when they first experienced the illness and how they sought to make sense of it. Unexpected, uncontrollable mental overwhelm highlighted how the men's lives were turned upside down. They weren't sure what was happening, their minds seemed to have shut down and they were experiencing strange things. An explanation why it happened demonstrated how the men tried to identify the causes of their illness.

Living with psychosis expressed the struggles the men experienced and consisted of five sub-themes. These related to their difficulties with accepting medication, the several losses they suffered, their feelings of hopelessness and wanting to die, the desire to conceal their illness rather than risk being stigmatised, and their urge to socially isolate themselves to stay safe versus the need for support and intimacy. 
Towards recovery highlighted the step-by-step process of rebuilding their life by developing a routine and engaging in activities. Followed by finding meaning and hope in their experience, accepting what had happened and moving forward.

\section{Conclusion}

There were some aspects that stood out to be particularly relevant to the unique experiences of men, which hinted toward ideas linked to masculinity. This included the shame the men felt once they realised that they were no longer able to do the things that they once could (socially and at work). As result they found that they had lost respect in the community, had lower self-esteem and felt either judged, ridiculed or excluded from society. Men tend to value their independence, autonomy and status. Thus, when they feel that they are not meeting these expectations they are likely to devalue themselves as well as feel devalued by others.

Due to men's difficulties in expressing emotions and showing vulnerability they may struggle to be dependent on others or seek support. From the studies it was clear that some men found it difficult to share their needs, they preferred to remain isolated or withdrew from others to protect themselves. However, once they were able to seek support, they found it to be valuable and felt more connected to others.

The rest of the findings confirmed the current literature regarding the experience of psychosis and the process of recovery. It was unclear whether these experiences were in fact unique to men. Comparing these findings with women's experiences would help to gain a better insight into gender differences. 


\section{References}

Addis, M. E., \& Mahalik, J. R. (2003). Men, masculinity, and the contexts of help seeking. American Psychologist, 58(1), 5-14.

Barajas, A., Ochoa, S., Obiols, J. E., \& Lalucat-Jo, L. (2015). Gender differences in individuals at high-risk of psychosis: a comprehensive literature review. The Scientific World Journal, 1, 1-13.

Lincoln, C. V., \& McGorry, P. (1995). Who cares? Pathways to psychiatric care for young people experiencing a first episode of psychosis. Psychiatric Services.

Malla, A. (2005). First-Episode Psychosis: Psychopathology, Quality of Life, and Functional Outcome. Schizophrenia Bulletin, 31(3), 650-671.

Penn, D. L., Waldheter, E. J., Perkins, D. O., Mueser, K. T., \& Lieberman, J. A. (2005). Psychosocial Treatment for First-Episode Psychosis: A Research Update. American Journal of Psychiatry, 162(12), 2220-2232.

Power, P. (2010). Suicide prevention in early psychosis. Promoting Recovery in Early Psychosis: A Practice Manual, 180-190. 


\section{Empirical Paper: Men's Experiences of Engaging in Psychological Therapy in a Forensic Mental Health Setting}

\section{Why did we do the study?}

- $95 \%$ of the prison population is male (Ministry of Justice, 2017).

- Men in prisons are six times more likely to take their life than men in the community (National Audit Office, 2017).

- Men don't like talking about their problems.

- Men find it hard to ask for support. (Addis \& Mahalik, 2003)

- Men in forensic mental health hospitals don't engage very well. They are likely to drop-out of therapy. (McMurran \& McCulloch, 2007)

- This means they stay in hospitals for longer. (Coid et al., 2001)

- Men view themselves as emotionally strong, tough, in control, independent and powerful. (Mahalik et al., 2003)

- This can make it hard for them to be vulnerable.

- This can impact on their engagement with therapy.

\section{What did we want to find out?}

- What are men's experiences of therapy?

- Does gender identity impact on the way men engage in therapy?

- What was helpful about therapy?

- What was unhelpful about therapy?

- What is the relationship with the psychologist like? 


\section{How did we do this?}

- The researcher went to the hospital to find out who wanted to participate.

- Nine men put their name forward and were interviewed.

- They were asked questions like, 'as a man, what ideas did you have about psychology?', 'what do you remember from your first psychology session?'.

- This allowed the men to share their stories and the researcher recorded this information.

\section{What did we find?}

- Everything the men talked about in their interviews was grouped together into three main themes:

\section{Theme 1: Shifting self}

This theme showed how the men responded differently to therapy at different times.

1. There were times when they were more guarded.

2. There were times when they wanted to appear strong but could also be aggressive.

3. There were times when they felt vulnerable and exposed.

4. Then there were times when they were able to open up and reveal more about themselves.

\section{Guarded}

Men did not want to talk about their problems so they stayed quiet and avoided therapy.

\section{Strong and aggressive}

Men thought it was important to be strong.

Sometimes they used aggression to show their strength to protect their reputation.

This got in the way of therapy.

\section{Vulnerable and exposed}

Men did not want to cry in therapy or appear weak.

\section{Open and revealing}

Some men found it easy to open up, for others it took time.

The men realised it was important if they wanted to get the help and move forward. 


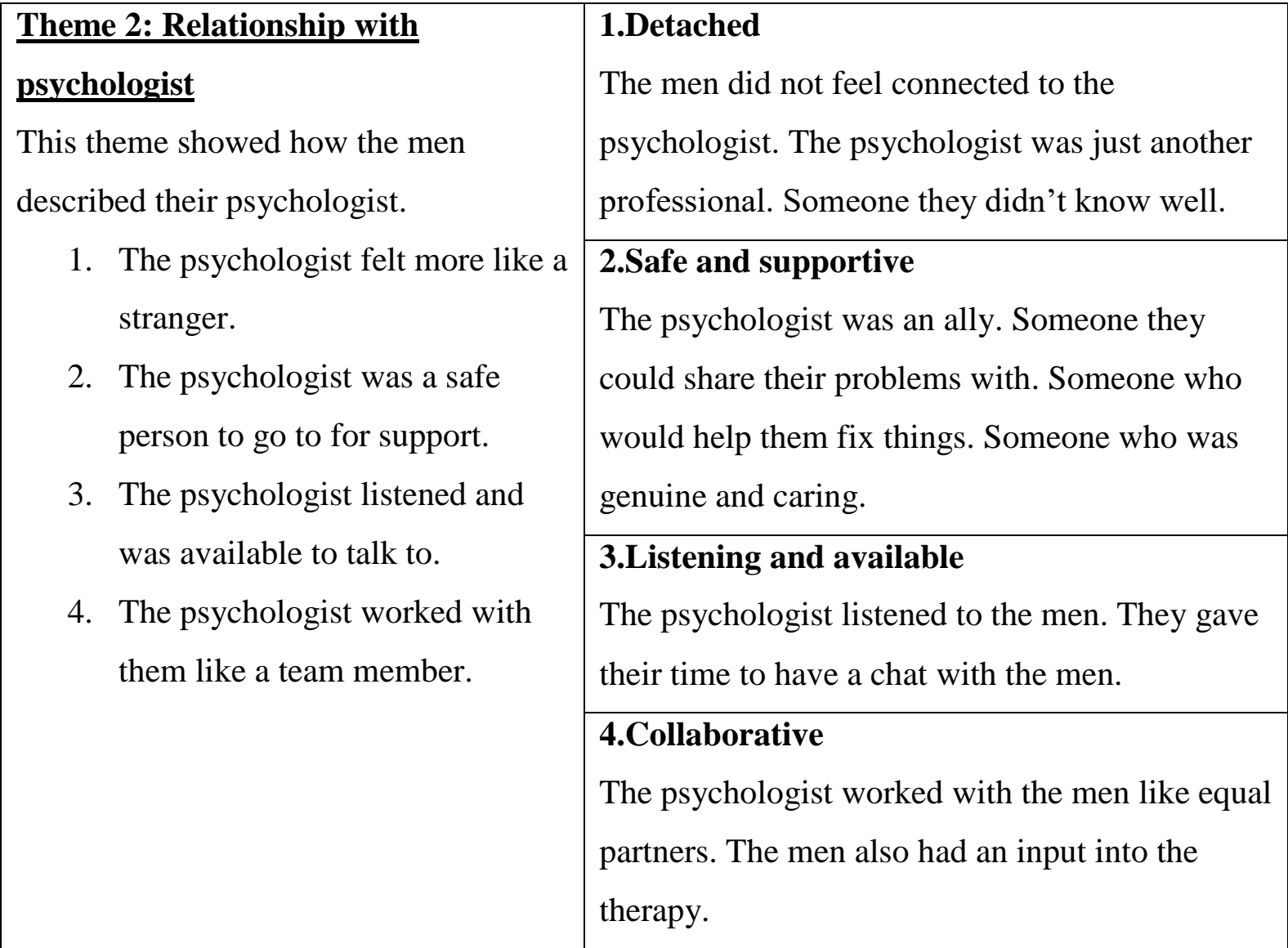

\section{Theme 3: Therapy Journey}

This theme showed the men's journey through therapy and how it changed.

1. Deciding whether to cooperate or whether to refuse and not engage.

2. Pacing of therapy was important.

3. Dealing with the past.

4. Learning about themselves.

5. The positive changes that came with therapy.

\section{Resist or co-operate}

It felt like therapy was pushed onto them and they had no choice. At first, they did not want to cooperate and did not want to engage. Not engaging meant the men stayed in hospital longer.

\section{Pacing}

The men were able to take it slow, rather than having to share everything all at once. The psychologist allowed them to take the therapy at their own pace without pressuring them.

\section{Dealing with the past}

The men had to face their past. This included their history, their destructive behaviour and their 


\begin{tabular}{|l|l|}
\hline & $\begin{array}{l}\text { offences. This brought many emotions such as fear, } \\
\text { shame, disappointment and grief. }\end{array}$ \\
\cline { 2 - 3 } & $\begin{array}{l}\text { 4.Self-understanding } \\
\text { They learnt knew skills to help them cope better. } \\
\text { They understood how their behaviour was linked to } \\
\text { their past and ways of thinking. They understood } \\
\text { why they had acted in the way they did. }\end{array}$ \\
\cline { 2 - 3 } & $\begin{array}{l}\text { 5.Positive Change } \\
\text { The men let go of negative emotions. They were able } \\
\text { to form better relationships. They were able to share } \\
\text { their feelings. They felt like stronger and better } \\
\text { people. They felt like they could tackle life. }\end{array}$ \\
\hline
\end{tabular}

\section{What does this tell us?}

- At the beginning of therapy men might be guarded about what they share due to feelings of mistrust and fear.

- Being in therapy can lead the men to feel like they can't cope. They may feel powerless and small.

- Shame can be a factor that gets in the way of men sharing their problems.

- Men can find it hard to express what is inside.

- Being vulnerable may be seen as a weakness, which makes it feel more threatening.

- When men build trust, feel confident and safe they can overcome these barriers.

- Men valued their relationship with their psychologist.

- The relationship was important to keeping the men engaged in therapy.

- The psychologist was viewed as genuine, helpful, non-judgemental and friendly.

- Men find it hard to talk about their past and offending behaviour.

- It is important for the men to feel that they have some choice. The psychologist can help with this.

- The men said that therapy had helped them to express their emotions, feel happier and more positive and feel stronger as a person.

- Therapy inspired the men to become "a better person". 


\section{References}

Addis, M. E., \& Mahalik, J. R. (2003). Men, masculinity, and the contexts of help seeking. American Psychologist, 58(1), 5-14.

Coid, J., Kahtan, N., Gault, S., Cook, A., \& Jarman, B. (2001). Medium secure forensic psychiatry services: comparison of seven English health regions. The British Journal of Psychiatry, 178(1), 55-61.

Mahalik, J. R., Good, G. E., \& Englar-Carlson, M. (2003). Masculinity scripts, presenting concerns, and help seeking: Implications for practice and training. Professional Psychology: Research and Practice, 34(2), 123-131.

McMurran, M., \& McCulloch, A. (2007). Why don't offenders complete treatment? Prisoners' reasons for non-completion of a cognitive skills programme. Psychology, Crime \& Law, 13(4), 345-354.

Ministry of Justice. (2017). Prison population figures: 2017. Retrieved from https://www.gov.uk/government/statistics/prison-population-figures-2017.

National Audit Office. (2017). Mental Health in Prisons. 
APPENDICES: LITERATURE REVIEW 
Appendix A: Quality Appraisal Checklist (NICE, 2012)

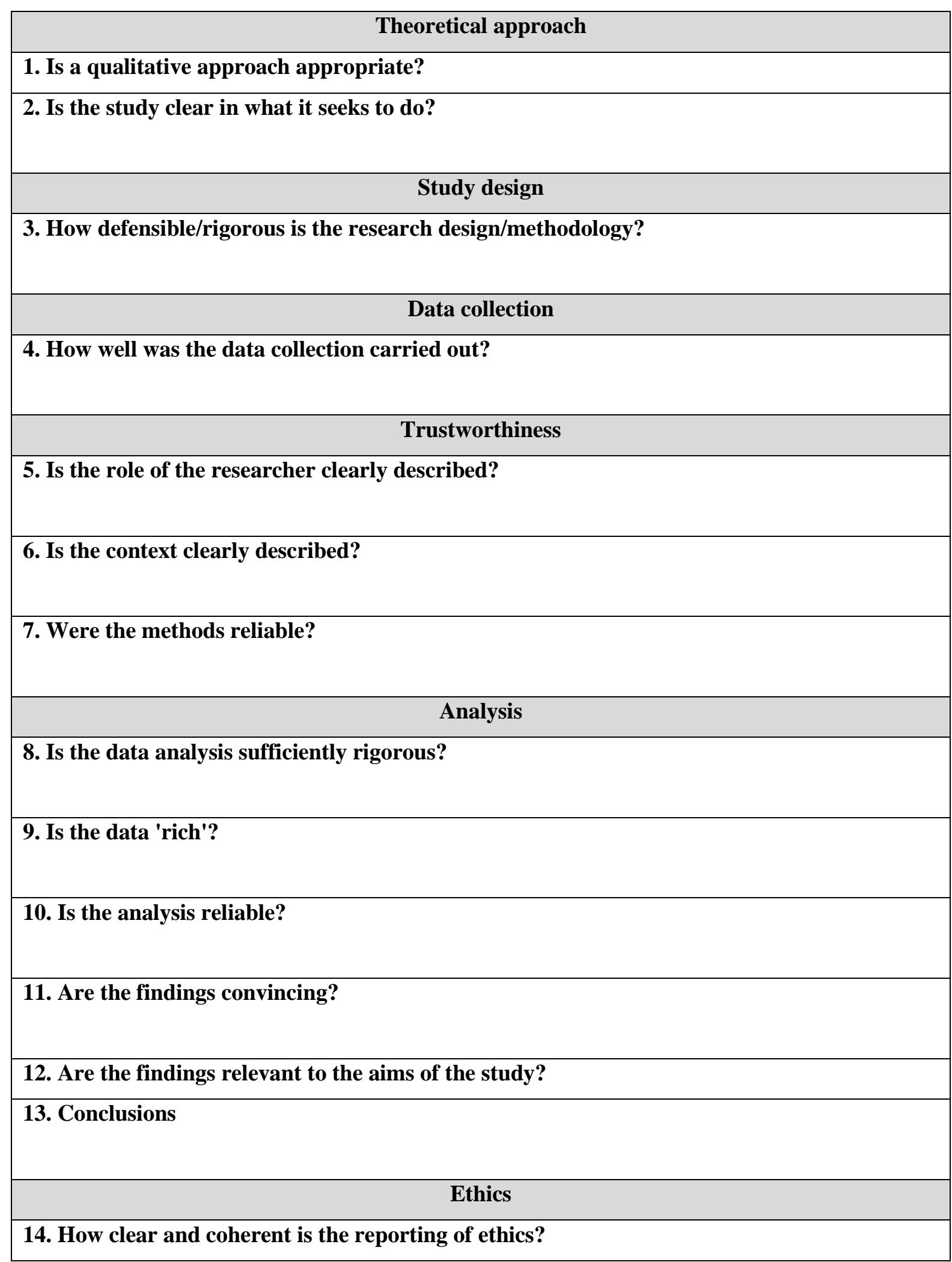




\section{Appendix B: Details of Quality Appraisal Check}

Table: Detailed account of quality check using NICE (2012) Quality Framework - Theoretical Approach, Study Design and Data Collection

\begin{tabular}{|c|c|c|c|c|}
\hline \multirow{2}{*}{ Author(s) } & \multicolumn{2}{|c|}{ Theoretical Approach } & \multirow{2}{*}{$\begin{array}{c}\text { Study Design } \\
\text { How defensible/rigorous is the } \\
\text { design/methodology? }\end{array}$} & \multirow{2}{*}{$\begin{array}{c}\text { Data Collection } \\
\text { How well was the data collection } \\
\text { carried out? }\end{array}$} \\
\hline & $\begin{array}{c}\text { Is a qualitative approach } \\
\text { appropriate? }\end{array}$ & $\begin{array}{l}\text { Is the study clear in what it } \\
\text { seeks to do? }\end{array}$ & & \\
\hline $\begin{array}{l}\text { Alshowkan, Curtis \& White, } \\
\qquad(2015) .\end{array}$ & \begin{tabular}{l}
\multicolumn{1}{c}{ Appropriate } \\
The study aimed to understand \\
participants perceptions of their \\
quality of life following \\
schizophrenia, to develop a holistic \\
understanding of how the illness had \\
impacted on their lives. With the \\
view of adding to the understanding \\
of quantitative studies.
\end{tabular} & \begin{tabular}{l}
\multicolumn{1}{c}{ Clear } \\
The research study proposes \\
an open question which seeks \\
to explore participants quality of \\
life.
\end{tabular} & $\begin{array}{l}\quad \checkmark \text { Defensible } \\
\text { The authors clearly state their } \\
\text { sampling and recruitment method. } \\
\text { They justify the use of a purposive } \\
\text { sample, restricting it to those who } \\
\text { were deemed well enough to } \\
\text { partake in an interview. The authors } \\
\text { were rigorous and transparent in } \\
\text { their methodological procedures. }\end{array}$ & \begin{tabular}{l}
\multicolumn{1}{c}{$\checkmark$ Appropriately } \\
The data collection method has \\
been clearly stated, including a \\
robust account of the interview \\
process, recording data, data \\
storage and transcription.
\end{tabular} \\
\hline $\begin{array}{l}\text { Gajwani, Larkin \& Jackson, } \\
\qquad(2017)\end{array}$ & $\begin{array}{l}\quad \checkmark \quad \text { Appropriate } \\
\text { The study aimed to explore the } \\
\text { personal meanings of suicide and } \\
\text { suicide in the context of psychosis. }\end{array}$ & \begin{tabular}{l}
\multicolumn{1}{c}{ Clear } \\
The authors clearly state their \\
aims and the experiential \\
phenomena they seek to \\
understand. The aims are \\
clearly linked to the research \\
literature.
\end{tabular} & $\begin{array}{l}\quad \checkmark \quad \text { Defensible } \\
\text { The authors clearly state their } \\
\text { sampling and recruitment method. } \\
\text { They specify the participant } \\
\text { population relevant to their research } \\
\text { question. The authors were rigorous } \\
\text { and transparent in their } \\
\text { methodological procedures. }\end{array}$ & \begin{tabular}{l}
\multicolumn{1}{c}{ Appropriately } \\
The data collection method has \\
been clearly stated, including an \\
account of the interview process and \\
data analysis.
\end{tabular} \\
\hline
\end{tabular}




\begin{tabular}{|c|c|c|c|c|}
\hline $\begin{array}{c}\text { Gee, Pearce, \& Jackson, } \\
\text { (2003). }\end{array}$ & $\begin{array}{l}\qquad \quad \text { Appropriate } \\
\text { The study aimed to explore the } \\
\text { subjective reflections individuals with } \\
\text { schizophrenia with the hope of } \\
\text { generating a better understanding of } \\
\text { their quality of life. }\end{array}$ & $\begin{array}{l}\quad \checkmark \text { Clear } \\
\text { The authors clearly state their } \\
\text { aims, the epistemology and } \\
\text { their ontological position. }\end{array}$ & $\begin{array}{l}\quad \checkmark \text { Defensible } \\
\text { The authors provided a robust, } \\
\text { detailed, comprehensive and } \\
\text { transparent account of their } \\
\text { methodological procedures, } \\
\text { including difficulties they } \\
\text { encountered and how these were } \\
\text { resolved. }\end{array}$ & $\begin{array}{l}\text { Appropriately } \\
\text { The data collection method has } \\
\text { been clearly stated, including an } \\
\text { account of the interview process and } \\
\text { data analysis. }\end{array}$ \\
\hline $\begin{array}{c}\text { Gould, DeSouza \& Rebeiro- } \\
\text { Gruhl (2005) }\end{array}$ & $\begin{array}{l}\text { V Appropriate } \\
\text { The study sought to understand the } \\
\text { experiences of individuals with } \\
\text { schizophrenia and so the use of } \\
\text { qualitative methodology was } \\
\text { appropriate. }\end{array}$ & $\begin{array}{l}\text { ? Unclear } \\
\text { The authors did not clearly } \\
\text { state the aims of the study. } \\
\text { They presented some } \\
\text { background of the relevant } \\
\text { literature regarding } \\
\text { occupational engagement and } \\
\text { schizophrenia, but they did not } \\
\text { explicitly or specifically state } \\
\text { the research question they } \\
\text { sought to answer. }\end{array}$ & $\begin{array}{l}\text { D Defensible } \\
\text { The authors provided a robust, } \\
\text { detailed, comprehensive and } \\
\text { transparent account of their } \\
\text { methodological procedures. }\end{array}$ & $\begin{array}{l}\text { Appropriately } \\
\text { The data collection method has } \\
\text { been clearly stated, including an } \\
\text { account of the interview process and } \\
\text { data analysis. }\end{array}$ \\
\hline Hirschfeld, et al., (2005). & $\begin{array}{l}\quad \checkmark \text { Appropriate } \\
\text { The study aimed to explore the } \\
\text { phenomenological experiences of } \\
\text { psychosis in men. }\end{array}$ & $\begin{array}{l}\quad \checkmark \quad \text { Clear } \\
\text { The authors clearly state their } \\
\text { aims and the experiential } \\
\text { phenomena they seek to } \\
\text { understand. They specify their } \\
\text { epistemology and put forward } \\
\text { their ontological position. }\end{array}$ & $\begin{array}{l}\quad \checkmark \quad \text { Defensible } \\
\text { The authors clearly state their } \\
\text { sampling and recruitment method. } \\
\text { They justify their use of a purposive } \\
\text { sample. The authors were rigorous } \\
\text { and transparent in their } \\
\text { methodological procedures. }\end{array}$ & $\begin{array}{l}\checkmark \text { Appropriately } \\
\text { The data collection method has } \\
\text { been clearly stated, including an } \\
\text { account of the data analysis. }\end{array}$ \\
\hline
\end{tabular}




\begin{tabular}{|c|c|c|c|c|}
\hline $\begin{array}{l}\text { Loganathan \& Murthy, } \\
\text { (2011). }\end{array}$ & $\begin{array}{l}\text { Appropriate } \\
\text { The study aimed to explore the } \\
\text { cultural beliefs and barriers to help- } \\
\text { seeking in men and women with } \\
\text { schizophrenia. The qualitative } \\
\text { method was used to analyse the } \\
\text { narrative to specific open-ended } \\
\text { questions on a semi-structured } \\
\text { interview questionnaire. }\end{array}$ & \begin{tabular}{l}
\multicolumn{1}{c}{ Clear } \\
The authors clearly state their \\
aims to contribute to a better \\
understanding of stigma in \\
relation to schizophrenia \\
amongst men and women \\
through the exploration of \\
beliefs, in order to gain an \\
insight into ways of tackling \\
these.
\end{tabular} & $\begin{array}{l}\qquad \quad \text { Defensible } \\
\text { The authors clearly state their } \\
\text { sampling and recruitment method. } \\
\text { They justify their use of a purposive } \\
\text { sample. The authors were rigorous } \\
\text { and transparent in their } \\
\text { methodological procedures. }\end{array}$ & $\begin{array}{l}\text { Appropriately } \\
\text { The data collection method has } \\
\text { been clearly stated, including an } \\
\text { account of the interview process and } \\
\text { data analysis. }\end{array}$ \\
\hline Liu, Ma, \& Zhao, (2012). & \begin{tabular}{l}
\multicolumn{1}{c}{ Appropriate } \\
The study aimed to explore Chinese \\
patients' experiences of \\
schizophrenia.
\end{tabular} & \begin{tabular}{l}
\multicolumn{1}{c}{ Clear } \\
The authors clearly state their \\
aims and provide a good \\
rationale for conducting the \\
study.
\end{tabular} & $\begin{array}{l}\text { The Defensible } \\
\text { The authors clearly state their } \\
\text { sampling and recruitment method. } \\
\text { They justify their use of a purposive } \\
\text { sample. The authors were rigorous } \\
\text { and transparent in their } \\
\text { methodological procedures. }\end{array}$ & $\begin{array}{l}\text { ' Appropriately } \\
\text { The data collection method has } \\
\text { been comprehensively stated in } \\
\text { detail. }\end{array}$ \\
\hline McCann \& Clark, (2004) & $\begin{array}{l}\text { Appropriate } \\
\text { The study aimed to explore } \\
\text { embodied experience of } \\
\text { schizophrenia and how individuals } \\
\text { find meaning in these experiences. }\end{array}$ & $\begin{array}{l}\quad \text { Clear } \\
\text { The authors clearly state their } \\
\text { aims and provide an adequate } \\
\text { rationale for conducting the } \\
\text { study. }\end{array}$ & $\begin{array}{l}\text { ? Not sure } \\
\text { The authors clearly state their study } \\
\text { design, sample and procedure; } \\
\text { however, these are brief and lacking } \\
\text { in necessary detail. }\end{array}$ & $\begin{array}{l}\text { ? Inadequately reported } \\
\text { The account is lacking in detail, } \\
\text { although the authors stated the } \\
\text { duration of interviews and where } \\
\text { they were conducted. }\end{array}$ \\
\hline Oliviera et al., (2013) & $\begin{array}{l}\text { Appropriate } \\
\text { The study aimed to explore the } \\
\text { meanings and implications of } \\
\text { schizophrenia to those admitted to } \\
\text { hospital. }\end{array}$ & $\begin{array}{l}\quad \text { Clear } \\
\text { The authors clearly state their } \\
\text { aims and provide a good } \\
\text { rationale for conducting the } \\
\text { study. }\end{array}$ & $\begin{array}{l}\text { The authors state their sampling } \\
\text { and recruitment method. Although } \\
\text { this could be enhanced with further } \\
\text { detail as to why this particular } \\
\text { sample was chosen and the } \\
\text { methodological procedure } \\
\text { employed. }\end{array}$ & $\begin{array}{l}\quad \text { ? Inadequately reported } \\
\text { The data collection method was only } \\
\text { briefly alluded to. }\end{array}$ \\
\hline
\end{tabular}




\begin{tabular}{|c|c|c|c|c|}
\hline $\begin{array}{l}\text { Roe, Chopra \& Rudnick, } \\
\qquad(2004) .\end{array}$ & $\begin{array}{l}\qquad \checkmark \quad \text { Appropriate } \\
\text { The study aimed to explore } \\
\text { individuals' coping processes over } \\
\text { the course of illness using a } \\
\text { qualitative method. }\end{array}$ & $\begin{array}{l}\quad \checkmark \quad \text { Clear } \\
\text { The authors clearly state their } \\
\text { aims and provide an adequate } \\
\text { rationale for conducting the } \\
\text { study. }\end{array}$ & \begin{tabular}{l}
\multicolumn{1}{c}{ Defensible } \\
The authors provided a robust, \\
comprehensive and transparent \\
account of their methodological \\
procedures,
\end{tabular} & \begin{tabular}{l}
\multicolumn{1}{c}{$\checkmark$ Appropriately } \\
The data collection method has \\
been clearly stated, including an \\
account of the data analysis.
\end{tabular} \\
\hline Saneesha et al. (2009) & $\begin{array}{l}\quad \checkmark \quad \text { Appropriate } \\
\text { The study aimed to explore } \\
\text { individuals' views of themselves in } \\
\text { light of their mental illness. }\end{array}$ & $\begin{array}{l}\quad \checkmark \quad \text { Clear } \\
\text { The authors clearly state their } \\
\text { aims and provide an adequate } \\
\text { rationale for conducting the } \\
\text { study. }\end{array}$ & \begin{tabular}{l}
\multicolumn{1}{c}{ Defensible } \\
The authors provided a \\
comprehensive and transparent \\
account of their methodological \\
procedures,
\end{tabular} & \begin{tabular}{l}
\multicolumn{1}{c}{ Appropriately } \\
The data collection method has \\
been clearly stated, including an \\
account of the data analysis.
\end{tabular} \\
\hline
\end{tabular}

Table: Detailed account of quality check using NICE (2012) Quality Framework - Trustworthiness and Ethics

\begin{tabular}{|c|c|c|c|c|}
\hline \multirow{2}{*}{ Author(s) } & \multicolumn{3}{|c|}{ Trustworthiness } & \multirow{2}{*}{$\begin{array}{l}\text { Ethics } \\
\text { How clear and coherent is the } \\
\text { reporting of the ethics? }\end{array}$} \\
\hline & $\begin{array}{l}\text { Is the role of the researcher clearly } \\
\text { described? }\end{array}$ & Is the context clearly described? & Were the methods reliable? & \\
\hline $\begin{array}{l}\text { Alshowkan, Curtis } \\
\text { \& White, (2015). }\end{array}$ & $\begin{array}{l}\text { ? Unclear } \\
\text { The researcher did not provide any } \\
\text { information regarding their role or } \\
\text { comment on issues of reflexivity. They } \\
\text { offered an account of how the interview } \\
\text { was conducted and the types of } \\
\text { questions put forward. There was no } \\
\text { description of how the aims of the study } \\
\text { were explained to participants. }\end{array}$ & $\begin{array}{l}\text { ? Unclear } \\
\text { Although the researcher offered a } \\
\text { description of the participants } \\
\text { characteristics and where they were } \\
\text { recruited from, no further details } \\
\text { regarding participants was included to } \\
\text { offer an insight into the lives of the } \\
\text { participants. This may be due to the } \\
\text { large sample size. }\end{array}$ & $\begin{array}{l}\text { ? Not sure } \\
\text { The authors did not provide } \\
\text { details of any reliability checks. }\end{array}$ & \begin{tabular}{l}
\multicolumn{1}{c}{ Appropriate } \\
Ethical considerations have been \\
sufficiently noted by the authors, \\
although aspects of these could have \\
been expanded on. There is a clear \\
description of ethical approval from an \\
Ethics Committee.
\end{tabular} \\
\hline $\begin{array}{l}\text { Gajwani, Larkin \& } \\
\text { Jackson, (2017) }\end{array}$ & $\begin{array}{l}\text { ? Unclear } \\
\text { The researcher did not comment on } \\
\text { issues of reflexivity. They did consider } \\
\text { the relationship between the }\end{array}$ & $\begin{array}{l}\quad \checkmark \quad \text { Clear } \\
\text { The authors provided an inclusive } \\
\text { summary of the participants which } \\
\text { offers an insight into their current }\end{array}$ & \begin{tabular}{l}
\multicolumn{1}{c}{ Reliable } \\
The researcher has adequately \\
described the degree of \\
involvement of other researchers
\end{tabular} & $\begin{array}{l}\text { ? Not sure } \\
\text { Although the researcher has stated } \\
\text { that the research was ethically } \\
\text { approved, they do not explicitly state }\end{array}$ \\
\hline
\end{tabular}




\begin{tabular}{|c|c|c|c|c|}
\hline & $\begin{array}{l}\text { phenomena under study and the } \\
\text { chosen participants. However, they did } \\
\text { not elaborate on how the aims of the } \\
\text { study were explained to participants. }\end{array}$ & $\begin{array}{l}\text { context, including the care they are } \\
\text { receiving, the state of their mental } \\
\text { illness and history of suicide. }\end{array}$ & $\begin{array}{l}\text { within the team, during the } \\
\text { research development and } \\
\text { analysis stage. }\end{array}$ & $\begin{array}{l}\text { the ethical considerations relevant to } \\
\text { the research. }\end{array}$ \\
\hline $\begin{array}{c}\text { Gee, Pearce, \& } \\
\text { Jackson, (2003). }\end{array}$ & $\begin{array}{l}\quad \checkmark \quad \text { Clear } \\
\text { The researcher offered some } \\
\text { background regarding their profession } \\
\text { and their role within the service where } \\
\text { participants were recruited, including } \\
\text { their relationship with participants. A } \\
\text { reflexive account would have further } \\
\text { strengthened this. }\end{array}$ & \begin{tabular}{l}
\multicolumn{1}{c}{ Clear } \\
The authors included a table with the \\
participant's characteristics and a \\
summary of the inclusion and \\
exclusion criteria. Further elaboration \\
of the service context would have \\
added to developing a picture of the \\
participants' world.
\end{tabular} & $\begin{array}{l}\quad \checkmark \quad \text { Reliable } \\
\text { The researcher maintained a } \\
\text { high degree of transparency in } \\
\text { their reporting and described the } \\
\text { measures they used to perform } \\
\text { validity checks. }\end{array}$ & $\begin{array}{l}\text { V Appropriate } \\
\text { Various ethical considerations have } \\
\text { been adequately noted by the authors. } \\
\text { There is a clear description of ethical } \\
\text { approval from an Ethics Committee. }\end{array}$ \\
\hline $\begin{array}{l}\text { Gould, DeSouza \& } \\
\text { Rebeiro-Gruhl } \\
\text { (2005) }\end{array}$ & $\begin{array}{l}\quad \checkmark \quad \text { Clear } \\
\text { The authors mentioned their } \\
\text { professional background and how they } \\
\text { were supported during the research } \\
\text { project. The use of personal notes and } \\
\text { personal journals would have increased } \\
\text { reflexivity. }\end{array}$ & $\begin{array}{l}\text { ? Unclear } \\
\text { Although the researcher offered a } \\
\text { description of the participants } \\
\text { characteristics and where they were } \\
\text { recruited from, further elaboration of } \\
\text { the context would have added to this. }\end{array}$ & \begin{tabular}{l}
\multicolumn{1}{c}{ Reliable } \\
The authors were transparent in \\
their reporting and utilised \\
multiple perspectives and \\
sources of data to ensure \\
credibility.
\end{tabular} & $\begin{array}{l}\text { ? Not sure } \\
\text { Although the researcher has stated } \\
\text { that the research was ethically } \\
\text { approved, they do not explicitly state } \\
\text { the ethical considerations relevant to } \\
\text { the research. }\end{array}$ \\
\hline $\begin{array}{l}\text { Hirschfeld, et al., } \\
\text { (2005). }\end{array}$ & $\begin{array}{l}\quad \checkmark \quad \text { Clear } \\
\text { The researcher offered some } \\
\text { background regarding their profession } \\
\text { and the personal context in which they } \\
\text { were conducting the research. }\end{array}$ & $\begin{array}{l}\quad \checkmark \quad \text { Clear } \\
\text { The authors included a table with the } \\
\text { participant's characteristics and a } \\
\text { summary of their personal contexts } \\
\text { (i.e. how much treatment they } \\
\text { received, current state of mental } \\
\text { health etc.). }\end{array}$ & \begin{tabular}{l}
\multicolumn{1}{c}{ Reliable } \\
The researcher performed \\
validity checks by having two \\
colleagues check the initial \\
codes from two transcripts. The \\
author also utilised various \\
sources to ensure credibility.
\end{tabular} & $\begin{array}{l}\quad \text { ? Not reported } \\
\text { Details regarding ethical approval } \\
\text { were not stated. }\end{array}$ \\
\hline $\begin{array}{l}\text { Loganathan \& } \\
\text { Murthy, (2011). }\end{array}$ & $\begin{array}{l}\text { ? Not described } \\
\text { The role of the researcher or their } \\
\text { personal context was not described. }\end{array}$ & $\begin{array}{l}\text { ? Unclear } \\
\text { The authors reported where they had } \\
\text { recruited from (including distinguishing } \\
\text { between rural and urban areas), the } \\
\text { gender and sample size. No further } \\
\text { details were provided beyond this. }\end{array}$ & $\begin{array}{l}\quad \checkmark \quad \text { Reliable } \\
\text { The researcher was transparent } \\
\text { in their reporting and described } \\
\text { the measures they used to } \\
\text { ensure reliability. }\end{array}$ & $\begin{array}{l}\quad \checkmark \quad \text { Appropriate } \\
\text { Brief reference was made to ethical } \\
\text { considerations by the authors, } \\
\text { however this could have been } \\
\text { expanded upon. There is recognition } \\
\text { of ethical approval. }\end{array}$ \\
\hline
\end{tabular}




\begin{tabular}{|c|c|c|c|c|}
\hline $\begin{array}{l}\text { Liu, Ma, \& Zhao, } \\
\text { (2012). }\end{array}$ & $\begin{array}{l}\text { The authors mentioned their } \\
\text { professional background and how they } \\
\text { were supported during the research } \\
\text { project. They reported that they had } \\
\text { reflected on their assumptions and how } \\
\text { this could impact on analysis. }\end{array}$ & $\begin{array}{l}\text { The authors included a table with the } \\
\text { participant's characteristics and a } \\
\text { summary of the inclusion and } \\
\text { exclusion criteria. Further elaboration } \\
\text { of the cultural context would have } \\
\text { added to this. }\end{array}$ & $\begin{array}{l}\text { The researcher was transparent } \\
\text { in their reporting and described } \\
\text { the measures they used to } \\
\text { ensure reliability. Two } \\
\text { researchers were involved in } \\
\text { conducting the interview, } \\
\text { whereby they regularly switched } \\
\text { roles (one as main interviewer, } \\
\text { the other as observer/note- } \\
\text { taker). This would have helped } \\
\text { minimise bias. Both transcribed } \\
\text { the data as well to ensure } \\
\text { accuracy. }\end{array}$ & $\begin{array}{l}\text { Issues of informed consent and mental } \\
\text { capacity were identified in the } \\
\text { recruitment stage and explicit } \\
\text { reference was made to ethical } \\
\text { approval. }\end{array}$ \\
\hline $\begin{array}{c}\text { McCann \& Clark, } \\
(2004)\end{array}$ & $\begin{array}{l}\quad \text { ? Unclear } \\
\text { The authors did not provide a great } \\
\text { amount of detail regarding their } \\
\text { background or relationship with the } \\
\text { participants. However, they noted the } \\
\text { use of journals to ensure reflexivity. }\end{array}$ & $\begin{array}{l}\quad \text { ? Unclear } \\
\text { There was no information provided } \\
\text { regarding the participants' individual } \\
\text { backgrounds. }\end{array}$ & \begin{tabular}{l}
\multicolumn{1}{c}{ ? Not sure } \\
The method appeared to \\
investigate what it claimed to but \\
was lacking in necessary detail.
\end{tabular} & $\begin{array}{l}\text { ? Not reported } \\
\text { Details regarding ethical approval } \\
\text { were not stated. }\end{array}$ \\
\hline $\begin{array}{l}\text { Oliviera et al., } \\
\text { (2013) }\end{array}$ & $\begin{array}{l}\text { ? Not described } \\
\text { The researcher did not provide an } \\
\text { account of their role in the research } \\
\text { and its potential impact on the findings. }\end{array}$ & $\begin{array}{l}\quad \checkmark \text { Clear } \\
\text { The author provided a comprehensive } \\
\text { account of the participants involved in } \\
\text { the research. }\end{array}$ & $\begin{array}{l}\text { ? Not sure } \\
\text { There was not sufficient detail to } \\
\text { confirm the reliability of the } \\
\text { methodology. }\end{array}$ & $\begin{array}{l}\quad \checkmark \quad \text { Appropriate } \\
\text { Issues of informed consent and mental } \\
\text { capacity were identified in the } \\
\text { recruitment stage. It was noted that } \\
\text { aspects of these could have been } \\
\text { expanded on. Explicit reference was } \\
\text { made to ethical approval. }\end{array}$ \\
\hline $\begin{array}{l}\text { Roe, Chopra \& } \\
\text { Rudnick, (2004). }\end{array}$ & $\begin{array}{l}\text { ? Not described } \\
\text { The researcher did not provide an } \\
\text { account of their role in the research } \\
\text { and its potential impact on the findings. }\end{array}$ & $\begin{array}{l}\quad \checkmark \text { Clear } \\
\text { The author provided a comprehensive } \\
\text { account of the participants involved in } \\
\text { the research. }\end{array}$ & $\begin{array}{l}\text { Theliable } \\
\text { The researcher was transparent } \\
\text { in their reporting of } \\
\text { methodological procedures, } \\
\text { which were relevant to the study } \\
\text { aims and systematic. This could }\end{array}$ & $\begin{array}{l}\quad \text { ? Not reported } \\
\text { Details regarding ethical approval } \\
\text { were not stated. }\end{array}$ \\
\hline
\end{tabular}




\begin{tabular}{|c|c|c|c|c|}
\hline & & & $\begin{array}{l}\text { have been further enhanced by } \\
\text { employing validity checks over } \\
\text { the course of the study. }\end{array}$ & \\
\hline $\begin{array}{l}\text { Saneesha et al. } \\
\qquad(2009)\end{array}$ & $\begin{array}{l}\quad \checkmark \quad \text { Clear } \\
\text { The authors reported that they } \\
\text { maintained a reflexive journal, an } \\
\text { analysis of the interview transcriptions, } \\
\text { and an analysis audit trail to ensure } \\
\text { dependability and confirmability. }\end{array}$ & $\begin{array}{l}\quad \checkmark \quad \text { Clear } \\
\text { The authors included details of the } \\
\text { participant's characteristics and a } \\
\text { summary of the inclusion and } \\
\text { exclusion criteria. }\end{array}$ & $\begin{array}{l}\text { The researcher was transparent } \\
\text { in their reporting and described } \\
\text { the measures they used to } \\
\text { ensure reliability. They used a } \\
\text { variety of systematised methods } \\
\text { to do this. }\end{array}$ & $\begin{array}{l}\quad \checkmark \quad \text { Appropriate } \\
\text { Issues of informed consent and mental } \\
\text { capacity were identified in the } \\
\text { recruitment stage and explicit } \\
\text { reference was made to ethical } \\
\text { approval. }\end{array}$ \\
\hline
\end{tabular}

Table: Detailed account of quality check using NICE (2012) Quality Framework - Analysis

\begin{tabular}{|c|c|c|c|c|c|c|}
\hline \multirow[b]{2}{*}{ Author(s) } & \multicolumn{6}{|c|}{ Analysis } \\
\hline & $\begin{array}{l}\text { Is the data analysis } \\
\text { sufficiently rigorous? }\end{array}$ & Is the data rich? & Is the analysis reliable? & $\begin{array}{l}\text { Are the findings } \\
\text { convincing? }\end{array}$ & $\begin{array}{l}\text { Are the findings relevant } \\
\text { to the aims of the study? }\end{array}$ & Conclusions \\
\hline $\begin{array}{c}\text { Alshowkan, Curtis \& } \\
\text { White, (2015). }\end{array}$ & \begin{tabular}{l}
\multicolumn{1}{c}{ Rigorous } \\
The authors present a \\
transparent account of the \\
analysis process. The \\
identified their analysis \\
method and the systematic \\
method used to derive \\
themes. They present a \\
table with a summary of the \\
number of participants that \\
contributed to each theme.
\end{tabular} & \begin{tabular}{l}
\multicolumn{1}{c}{ Rich } \\
The authors have made \\
attempts to best describe \\
the majority of data from a \\
large sample size. They \\
provide sufficient context \\
to the raw data that has \\
been presented to offer a \\
comprehensive account of \\
participants perspectives.
\end{tabular} & $\begin{array}{l}\quad \text { ? Not reported } \\
\text { There were no details } \\
\text { regarding how the } \\
\text { reliability of the themes } \\
\text { derived from the data } \\
\text { were checked. }\end{array}$ & \begin{tabular}{l}
\multicolumn{1}{c}{ Convincing } \\
The findings of the study \\
are well-organised and \\
coherently stated. The \\
extracts inform (and \\
appeared to be relevant \\
to) the themes they \\
represent.
\end{tabular} & \begin{tabular}{l}
\multicolumn{1}{c}{ Relevant } \\
The findings are clearly \\
linked to the aims of the \\
study as they provide \\
evidence for the \\
facilitators and barriers \\
to quality of life in those \\
suffering from \\
schizophrenia.
\end{tabular} & \begin{tabular}{l}
\multicolumn{1}{c}{ Adequate } \\
The conclusions \\
drawn are grounded \\
in the results and \\
linked to relevant \\
literature.
\end{tabular} \\
\hline $\begin{array}{l}\text { Gajwani, Larkin \& } \\
\text { Jackson, (2017) }\end{array}$ & \begin{tabular}{l}
\multicolumn{1}{c}{ Rigorous } \\
The authors present a \\
transparent account of the \\
analysis process. They \\
identified their analysis
\end{tabular} & $\begin{array}{l}\quad \checkmark \text { Rich } \\
\text { The author has included } \\
\text { numerous extracts to } \\
\text { present a 'rich' and fuller }\end{array}$ & \begin{tabular}{l}
\multicolumn{1}{c}{ Reliable } \\
The researcher worked \\
closely with other \\
authors to ensure
\end{tabular} & $\begin{array}{l}\quad \checkmark \quad \text { Convincing } \\
\text { The findings of the study } \\
\text { are well-organised and } \\
\text { coherently stated. The } \\
\text { sub-theme of 'shared }\end{array}$ & \begin{tabular}{l}
\multicolumn{1}{c}{ Relevant } \\
The findings are clearly \\
linked to the aims of the \\
study and have been \\
linked to the relevant
\end{tabular} & \begin{tabular}{l}
\multicolumn{1}{c}{ Adequate } \\
The insights form \\
the results have \\
been used to inform \\
what is already
\end{tabular} \\
\hline
\end{tabular}




\begin{tabular}{|c|c|c|c|c|c|c|}
\hline & $\begin{array}{l}\text { method and the systematic } \\
\text { method used to derive } \\
\text { themes. }\end{array}$ & $\begin{array}{l}\text { account of the participants } \\
\text { experiences. }\end{array}$ & $\begin{array}{l}\text { reliability and minimise } \\
\text { bias. }\end{array}$ & $\begin{array}{l}\text { meaning and burden' } \\
\text { could have been } \\
\text { elaborated to increase } \\
\text { clarity. }\end{array}$ & $\begin{array}{l}\text { literature and } \\
\text { psychological theory. }\end{array}$ & $\begin{array}{l}\text { known in the } \\
\text { literature regarding } \\
\text { suicide. The } \\
\text { conclusions drawn } \\
\text { are plausible. }\end{array}$ \\
\hline $\begin{array}{l}\text { Gee, Pearce, \& } \\
\text { Jackson, (2003). }\end{array}$ & $\begin{array}{l}\quad \checkmark \text { Rigorous } \\
\text { The authors present a } \\
\text { transparent account of the } \\
\text { analysis process. They } \\
\text { identified their analysis } \\
\text { method and the systematic } \\
\text { method used to derive } \\
\text { themes. }\end{array}$ & $\begin{array}{l}\text { Rich } \\
\text { The author has included } \\
\text { numerous extracts to } \\
\text { present a 'rich' and fuller } \\
\text { account of the participants } \\
\text { experiences. }\end{array}$ & \begin{tabular}{l}
\multicolumn{1}{c}{ Reliable } \\
The researcher reported \\
that transcripts were \\
blind rated by a second \\
psychologist.
\end{tabular} & \begin{tabular}{l}
\multicolumn{1}{c}{ Convincing } \\
The findings of the study \\
are well-organised and \\
coherently stated. \\
elaborated to increase \\
clarity. However, the \\
author did state in the \\
discussion that some \\
themes were endorsed \\
to a greater degree than \\
others, with 5 themes \\
being most salient.
\end{tabular} & \begin{tabular}{l}
\multicolumn{1}{c}{ Relevant } \\
The findings are clearly \\
linked to the aims of the \\
study. A proposal was \\
made about how these \\
findings could contribute \\
to the development of a \\
quality of life measure \\
specific to this \\
population.
\end{tabular} & \begin{tabular}{l}
\multicolumn{1}{c}{ ? Not sure } \\
The conclusions are \\
tentative and have \\
been critically \\
appraised. The \\
author makes \\
suggestion for future \\
advancement of the \\
research, though \\
additional links to \\
the relevant \\
literature and \\
interpretation of \\
themes would have \\
been beneficial.
\end{tabular} \\
\hline $\begin{array}{l}\text { Gould, DeSouza \& } \\
\text { Rebeiro-Gruhl } \\
\text { (2005) }\end{array}$ & $\begin{array}{l}\text { Rigorous } \\
\text { The authors present a } \\
\text { transparent account of the } \\
\text { analysis process. They } \\
\text { identified their analysis } \\
\text { method and the systematic } \\
\text { method used to derive } \\
\text { themes. }\end{array}$ & $\begin{array}{l}\text { Thich } \\
\text { The author has included } \\
\text { numerous extracts to } \\
\text { present a 'rich' and fuller } \\
\text { account of the participants } \\
\text { experiences. }\end{array}$ & \begin{tabular}{l}
\multicolumn{1}{c}{ Reliable } \\
They reported that \\
transcripts were \\
independently coded by \\
both authors, the \\
emerging themes were \\
critically evaluated to \\
ensure that all \\
participants experiences \\
were captured.
\end{tabular} & $\begin{array}{l}\text { V Convincing } \\
\text { The narrative is } \\
\text { coherently written and is } \\
\text { in line with the extracts } \\
\text { presented. It offers a full } \\
\text { and detailed temporal } \\
\text { account of the } \\
\text { participants experiences } \\
\text { of schizophrenia. }\end{array}$ & $\begin{array}{l}\quad \text { ? Not sure } \\
\text { It was unclear from the } \\
\text { beginning whether the } \\
\text { authors wanted to } \\
\text { explore the participants } \\
\text { experiences of their } \\
\text { illness or their } \\
\text { experiences of } \\
\text { engagement with } \\
\text { occupational activities. } \\
\text { However, the findings } \\
\text { appeared to offer the }\end{array}$ & $\begin{array}{l}\text { The findings } \\
\text { regarding the } \\
\text { participants } \\
\text { experiences of } \\
\text { mental illness have } \\
\text { been used to } \\
\text { understand their } \\
\text { engagement in the } \\
\text { discussion. These } \\
\text { were plausible and }\end{array}$ \\
\hline
\end{tabular}




\begin{tabular}{|c|c|c|c|c|c|c|}
\hline & & & & & $\begin{array}{l}\text { relevant insight sought } \\
\text { by the researchers. }\end{array}$ & $\begin{array}{l}\text { grounded in } \\
\text { research evidence. }\end{array}$ \\
\hline $\begin{array}{l}\text { Hirschfeld, et al., } \\
\text { (2005). }\end{array}$ & $\begin{array}{l}\qquad \text { Rigorous } \\
\text { The authors present a } \\
\text { transparent and systematic } \\
\text { account of the analysis } \\
\text { process. }\end{array}$ & $\begin{array}{l}\text { Rich } \\
\text { The author has included } \\
\text { numerous extracts to } \\
\text { present a 'rich' and fuller } \\
\text { account of the participants } \\
\text { experiences. }\end{array}$ & \begin{tabular}{l}
\multicolumn{1}{c}{ Reliable } \\
The researcher worked \\
with other colleagues to \\
ensure reliability and \\
minimise bias.
\end{tabular} & $\begin{array}{l}\quad \text { Convincing } \\
\text { The findings of the study } \\
\text { are well-organised and } \\
\text { coherently stated. The } \\
\text { extracts were interpreted } \\
\text { in-depth to offer a more } \\
\text { comprehensive insight } \\
\text { into the individual's } \\
\text { experience. }\end{array}$ & \begin{tabular}{l}
\multicolumn{1}{c}{ Relevant } \\
The findings are clearly \\
linked to the aims of the \\
study and have been \\
linked to the relevant \\
literature and \\
psychological theory.
\end{tabular} & $\begin{array}{l}\text { Adequate } \\
\text { The insights form } \\
\text { the results have } \\
\text { been interpreted to } \\
\text { draw final } \\
\text { conclusions that are } \\
\text { plausible and } \\
\text { develop the } \\
\text { phenomenological } \\
\text { understanding of } \\
\text { young men's } \\
\text { experiences of } \\
\text { psychosis. }\end{array}$ \\
\hline $\begin{array}{l}\text { Loganathan \& } \\
\text { Murthy, (2011). }\end{array}$ & $\begin{array}{l}\quad \text { ? Not sure } \\
\text { The authors present a } \\
\text { transparent account. They } \\
\text { utilised thematic analysis } \\
\text { which appeared to be } \\
\text { systematic, however this } \\
\text { could have been elaborated } \\
\text { on. }\end{array}$ & $\begin{array}{l}\text { Rich } \\
\text { The authors present the } \\
\text { extracts of data and } \\
\text { provide good cultural } \\
\text { context in relation to the } \\
\text { wider sample. However, } \\
\text { the depth of the analysis is } \\
\text { sparse. Specific themes } \\
\text { were found to be more } \\
\text { relevant to a specific } \\
\text { gender which has been } \\
\text { clearly demonstrated. }\end{array}$ & \begin{tabular}{l}
\multicolumn{1}{c}{ Reliable } \\
They reported that \\
transcripts were coded \\
by both authors. \\
Findings were \\
triangulated by \\
comparing the narrative \\
themes to the findings \\
from the questionnaire, \\
to see if congruent \\
patterns emerged to \\
strengthen \\
interpretations.
\end{tabular} & $\begin{array}{l}\text { Convincing } \\
\text { The findings of the study } \\
\text { are well-organised and } \\
\text { coherently stated. The } \\
\text { extracts inform (and } \\
\text { appeared to be relevant } \\
\text { to) the themes they } \\
\text { represent. The themes } \\
\text { were 'descriptive' in } \\
\text { nature. }\end{array}$ & \begin{tabular}{l}
\multicolumn{1}{c}{ Relevant } \\
The findings are clearly \\
linked to the aims of the \\
study.
\end{tabular} & $\begin{array}{l}\quad \checkmark \text { Adequate } \\
\text { A plausible model } \\
\text { was presented } \\
\text { based on the } \\
\text { findings from the } \\
\text { interviews to } \\
\text { develop an insight } \\
\text { into the } \\
\text { consequences of } \\
\text { stigma in men and } \\
\text { women. This was } \\
\text { supported by } \\
\text { research evidence. }\end{array}$ \\
\hline $\begin{array}{l}\text { Liu, Ma, \& Zhao, } \\
\text { (2012). }\end{array}$ & \begin{tabular}{l}
\multicolumn{1}{c}{ Rigorous } \\
The authors present a \\
transparent and systematic \\
account of the analysis \\
process, with great detail.
\end{tabular} & $\begin{array}{l}\text { Rich } \\
\text { The author has included } \\
\text { numerous extracts to } \\
\text { present a 'rich' and fuller }\end{array}$ & $\begin{array}{l}\quad \checkmark \quad \text { Reliable } \\
\text { Two researchers coded } \\
\text { the data independently } \\
\text { which was then cross- } \\
\text { checked. Additional }\end{array}$ & $\begin{array}{l}\text { Convincing } \\
\text { The findings of the study } \\
\text { are well-organised and } \\
\text { coherently stated. The } \\
\text { extracts were }\end{array}$ & $\begin{array}{l}\text { r Relevant } \\
\text { The findings are clearly } \\
\text { linked to the aims of the } \\
\text { study. }\end{array}$ & $\begin{array}{l}\text { Adequate } \\
\text { The conclusions } \\
\text { have been clearly } \\
\text { linked to the findings } \\
\text { and have been }\end{array}$ \\
\hline
\end{tabular}




\begin{tabular}{|c|c|c|c|c|c|c|}
\hline & & $\begin{array}{l}\text { account of the participants } \\
\text { experiences. }\end{array}$ & $\begin{array}{l}\text { consultation with } \\
\text { psychologists } \\
\text { independent of the } \\
\text { research was sought to } \\
\text { minimise bias. }\end{array}$ & $\begin{array}{l}\text { contextualised and } \\
\text { sufficiently interpreted. }\end{array}$ & & $\begin{array}{l}\text { explained in light of } \\
\text { the current research } \\
\text { evidence. }\end{array}$ \\
\hline $\begin{array}{c}\text { McCann \& Clark, } \\
\text { (2004) }\end{array}$ & $\begin{array}{l}\text { ? Not sure } \\
\text { The author reported that the } \\
\text { transcripts were read and re- } \\
\text { read, however there was no } \\
\text { systematic approach to } \\
\text { analysis reported. }\end{array}$ & $\begin{array}{l}\text { Rich } \\
\text { The author has included } \\
\text { numerous extracts to } \\
\text { present a 'rich' and fuller } \\
\text { account of the participants } \\
\text { experiences. }\end{array}$ & $\begin{array}{l}\quad \text { ? Not sure } \\
\text { The author reported that } \\
\text { the analysis was } \\
\text { confirmed by a } \\
\text { secondary individual. No } \\
\text { details were provided } \\
\text { about the process by } \\
\text { which this was achieved. }\end{array}$ & $\begin{array}{l}\text { Convincing } \\
\text { The findings of the study } \\
\text { are adequately } \\
\text { organised and } \\
\text { coherently stated. The } \\
\text { extracts inform the } \\
\text { themes they represent. } \\
\text { Though there is some } \\
\text { question regarding the } \\
\text { impact of the } \\
\text { researcher's perspective } \\
\text { on the interpretation. }\end{array}$ & \begin{tabular}{l}
\multicolumn{1}{c}{ Relevant } \\
The findings are clearly \\
linked to the aims of the \\
study.
\end{tabular} & $\begin{array}{l}\text { T Adequate } \\
\text { The conclusions } \\
\text { have been clearly } \\
\text { linked to the findings } \\
\text { and have been } \\
\text { explained in light of } \\
\text { the current research } \\
\text { evidence. }\end{array}$ \\
\hline $\begin{array}{l}\text { Oliviera et al., } \\
\qquad(2013)\end{array}$ & $\begin{array}{l}\quad \text { ? Not sure } \\
\text { There was no systematic } \\
\text { approach to analysis } \\
\text { reported. }\end{array}$ & $\begin{array}{l}\quad \text { ? Not sure } \\
\text { The author used sufficient } \\
\text { extracts which were } \\
\text { contextualised. However, } \\
\text { the narrative was } \\
\text { dominated by references } \\
\text { to research evidence } \\
\text { rather than an exploration } \\
\text { of the individual narratives. }\end{array}$ & $\begin{array}{l}\quad \text { ? Not sure } \\
\text { This was not specified in } \\
\text { the study. }\end{array}$ & \begin{tabular}{l}
\multicolumn{1}{c}{ Convincing } \\
The findings of the study \\
are adequately \\
organised and \\
coherently stated. The \\
extracts inform the \\
themes they represent.
\end{tabular} & \begin{tabular}{l}
\multicolumn{1}{c}{ Relevant } \\
The findings are clearly \\
linked to the aims of the \\
study.
\end{tabular} & \begin{tabular}{l}
\multicolumn{1}{c}{ Adequate } \\
The conclusions \\
have been clearly \\
linked to the findings \\
and offer greater \\
insight into the \\
experiences of \\
schizophrenia in \\
hospitalised \\
individuals.
\end{tabular} \\
\hline $\begin{array}{l}\text { Roe, Chopra \& } \\
\text { Rudnick, (2004). }\end{array}$ & \begin{tabular}{l}
\multicolumn{1}{c}{ Rigorous } \\
The authors present a \\
transparent account of the \\
analysis process. However, \\
issues if reflexivity are not \\
accounted for.
\end{tabular} & $\begin{array}{l}\checkmark \quad \text { Rich } \\
\text { The author has included } \\
\text { numerous extracts to } \\
\text { present a 'rich' and fuller } \\
\text { account of the participants } \\
\text { experiences. These were }\end{array}$ & $\begin{array}{l}\text { ? Not sure } \\
\text { The validity of the } \\
\text { categories was checked } \\
\text { alongside the individual } \\
\text { narratives throughout }\end{array}$ & \begin{tabular}{l}
\multicolumn{1}{c}{ Convincing } \\
The findings of the study \\
are adequately \\
organised and \\
coherently stated. The \\
extracts inform the
\end{tabular} & \begin{tabular}{l}
\multicolumn{1}{c}{ Relevant } \\
The findings are clearly \\
linked to the aims of the \\
study.
\end{tabular} & $\begin{array}{l}\quad \checkmark \quad \text { Adequate } \\
\text { The conclusions } \\
\text { have been clearly } \\
\text { linked to the findings } \\
\text { and have been } \\
\text { explained in relation }\end{array}$ \\
\hline
\end{tabular}




\begin{tabular}{|c|c|c|c|c|c|c|}
\hline & & $\begin{array}{l}\text { appropriately } \\
\text { contextualised. Similarities } \\
\text { and differences are } \\
\text { presented. }\end{array}$ & $\begin{array}{l}\text { the study. The author } \\
\text { reported that the } \\
\text { findings were not } \\
\text { triangulated which limits } \\
\text { the study. }\end{array}$ & $\begin{array}{l}\text { themes they represent } \\
\text { and have been explored } \\
\text { in sufficient depth. }\end{array}$ & & $\begin{array}{l}\text { to the current } \\
\text { research evidence. }\end{array}$ \\
\hline $\begin{array}{l}\text { Saneesha et al. } \\
\qquad(2009)\end{array}$ & \begin{tabular}{l}
\multicolumn{1}{c}{ Rigorous } \\
The authors present a \\
transparent account of the \\
analysis process. They \\
identified their analysis \\
method and referenced the \\
systematic method they had \\
adopted.
\end{tabular} & \begin{tabular}{l}
\multicolumn{1}{c}{ Rich } \\
The author used sufficient \\
extracts which were \\
contextualised. At times, \\
the inclusion of research \\
evidence impeded the in- \\
depth exploration of the \\
participant narratives.
\end{tabular} & \begin{tabular}{l}
\multicolumn{1}{c}{ Reliable } \\
The researcher used a \\
number of methods to \\
ensure reliability over \\
the course of the study.
\end{tabular} & \begin{tabular}{l}
\multicolumn{1}{c}{ Convincing } \\
The findings of the study \\
are well-organised and \\
coherently stated. The \\
extracts appeared to \\
coincide with the \\
distinguished themes.
\end{tabular} & \begin{tabular}{l}
\multicolumn{1}{c}{ Relevant } \\
The findings are clearly \\
linked to the aims of the \\
study and have been \\
linked to the relevant \\
literature.
\end{tabular} & $\begin{array}{l}\checkmark \checkmark \text { Adequate } \\
\text { The links to } \\
\text { research were made } \\
\text { in the results section } \\
\text { and were not } \\
\text { expanded on in the } \\
\text { discussion or } \\
\text { conclusion, however } \\
\text { they were plausible. }\end{array}$ \\
\hline
\end{tabular}




\section{Appendix C: Sample of line-by-line coding}

Table: Sample of coded data and clustering of common concepts to establish 'descriptive' themes (evidence through colour coding) (Thomas \& Harden, 2008)

\begin{tabular}{|c|c|c|}
\hline \multicolumn{3}{|l|}{ Gould et al. (2005) } \\
\hline Coding & Extracted Data & $\begin{array}{l}\text { Original } \\
\text { theme }\end{array}$ \\
\hline Before and after & $\begin{array}{l}\text { Usually I liked to go for bike rides and skateboard } \\
\text { and hang out with friends and stuff like that ... play } \\
\text { games ... watch TV ... (pg 470) }\end{array}$ & $\begin{array}{l}\text { Life before; } \\
\text { Computer } \\
\text { crashes }\end{array}$ \\
\hline Loss of self & $\begin{array}{l}\text { Whole psychological map was taken away from } \\
\text { [him] and [he] was kinda left lost. If you don't have } \\
\text { a map, you don't know where you are or where } \\
\text { you're going ... You could be lost. (pg 470) }\end{array}$ & \\
\hline $\begin{array}{l}\text { Loss of past life } \\
\text { Loss of confidence }\end{array}$ & $\begin{array}{l}\text { a time when, before illness, they had dreams and } \\
\text { goals. The participants were then confident, in } \\
\text { control of their lives and healthy. (pg 469) }\end{array}$ & \\
\hline $\begin{array}{l}\text { Sudden/ unexpected/ } \\
\text { uncontrollable }\end{array}$ & $\begin{array}{l}\text { I remember one day ... that everything crumbled } \\
\ldots . \text { It was probably one of the worst days of my life } \\
\ldots \text { Before that I was just kinda complacent ... you } \\
\text { know, not just coasting through life, you know, } \\
\text { normally ... Then everything dormant and then all } \\
\text { of a sudden ... it's like your whole mind just gets } \\
\text { wiped clean and ... you gotta restart your whole } \\
\text { life because all these negative things kinda get } \\
\text { written on the blackboard. (pg 470) } \\
\text { shared experiences of the illness as being scary, } \\
\text { frightening and unexpected (pg 470) }\end{array}$ & $\begin{array}{l}\text { Computer } \\
\text { crashes }\end{array}$ \\
\hline $\begin{array}{l}\text { Rebuilding/ Taking } \\
\text { action }\end{array}$ & $\begin{array}{l}\text { If you have surgery or something, you spend time } \\
\text { healing ... the brain is like that ... those } \\
\text { associations that were broken between, say, school } \\
\text { and future were broken and you have to rebuild } \\
\text { those. (pg 470) } \\
\text { They did, however, speak of a negotiation and } \\
\text { renegotiation of self, goals, dreams and abilities. } \\
\text { In short, the participants described a process of } \\
\text { renegotiating themselves in this world based upon } \\
\text { what they now knew about schizophrenia. (pg 471) }\end{array}$ & $\begin{array}{l}\text { Coasting } \\
\text { through life; } \\
\text { Remake life }\end{array}$ \\
\hline
\end{tabular}




\section{Appendix D: Identifying 'descriptive' themes.}

Table: Example of converting codes across studies into 'descriptive' themes, including the studies that contributed to each theme (study number indicated in square bracket).

\begin{tabular}{|c|c|}
\hline Codes & Descriptive Themes \\
\hline Isolated/alienated/lonely [2] & \multirow{5}{*}{$\begin{array}{l}\text { Social withdrawal } \\
{[2,6,5,3,9]}\end{array}$} \\
\hline Social withdrawal/isolation [6] & \\
\hline $\begin{array}{l}\text { Mistrust/paranoia } \\
\text { Isolating/difficulties with intimacy [5] }\end{array}$ & \\
\hline $\begin{array}{l}\text { Mistrust/paranoia } \\
\text { Problems in relationships [3] }\end{array}$ & \\
\hline Missing out [9] & \\
\hline $\begin{array}{l}\text { Separation/ Parental Abuse/ Bullying/ } \\
\text { Trauma/ Ruminating [2] }\end{array}$ & \multirow[t]{4}{*}{$\begin{array}{l}\text { Causes of illness } \\
{[2,5,9,11]}\end{array}$} \\
\hline $\begin{array}{l}\text { Punishment } \\
\text { Cumulative build up } \\
\text { Role of drugs [5] }\end{array}$ & \\
\hline Lack of understanding [9] & \\
\hline $\begin{array}{l}\text { Spiritual } \\
\text { Accident [11] }\end{array}$ & \\
\hline Out of control [2] & \multirow{8}{*}{$\begin{array}{l}\text { Sudden, overwhelming and } \\
\text { uncontrollable } \\
{[2,9,7,5,3,11,4,8]}\end{array}$} \\
\hline Unpredictable/ Uncontrollable [9] & \\
\hline Anger/confusion/lack of control [7] & \\
\hline $\begin{array}{l}\text { Violence/anger } \\
\text { Overwhelmed [5] }\end{array}$ & \\
\hline Loss of control $[3]$ & \\
\hline $\begin{array}{l}\text { Medication to control/chronic } \\
\text { Unpredictable/ chronic [11] }\end{array}$ & \\
\hline Sudden/ unexpected/ uncontrollable [4] & \\
\hline Overwhelm [8] & \\
\hline Fear of stigma [11] & \multirow{4}{*}{$\begin{array}{l}\text { Stigma } \\
{[11,1,3,6]}\end{array}$} \\
\hline Stigma/Hiding [1] & \\
\hline Fear of stigma [3] & \\
\hline $\begin{array}{l}\text { Reduce Stigma } \\
\text { Abuse from others [6] }\end{array}$ & \\
\hline
\end{tabular}




\section{Appendix E: Transforming 'descriptive' themes into 'analytical' themes.}

Table: Final themes and the studies contributing to each theme.

\begin{tabular}{|c|c|c|}
\hline First-Order Themes & Second-order Themes & Third-order Theme \\
\hline $\begin{array}{l}\text { Social withdrawal } \\
{[2,6,5,3,8]}\end{array}$ & \multirow[t]{2}{*}{$\begin{array}{l}\text { Stay Lonely or Reach Out } \\
{[2,3,4,5,6,8,10]}\end{array}$} & \multirow{7}{*}{$\begin{array}{l}\text { Living with Psychosis } \\
(11 / 11) \\
{[1,2,3,4,5,6,7,8,9,10,} \\
11]\end{array}$} \\
\hline $\begin{array}{l}\text { Seeking support } \\
{[2,3,4,5,8,10]}\end{array}$ & & \\
\hline $\begin{array}{l}\text { Stigma } \\
{[11,1,3,6]}\end{array}$ & \multirow[t]{2}{*}{$\begin{array}{l}\text { Shame and Stigmatization } \\
{[1,2,3,6,7,8,11]}\end{array}$} & \\
\hline $\begin{array}{l}\text { Hiding/ Don't Talk } \\
{[1,2,3,6,7,8]}\end{array}$ & & \\
\hline $\begin{array}{l}\text { Hopelessness/ Depression } \\
\text { Apathy } \\
{[2,3,4,5,8]}\end{array}$ & $\begin{array}{l}\text { Existential Apathy } \\
{[2,3,4,5,8]}\end{array}$ & \\
\hline $\begin{array}{l}\text { Loss } \\
{[2,3,4,5,6,7]}\end{array}$ & $\begin{array}{l}\text { Loss of Manhood } \\
{[2,3,4,5,6,7]}\end{array}$ & \\
\hline $\begin{array}{l}\text { Medication } \\
{[2,3,8,9,11]}\end{array}$ & $\begin{array}{l}\text { Challenges with Medication } \\
{[2,3,8,9,11]}\end{array}$ & \\
\hline $\begin{array}{l}\text { Sudden, uncontrollable } \\
\text { mental overwhelm } \\
{[2,9,7,5,3,11,4,8]} \\
\text { An explanation why it } \\
\text { happened? } \\
{[2,5,9,1]}\end{array}$ & \multicolumn{2}{|c|}{$\begin{array}{l}\text { Shock followed by Understanding }(9 / 11) \\
{[1,2,3,4,5,7,8,9,11]}\end{array}$} \\
\hline $\begin{array}{l}\text { Rebuilding, one step at a time } \\
{[2,4,5,10]} \\
\text { Finding hope and meaning } \\
{[1,2,3,4,5,9,10]}\end{array}$ & $\begin{array}{l}\text { Towards Recovery }(7 / 11) \\
{[1,2,3,4,5,9,10]}\end{array}$ & \\
\hline
\end{tabular}


APPENDICES: EMPIRICAL PAPER 







